\title{
TUBERCULOSIS AND THE "SOCIAL COMPLEX" IN GLASGOW
}

\author{
BY \\ LILLI STEIN \\ Department of Social Medicine, University of Edinburgh
}

In recent years, the high mortality and incidence of respiratory tuberculosis in Scotland have caused much concern. This concern became intensified after the war, when Scottish tuberculosis rates remained at their high war-time level or rose even higher; in other countries which had suffered early war-time increases in tuberculosis the declining rates of the 1930s returned. Neither discussion nor investigation has succeeded in identifying the cause of this dissimilarity, and without precise knowledge of the environmental and sociological background of tuberculosis, such discussion must inevitably be speculative.

In 1949 and 1950 the total mortality from respiratory tuberculosis in Scotland fell, but notifications continued to mount, and even in 1950 the new cases, though slightly fewer than in 1949, were more numerous than in any year in the previous three decades. Apparently the considerable fall in mortality did not signify a similar fall in incidence. Moreover, in the younger age groups, the age-specific rates of death as well as of notification reveal disturbing increases; and these increases at the susceptible ages were manifest even before the war (Scotland, Department of Health, 1951). Any attempt to understand these trends against their background and to determine the factors operative in them must include a detailed investigation of tuberculosis in Glasgow. Within this city lives one-fifth of the population of Scotland, contributing one-third of the Scottish tuberculosis cases and deaths; and surrounding the city are burghs and urbanized areas containing almost another fifth of the population, among whom similar tuberculosis rates prevail.

Before 1939 the death and notification rates in Glasgow did not display the same pattern as those of the rest of Scotland. In the 1930s tuberculosis in Glasgow rose and fell irregularly, always remaining at a high level with little evidence of any real decline. By contrast, both mortality and notification rates in Scotland as a whole fell fairly steadily. War-time increases in tuberculosis were greater in Glasgow than in the rest of Scotland, and the end of the war brought no decline. In 1949 and 1950 the Glasgow mortality fell, and this was a major factor in the total Scottish reduction. At the same time the notifications in Glasgow fell, and this influenced the Scottish total in 1950.

The present tuberculosis position in Scotland is not such as to encourage complacency. The recent drop in the death rate does not necessarily imply a fall in prevalence. Improved methods of treatment have undoubtedly prolonged the survival of notified cases, but while the spread of infection continues and so many new cases are notified annually, tuberculosis cannot be considered to be under control. The urgent 
need now is precise knowledge of the environmental background of the disease, of the origins of the Scottish trends, and of the causes of the high Glasgow rates. The vague general belief that tuberculosis is a social disease is of little aid in preventing its further spread or in ameliorating the conditions most closely associated with its incidence. General references to "social conditions" do not lead to specific actions. To achieve control, the influence of different social factors upon mortality and incidence must be established, and the effects of past circumstances and present policy assessed.

A number of statistical studies have been undertaken to demonstrate the influence of social conditions on tuberculosis, and some have sought to isolate specific environmental circumstances. Greenwood (1926) investigated the connexion between housing and respiratory tuberculosis in the boroughs of London. Hart and Wright (1939) demonstrated the relationship between this disease and a number of social indices in the cities and counties of England. McKinlay (1947) examined overcrowding and tuberculosis mortality changes in Scotland in pre-war years. Stein (1950) showed the association between tuberculosis rates and housing conditions in the wards of Edinburgh. Studies in other countries point to similar conclusions; Copenhagen data for 1865 to 1874 , Hamburg records from 1896 to 1900 , Buffalo data from the 1940 Census (Terris, 1948), and many other analyses consistently disclose the influence of socio-economic circumstances on tuberculosis. But the relative importance of individual constituents in the "social complex" has not been determined, and the interaction of economic and social factors is such that components of great importance in one country may, in another, in the presence of exceptional local conditions, have a comparatively minor influence. The present study of Glasgow tuberculosis in the period 1930-47 aims at separating the influence of certain social factors as they occurred, and ascertaining the relative importance of their contributions. As a result it appears that, in Glasgow, housing conditions form the largest single factor in the "complex". This may seem remarkable, but in Scotland, and particularly in Glasgow (see Appendix B.1), housing is of such an unusual character as to constitute an exceptional local circumstance. Elsewhere a lesser association between disease and housing may be found, but in Glasgow the association is of an unusual nature.

\section{Trends of Respiratory Tuberculosis in Glasgow}

The mortality and notification rates in Glasgow are among the highest in Great Britain, and for the last 100 years have been considerably higher than the Scottish averages (Fig. 1, opposite).

Nevertheless, there was a considerable decline in Glasgow mortality throughout the late nineteenth and early twentieth centuries. In 1908 this improvement was halted, but the rate again declined steadily during and after World War I except for the period of the 1920-23 depression. In 1926 the lowest death rate so far recorded, less than 8.8 per 10,000 , was reached. But from then onwards there was no marked change; downward fluctuations during the 1930-34 depression were followed by slight increases from 1934 until 1939. In 1940 the death rate rose from 8.6 to $11 \cdot 3$; it continued at this high level, and in 1948 reached $11 \cdot 4$, the highest rate for 30 years. 


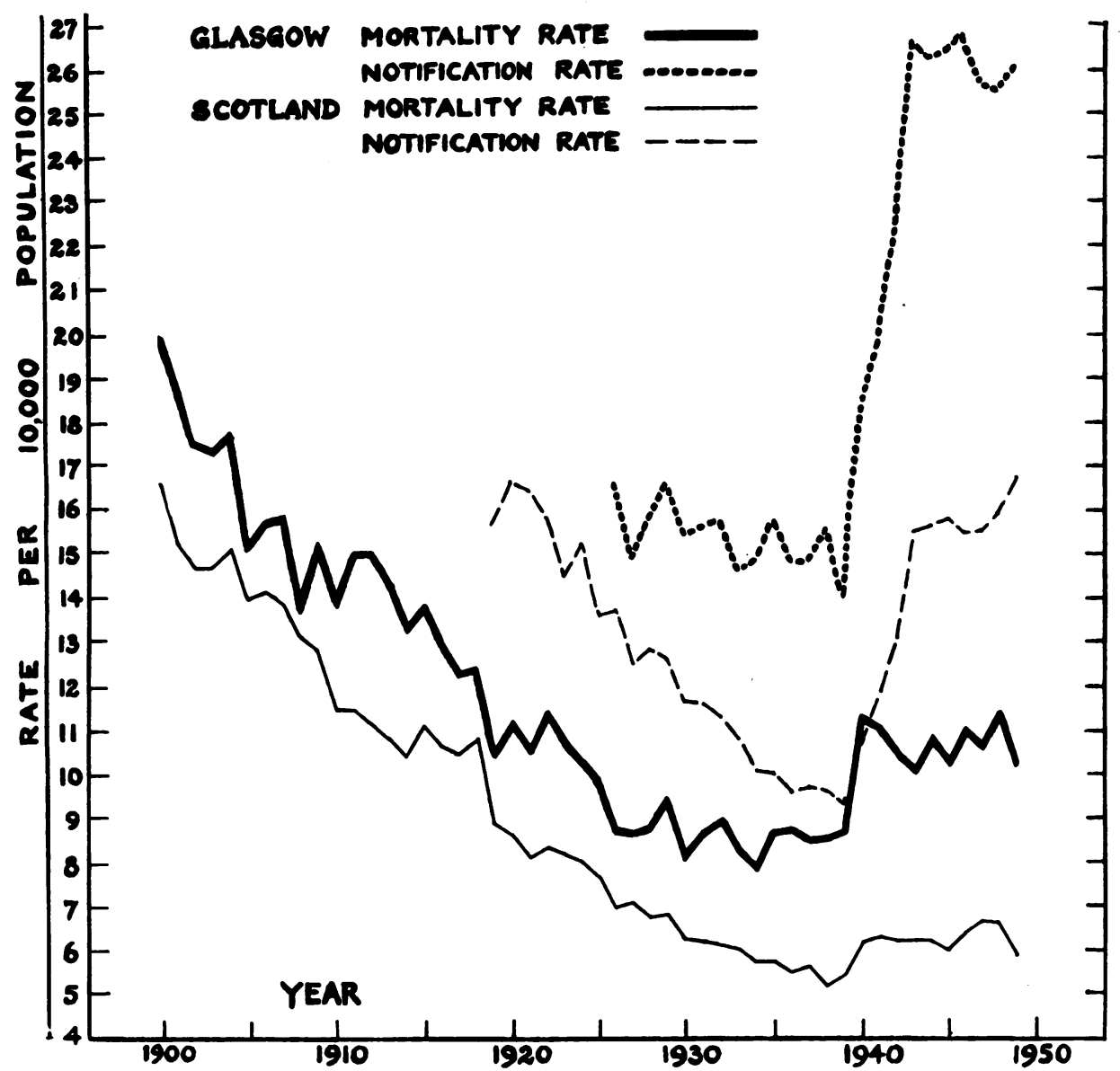

FIG. 1.-Respiratory tuberculosis rates in Glasgow, and in the whole of Scotland, 1900-50.

In 1949, and again in 1950, there was a considerable decline, which has been carried further in the first half of 1951. Yet Glasgow mortality is still higher than the Scottish average, and is above the rate of other large towns (Table I, overleaf).

When compared with the trends in cities of England and Wales, the contrast is more marked, for until the early 1930s the Glasgow rates were lower than those in many industrial areas. But in Liverpool, Manchester, Newcastle, and Cardiff, where the mortality rates at the beginning of the 1930 s were 10 or more, the earlier decline continued until 1939. And though in these towns the rates rose sharply in the initial years of war, the decline soon reappeared; and the rates have fallen markedly since 1945. Thus the Glasgow rate, in spite of the great improvements in the last two years, is still the highest of the larger cities of Great Britain.

A study of the notifications of new cases each year similarly reveals that from 1930-39 there was little improvement; and a comparison with other localities again 
TABLE I

Respiratory Tuberculosis Mortality, 1932-49, in the largest cities of Scotland, England AND WALES. Crude mortality rate per 10,000 population.

\begin{tabular}{|c|c|c|c|c|c|c|c|c|c|c|c|c|}
\hline Year & 1932 & 1933 & 1934 & 1937 & 1938 & 1939 & 1945 & 1946 & 1947 & 1948 & 1949 & 1950 \\
\hline Glasgow & $8 \cdot 9$ & $8 \cdot 2$ & $7 \cdot 9$ & $8 \cdot 5$ & $8 \cdot 5$ & $8 \cdot 6$ & $10 \cdot 3$ & $11 \cdot 0$ & $10 \cdot 7$ & $11 \cdot 4$ & $10 \cdot 1$ & $8 \cdot 5$ \\
\hline $\begin{array}{ll}\text { Edinburgh } & . \\
\text { Dundee } & \ldots \\
\text { Aberdeen } & .\end{array}$ & $\begin{array}{l}7 \cdot 0 \\
6 \cdot 1 \\
4 \cdot 7\end{array}$ & $\begin{array}{l}7 \cdot 1 \\
5 \cdot 8 \\
5 \cdot 4\end{array}$ & $\begin{array}{l}6 \cdot 6 \\
5 \cdot 4 \\
5 \cdot 2\end{array}$ & $\begin{array}{l}6 \cdot 4 \\
5 \cdot 7 \\
4 \cdot 0\end{array}$ & $\begin{array}{l}6 \cdot 1 \\
6 \cdot 2 \\
3 \cdot 8\end{array}$ & $\begin{array}{l}6 \cdot 0 \\
6 \cdot 1 \\
3 \cdot 8\end{array}$ & $\begin{array}{l}5 \cdot 1 \\
6 \cdot 8 \\
4 \cdot 3\end{array}$ & $\begin{array}{l}6 \cdot 4 \\
7 \cdot 0 \\
4 \cdot 0\end{array}$ & $\begin{array}{l}6 \cdot 5 \\
8 \cdot 2 \\
3 \cdot 5\end{array}$ & $\begin{array}{l}6 \cdot 5 \\
6 \cdot 5 \\
3 \cdot 2\end{array}$ & $\begin{array}{l}5 \cdot 5 \\
7 \cdot 5 \\
3 \cdot 1\end{array}$ & $\begin{array}{l}4 \cdot 9 \\
5 \cdot 9 \\
2 \cdot 1\end{array}$ \\
\hline $\begin{array}{l}\text { London } \\
\text { Birmingham } \\
\text { Liverpool .. } \\
\text { Manchester.. } \\
\text { Newcastle .. }\end{array}$ & $\begin{array}{r}8 \cdot 0 \\
8 \cdot 4 \\
11 \cdot 3 \\
10 \cdot 0 \\
9 \cdot 8\end{array}$ & $\begin{array}{r}8 \cdot 0 \\
8 \cdot 6 \\
11 \cdot 8 \\
10 \cdot 4 \\
9 \cdot 2\end{array}$ & $\begin{array}{r}7 \cdot 4 \\
7 \cdot 2 \\
10 \cdot 1 \\
10 \cdot 1 \\
9 \cdot 8\end{array}$ & $\begin{array}{l}6 \cdot 9 \\
7 \cdot 3 \\
8 \cdot 4 \\
9 \cdot 2 \\
9 \cdot 4\end{array}$ & $\begin{array}{l}6 \cdot 2 \\
6 \cdot 9 \\
8 \cdot 1 \\
8 \cdot 6 \\
8 \cdot 6\end{array}$ & $\begin{array}{l}6 \cdot 9 \\
7 \cdot 7 \\
8 \cdot 0 \\
8 \cdot 6 \\
8 \cdot 3\end{array}$ & $\begin{array}{l}7 \cdot 8 \\
6 \cdot 6 \\
8 \cdot 9 \\
8 \cdot 0 \\
8 \cdot 3\end{array}$ & $\begin{array}{l}6 \cdot 2 \\
5 \cdot 8 \\
7 \cdot 8 \\
6 \cdot 9 \\
7 \cdot 8\end{array}$ & $\begin{array}{l}6 \cdot 3 \\
6 \cdot 2 \\
7 \cdot 8 \\
6 \cdot 6 \\
8 \cdot 8\end{array}$ & $\begin{array}{l}5 \cdot 7 \\
5 \cdot 7 \\
7 \cdot 8 \\
6 \cdot 9 \\
7 \cdot 4\end{array}$ & $\begin{array}{l}4 \cdot 7 \\
5 \cdot 3 \\
6 \cdot 8 \\
6 \cdot 0 \\
7 \cdot 6\end{array}$ & \\
\hline Cardiff & $10 \cdot 4$ & $10 \cdot 3$ & $9 \cdot 1$ & $8 \cdot 0$ & $8 \cdot 4$ & $8 \cdot 7$ & $8 \cdot 2$ & $7 \cdot 3$ & $7 \cdot 0$ & $6 \cdot 8$ & $6 \cdot 4$ & \\
\hline
\end{tabular}

demonstrates the divergence of the Glasgow trend. In the early 1930s the notification rate in Glasgow was higher than that in Scotland as a whole, and throughout the decade, whilst the Scottish rate fell progressively, the Glasgow rate continued at its high level. In England and Wales the notification rate decreased greatly, and though it increased sharply in the early years of war the decline was soon resumed. But in Glasgow (as in the rest of Scotland) notifications mounted continuously during the war, and remained at these higher levels after the war. New notifications in Glasgow averaged 15 per 10,000 persons in the 1930 s; in recent years they have averaged 26 to 27 per 10,000 persons. In 1949 the number of new cases recorded was the highest since 1910, and the Medical Officer of Health for Glasgow (1949a), reporting on

TAB弱

RESPIRATORY TUBERCULOSIS IN

Rates of Mortality (M) and Notifications (N)

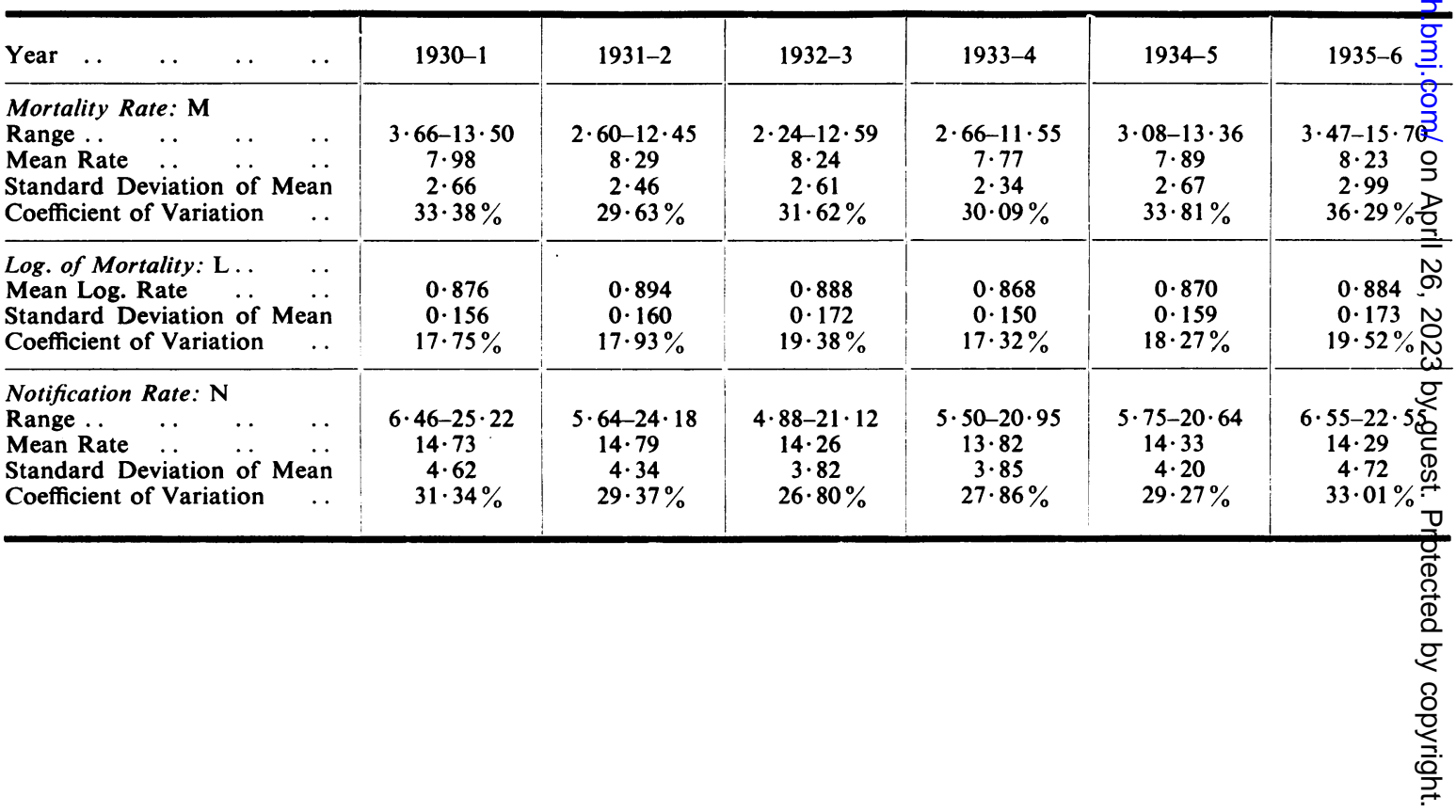


hospital accommodation and general deficiencies, wrote:

Of these the waiting list for pulmonary tuberculosis is the largest, and the position both from the point of view of the patients and of the community is most grave. . . Glasgow to-day has over 12,000 tubercular persons on the registers of this Department, this number being 3,000 more than the figure prior to the war.

One of the most disturbing features of the tuberculosis position in Glasgow (and indeed in Scotland) is the fact that the increases in new cases have particularly affected the younger age groups. Actual notifications in these vulnerable groups are shown in Fig. 2 (overleaf). Since 1945 the rate for young women aged 15-24 has been nearly 65 new cases per 10,000; and for young men of similar age the annual rate of new notifications has until recently been well above 40 per 10,000 . Moreover, although the crude mortality rate has fallen markedly since 1948, the specific mortality rates for certain age-sex groups have not declined, and the rates for young women are considerably above the levels of 20 years ago.

The rates for Glasgow as a whole were, of course, exceeded in many of the wards (Table II). Throughout the 1930s the annual averages of the ward rates of mortality and notifications wavered about 8 and $14 \cdot 5$ per 10,000 respectively; but at least twelve of the larger wards had rates from 25 to 75 per cent. higher than these averages. Since the war, the mean of the ward mortality rates has been well above 10 per 10,000 , and that of the notification rates above 25 per 10,000; but in the larger wards mortality ranged from 12 to 18 per 10,000 , whilst in seven wards notifications were between 33 and 38 per 10,000 each year.

The Edinburgh ward rates for the 1930s presented a different picture. Some decline was apparent in both mortality and notification rates, the mean of mortality rates falling from $7 \cdot 5$ to $6 \cdot 3$ and of notification rates from $12 \cdot 3$ to $10 \cdot 6$. Thus the differences between the Edinburgh and Glasgow averages were consistent though small in the

II

GLASGOW WaRds, 1930-47

10,000 Ward Population (2-year moving averages.).

\begin{tabular}{|c|c|c|c|c|c|c|c|}
\hline $1936-7$ & $1937-8$ & 1938-9 & $1939-40$ & $1940-1$ & $1944-5$ & $1945-6$ & $1946-7$ \\
\hline $\begin{array}{c}2 \cdot 41-14 \cdot 47 \\
8 \cdot 20 \\
2 \cdot 64 \\
32 \cdot 23 \%\end{array}$ & $\begin{array}{c}1 \cdot 74-12 \cdot 76 \\
8 \cdot 17 \\
2 \cdot 77 \\
33 \cdot 97 \%\end{array}$ & $\begin{array}{c}2 \cdot 46-16 \cdot 10 \\
8 \cdot 32 \\
2 \cdot 92 \\
35 \cdot 10 \%\end{array}$ & $\begin{array}{c}2 \cdot 57-15 \cdot 23 \\
9 \cdot 61 \\
3 \cdot 09 \\
32 \cdot 20 \%\end{array}$ & $\begin{array}{c}3 \cdot 11-16 \cdot 80 \\
10 \cdot 72 \\
3 \cdot 17 \\
29 \cdot 54 \%\end{array}$ & $\begin{array}{c}3 \cdot 10-16 \cdot 91 \\
10 \cdot 34 \\
3 \cdot 25 \\
31 \cdot 45 \%\end{array}$ & $\begin{array}{c}2 \cdot 69-16 \cdot 18 \\
10 \cdot 24 \\
3 \cdot 30 \\
32 \cdot 23 \%\end{array}$ & $\begin{array}{c}3 \cdot 57-18 \cdot 41 \\
10 \cdot 57 \\
3 \cdot 06 \\
28 \cdot 96 \%\end{array}$ \\
\hline $\begin{array}{c}0 \cdot 887 \\
0 \cdot 166 \\
18 \cdot 69 \%\end{array}$ & $\begin{array}{c}0 \cdot 879 \\
0 \cdot 188 \\
21 \cdot 35 \%\end{array}$ & $\begin{array}{c}0 \cdot 889 \\
0 \cdot 177 \\
19 \cdot 87 \%\end{array}$ & $\begin{array}{c}0.955 \\
0 \cdot 169 \\
17 \cdot 65 \%\end{array}$ & $\begin{array}{c}1 \cdot 007 \\
0 \cdot 155 \\
15 \cdot 40 \%\end{array}$ & $\begin{array}{c}0 \cdot 989 \\
0 \cdot 161 \\
16 \cdot 32 \%\end{array}$ & $\begin{array}{c}0.983 \\
0 \cdot 169 \\
17 \cdot 19 \%\end{array}$ & $\begin{array}{c}1 \cdot 003 \\
0 \cdot 145 \\
14 \cdot 45 \%\end{array}$ \\
\hline $\begin{array}{c}4 \cdot 89-21 \cdot 44 \\
14 \cdot 04 \\
4 \cdot 62 \\
32 \cdot 94 \%\end{array}$ & $\begin{array}{c}5 \cdot 76-23 \cdot 04 \\
14 \cdot 64 \\
4 \cdot 66 \\
31 \cdot 84 \%\end{array}$ & $\begin{array}{c}5 \cdot 86-23 \cdot 89 \\
14 \cdot 42 \\
4 \cdot 24 \\
29 \cdot 42 \%\end{array}$ & $\begin{array}{c}6 \cdot 88-27 \cdot 19 \\
15 \cdot 73 \\
4 \cdot 66 \\
29 \cdot 64 \%\end{array}$ & $\begin{array}{c}8 \cdot 69-27 \cdot 93 \\
18 \cdot 56 \\
5 \cdot 48 \\
29 \cdot 53 \%\end{array}$ & $\begin{array}{c}10 \cdot 27-38 \cdot 18 \\
25 \cdot 21 \\
6 \cdot 55 \\
25 \cdot 97 \%\end{array}$ & $\begin{array}{c}12 \cdot 28-35 \cdot 62 \\
25 \cdot 46 \\
6 \cdot 48 \\
25 \cdot 47 \%\end{array}$ & $\begin{array}{c}11 \cdot 80-38 \cdot 18 \\
25 \cdot 70 \\
6 \cdot 70 \\
26 \cdot 06 \%\end{array}$ \\
\hline
\end{tabular}



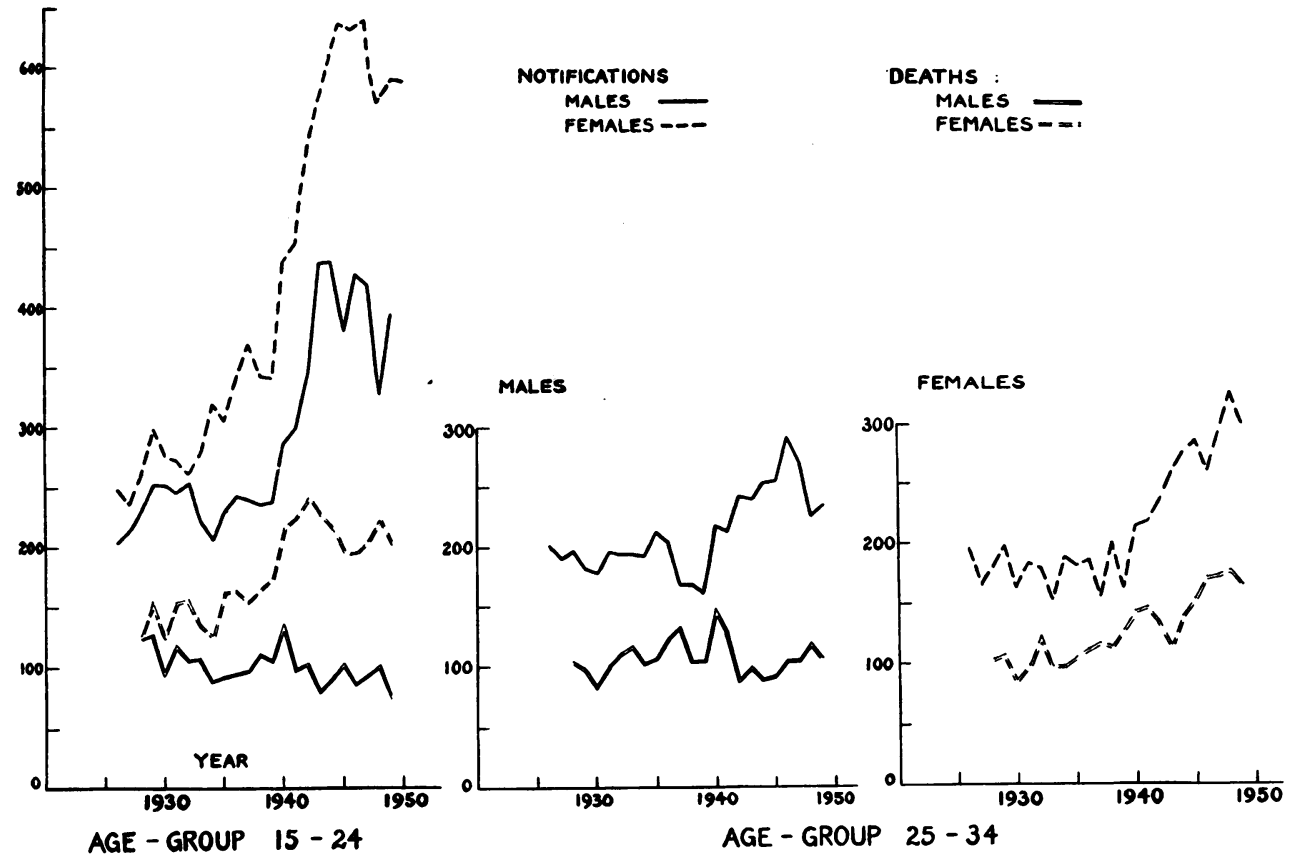

FIG. 2.-Respiratory tuberculosis notifications and deaths in Glasgow, 1926-49. Annual numbers for certain age-sex groups.

early 1930s. But the divergence increased gradually, and just before the war the differences were significant.

It appears, then, that in Glasgow the trends of respiratory tuberculosis have not been similar to those in towns of England and Wales, nor to those in other Scottish cities. In the last 20 years particularly, the movements of the Glasgow rates have exhibited a highly individual character which requires to be more fully examined.

\section{SCOPE OF THIS STUdY}

The main purpose of this study is to investigate the influence of socio-economic conditions in Glasgow on tuberculosis rates from 1930 to 1947, and to break down the "social complex" into components the relative importance of which can be evaluated. It must also be considered whether the contributions of certain social factors vary at different times or in different cities; and whether the findings of the Edinburgh study (Stein, 1950), which demonstrated a strong association between housing and tuberculosis, are confirmed. Finally, the relationships between respiratory tuberculosis and the social complex are compared with those exhibited by other diseases.

This investigation has concentrated on the smallest administrative units for which records are available, the wards of Glasgow. The smaller and more homogeneous the areas considered, the more genuinely do social or economic indices represent characteristics of real meaning in the locality. Besides the main investigation of the 38 wards, some analyses have also been made of tuberculosis in the ten Employment 
Exchange Areas of Glasgow; these areas are larger and more heterogeneous, and the results of these analyses are less clear-cut.

The present study deals firstly with the relationships of several social variables and the incidence and mortality rates of respiratory tuberculosis from 1930 to 1947. General crowding in houses, additional overcrowding defined by statutory standards, unemployment, and poverty are discussed. The results are also compared with previous analyses of Edinburgh data, to find whether the association between disease and housing conditions is of a similar order in the two cities.

For the same period, 1930-47, the relationship between respiratory tuberculosis mortality and previous notification is examined; and some confirmation of Edinburgh findings is given.

The two decades investigated have been remarkable not only for the increases in tuberculosis but also for the frequency and variety of social and economic disturbances. A detailed examination is therefore made of tuberculosis mortality and notification in the pre-war and post-war periods, and of the increases which occurred in the interval. The increases in the tuberculosis rates in individual wards are examined to see whether they are related to pre-war environmental circumstances in those wards.

In the first place the direct relationship between each disease rate and each social variable is examined, but since this does not take into account the interaction of various social factors, the influence of social variables operating simultaneously is also examined, and thus a measure of the relative importance of the contribution of each is obtained. The complex relationships between respiratory tuberculosis and the combined distributions of ordinary crowding, overcrowding, unemployment, and poverty, show that the major portion of the ward differences in tuberculosis corresponds to the ward divergencies in this "complex".

Additional analyses are included of the associations of these social factors with non-respiratory tuberculosis mortality and incidence, with infant mortality, and with total mortality from all causes in the period 1930-47. Comparisons between these associations and the relationships found for respiratory tuberculosis indicate the differing importance of different social factors. The social distributions themselves are also examined in detail, and the inter-relations between ordinary crowding, overcrowding, poverty, and unemployment, at different periods of the two decades, are analysed.

It would have been desirable to consider also other factors commonly believed to be relevant to the incidence of tuberculosis. But the dearth of recorded data for small definable areas hampers precise investigation, and this study has been restricted to material for which reliable and continuous data were available.

\section{Statistical Methods}

The methods used throughout the following analyses of relationships between two or more distributions are those of correlation and regression analysis; and the importance of any relationship is assessed by analysis of variance, and by consideration of the proportions of "explained" variance, and of residual "unexplained" variance, in the different regressions.

In the descriptions of each separate distribution, whether of a disease or of a social index, the 
ranges, means, and standard deviations of the means are given. The limits of the ranges and means show the time-trends of the rates in general and in the worst or best wards. The standard deviations of the means show the extent to which the individual ward rates are scattered about the means. The timetrends of these dispersions are indicated by the coefficients of variation, measures of dispersion which relate each standard deviation to the appropriate mean. In the various distributions of disease rates and social conditions, the scale of the divergencies between the wards may be compared by direct comparison of these coefficients of variation.

In the single relationship between a disease variable and a social variable, direct correlation coefficients and simple regression coefficients and equations are calculated, and the proportions of "explained" variance and residual variance "unexplained" are shown. In the case of mortality relationships, curvilinear regression equations are used.

Correlation coefficients measure the simultaneous variations of the two distributions, and thus indicate the significance or otherwise of the association investigated.

Regression coefficients measure the estimated response of the disease variable to a unit change in the independent social variable, and thus indicate the differences in numbers of deaths (or cases) associated with social differences in wards.

"Explained" variance measures the extent to which the estimate represented by the regression equation agrees with the mortality (or notification) rates actually observed; thus it indicates the magnitude of the contribution of that social factor to mortality (or incidence). Further, the ratio of "explained" variance to residual variance shows the significance and reliability of the estimate.

This is, in the main, the standard procedure generally adopted to ascertain the importance of relationships between disease rates and external factors (though frequently only correlation coefficients are examined). It is a reliable method on the whole, provided that the units in the distributions so brought into relation do genuinely represent homogeneous groups. In general, the higher the correlation, the more important is the relationship found, and the greater is the influence of that factor on the disease. But if the social factor represented by the independent variable were itself partly dependent on some other important social condition, it might appear to have a greater influence, in connexion with the disease, than is actually attributable to it alone. A high correlation coefficient need not always indicate a high degree of direct association between the two specified distributions, but may express the strong influence of the whole social complex on disease. A rigid analysis has to separate the explicit effect of one social variable from the effects implicit in its interrelation with other social factors; it has to examine a compound relationship in which the most important factors are introduced together and their interaction is taken into account.

For this reason, a considerable part of the investigation carried out in the first place by direct correlation and simple regression analysis is repeated and enlarged by multiple correlation and multiple regression analysis. The analysis of variance in the multiple regression, the proportion of the variance explained, and the separation of the latter into the components contributed by the different social variables, together give a better picture of the compound relationship and a more precise estimate of each factor's importance.

The duplication entailed in successive multiple analyses of relationships already investigated in the preliminary simple regressions and direct correlations was undertaken for two purposes. Firstly, in the Edinburgh study the only social indices used were those for ordinary crowding and overcrowding; it is therefore desirable to show that the strong associations found in those analyses were indeed direct associations of high order, and not the implicit effects of some other influence. Secondly, the recapitulation by multiple regressions discloses that some of the high direct correlations in simple regressions are due to the indirect effect of inter-relation between the social factors; the multiple relationships reveal which of the social variables are dominant factors. Although direct correlations in simple regressions do, on the whole, show the order of importance of the various social indices, they do not give reliable estimates of the magnitudes of the respective contributions. The recapitulation by multiple association exposes the possible weakness of a conclusion based only on a direct correlation coefficient.

In addition, the complex equations disclose the partial correlations between the disease variable and each component of the social complex. The residual intercorrelations between the component social factors are also revealed.

Standard errors of correlation and regression coefficients are tabled, and significance can be assessed by the ratio of a statistic to its standard error; if this ratio be greater than 2 , the statistic is usually held to be significant, since the likelihood of such a value arising by pure chance is less than 
1 in 20. In this study, however, the more rigorous " $F$ " test" of the ratio of "explained" variance to residual variance is used to judge the level of significance of any relationship expressed as a regression. For significance levels of partial correlation and regression coefficients, the " $t$ " test $t$ is applied.

In addition to the tables of data and results of the analyses outlined above, diagrams illustrate the closeness and consistency of the associations found. Scatter diagrams, with regression lines or curves fitted, indicate the progressive increase in disease rates as social conditions in the wards deteriorate, and show the nearness of the actual ward rates to the regression estimates. Variance analysis diagrams, showing the relationships involving each social factor singly and in combination, also demonstrate the small proportion of the variance unaccounted for by the complex relationships.

\section{Respiratory Tuberculosis in Relation to Different Social Factors}

The separate relationships between each mortality or notification distribution and each social variable from 1930 to 1947 are summarized in Table III (overleaf, pp. 10-11); coefficients of correlation and regression are given, and the variance "explained" by each regression is shown. These results demonstrate that each social factor was closely and continuously associated with ward differences in respiratory tuberculosis. Correlation coefficients, regressions, and "explained" variance all show the high level of significance of each relationship. But the closeness of the connection between the distribution of mortality or notifications and the various social distributions was not the same. Certain social factors were more strongly associated with the distribution of mortality than with that of notification; and the influence of some social factors became more important in the post-war years.

The most consistent and largest associations of tuberculosis mortality were those with ordinary crowding, and the correspondence between these two distributions was even more marked in the post-war period. Overcrowding was highly correlated with mortality in the early 1930s, but the association lessened slightly in later years. Unemployment was less markedly associated with mortality than was ordinary crowding or overcrowding; nevertheless, the connexion with unemployment was highly significant at all times. Equally, the distribution of poverty corresponded most significantly with ward differences in mortality, and this correspondence became even closer after 1945.

The correlations between ward notification rates and the various social distributions differed only a little from those described for mortality, and all were highly significant. The distribution of ordinary crowding corresponded closely with that of notifications, but this was not so marked as with mortality; notification rates in the early 1930s were as closely associated with overcrowding and unemployment as with ordinary crowding. In the later ' 30 s the connexion between notifications and unemployment increased steadily, whilst the influence of overcrowding became still greater. Poverty in the district, on the other hand, was not markedly associated with ward notification rates before 1939, correlations being rather lower than in the case of mortality; in the post-war period, notifications corresponded more markedly with the distribution of poverty than with any other social factor.

* Fisher (1925) first introduced the statistic $z$, which relates to two different estimates of variance, and published tables of the $z$ distribution. From these Snedecor (1934) extracted a table for the variance ratio, and he named this ratio " $F$ " after Fisher.

†The statistic " $t$ " represents the ratio of a deviation to its estimated standard error. 
TABL家

RESPIRATORY TUBERCULOSIS IN RELATION TO SOCIAi Correlations, Regressions, and Analyses of Variance of TubERculosis MoRTALITY and NotifiCATIONG M: Mortality Rate per 10,000 Ward Population.

L: $\quad$ Log. of Mortality Rate.

N: Notification Rate per 10,000 Ward Population.

A: ORDINARY CROWDING-density of dwelling-occupation (average persons per house in each ward).

U: UNEMPLOYMENT-adult males registered as unemployed in relation to total population (males unemployed per cent. of ward population).

P: OVERCROWDING-density of room-occupation (average persons per room in each ward).

T: $\quad$ Excess room-crowding of population (percentage of ward population living $2+$ per room).

O: $\quad$ Statutory overcrowding (percentage of houses found to be overcrowded).

Respiratory TUberculosis MORTality and Notifications in relation to Ordinary Crowding

\begin{tabular}{|c|c|c|c|c|c|c|c|c|c|c|c|}
\hline Ordinary Crowding: A & 1930 & 1931 & 1932 & 1933 & 1934 & 1935 & 1936 & 1937 & 1938 & 1939 & 1940 \\
\hline Mortality Rate: M & $1930-1$ & $1931-2$ & $1932-3$ & $1933-4$ & $1934-5$ & $1935-6$ & $1936-7$ & $1937-8$ & $1938-9$ & $1939-40$ & دـ-1940 \\
\hline $\begin{array}{l}\text { Correlation Coefficient } r \ldots \\
\text { Regression Coefficient } b \\
\text { Standard Error of } b\end{array}$ & $\begin{array}{l}\cdot 689 \\
6 \cdot 74 \\
1 \cdot 17\end{array}$ & $\begin{array}{l}\cdot 747 \\
6 \cdot 27 \\
0 \cdot 96\end{array}$ & $\begin{array}{l}\cdot 657 \\
6 \cdot 74 \\
1 \cdot 31\end{array}$ & $\begin{array}{l}\cdot 713 \\
6 \cdot 64 \\
1 \cdot 09\end{array}$ & $\begin{array}{l}\cdot .665 \\
7 \cdot 06 \\
1 \cdot 32\end{array}$ & $\begin{array}{l}\cdot 620 \\
6 \cdot 30 \\
1 \cdot 33\end{array}$ & $\begin{array}{l}\cdot 760 \\
6 \cdot 82 \\
0 \cdot 97\end{array}$ & $\begin{array}{l}\cdot 804 \\
7 \cdot 73 \\
0 \cdot 91\end{array}$ & $\begin{array}{l}\cdot 760 \\
7 \cdot 72 \\
1 \cdot 10\end{array}$ & $\begin{array}{l}\cdot .644 \\
7 \cdot 00 \\
1 \cdot 38\end{array}$ & $\begin{array}{l}\cdot 709 \text { ב } \\
8 \cdot 47 \stackrel{\text { c }}{1.40 ~} \\
\end{array}$ \\
\hline $\begin{array}{l}\text { Log. of Mortality: L } \\
\text { Correlation Coefficient } r \ldots \\
\text { Regression Coefficient } b \\
\text { Standard Error of } b \\
\text { "Explained" Variance } \\
\text { Variance Ratio F . . }\end{array}$ & $\begin{array}{l}\cdot 723 \\
\cdot 444 \\
\cdot 071 \\
52 \% \\
38 \cdot 3\end{array}$ & $\begin{array}{l}\cdot 770 \\
.416 \\
.058 \\
59 \% \\
51 \cdot 0\end{array}$ & $\begin{array}{l}\cdot 633 \\
.429 \\
\cdot 089 \\
40 \% \\
23 \cdot 4\end{array}$ & $\begin{array}{c}\cdot 699 \\
\cdot 418 \\
\cdot 071 \\
49 \% \\
34 \cdot 4\end{array}$ & $\begin{array}{l}\cdot 694 \\
.439 \\
\cdot 076 \\
48 \% \\
33 \cdot 5\end{array}$ & $\begin{aligned} \cdot 661 \\
\cdot 387 \\
\cdot 073 \\
44 \% \\
27 \cdot 9\end{aligned}$ & $\begin{array}{l}\cdot 766 \\
\cdot 449 \\
\cdot 063 \\
59 \% \\
51 \cdot 1\end{array}$ & $\begin{array}{l}\cdot 820 \\
\cdot 533 \\
\cdot 062 \\
67 \% \\
73 \cdot 7\end{array}$ & $\begin{array}{l}\cdot 812 \\
.499 \\
.060 \\
66 \% \\
69 \cdot 7\end{array}$ & $\begin{array}{l}\cdot 675 \\
\cdot 400 \\
\cdot 073 \\
46 \% \\
30 \cdot 1\end{array}$ & 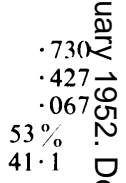 \\
\hline 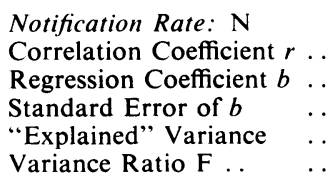 & $\begin{array}{l}\cdot 626 \\
12 \cdot 43 \\
2 \cdot 61 \\
39 \% \\
22 \cdot 6\end{array}$ & $\begin{array}{l}\cdot 708 \\
10 \cdot 36 \\
1 \cdot 75 \\
50 \% \\
35 \cdot 2\end{array}$ & $\begin{array}{l}\cdot 706 \\
10 \cdot 64 \\
1 \cdot 80 \\
50 \% \\
34 \cdot 9\end{array}$ & $\begin{array}{l}\cdot 655 \\
10 \cdot 02 \\
1 \cdot 93 \\
43 \% \\
27 \cdot 0\end{array}$ & $\begin{array}{c}\cdot 666 \\
11 \cdot 11 \\
2 \cdot 07 \\
44 \% \\
28 \cdot 7\end{array}$ & $\begin{array}{l}\cdot 610 \\
9 \cdot 76 \\
2 \cdot 12 \\
37 \% \\
21 \cdot 3\end{array}$ & $\begin{array}{c}\cdot 680 \\
10 \cdot 67 \\
1.92 \\
46 \% \\
30.9\end{array}$ & $\begin{array}{c}\cdot 769 \\
12 \cdot 43 \\
1 \cdot 72 \\
59 \% \\
52 \cdot 2\end{array}$ & $\begin{array}{c}\cdot 746 \\
11 \cdot 02 \\
1 \cdot 64 \\
56 \% \\
45 \cdot 2\end{array}$ & $\begin{array}{c}\cdot 687 \\
11 \cdot 25 \\
1 \cdot 98 \\
47 \% \\
32 \cdot 2\end{array}$ & 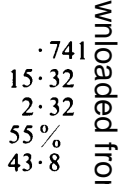 \\
\hline
\end{tabular}

Respiratory TUberculosis MORTAlity and Notifications in relation to UNemployment

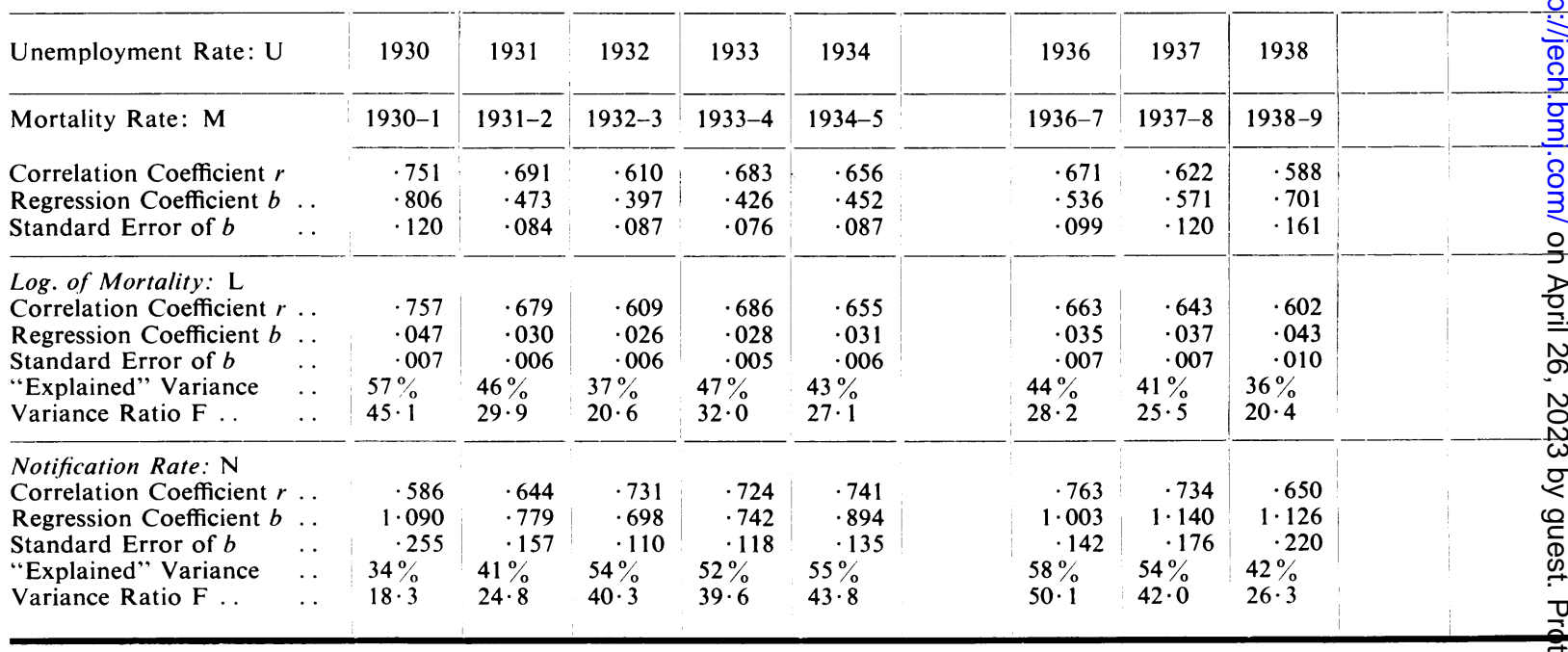


III

FACTORS IN WARDS OF GLASGOW, 1930-1947

in individual relationships with Ordinary Crowding, Overcrowding, Unemployment, and Poverty.

V: POVERTY - valuation of district (proportion of houses of high rentals in relation to other rentals in each ward).

R: Poor relief according to Outdoor Rolls of Welfare Department (percentage of ward population chargeable to Welfare Department).

Correlation Coefficient $r$ : in individual relationship between distribution of disease rate and distribution of social condition.

Regression Coefficient $b$ : in individual relationship, average difference in disease rate associated with a unit increase in social index.

Standard Error of $b$ : extent of variation of $b$ which might be expected.

"Explained" Variance, \%: proportion of variance in disease rate associated with ward differences in social conditions.

Variance Ratio $F$ : significance level of relationship between disease distribution and distribution of social condition.

\begin{tabular}{|c|c|c|c|c|c|c|c|c|}
\hline \multirow{3}{*}{$\frac{1944}{1944-5}$} & \multirow{3}{*}{$\begin{array}{c}1945 \\
1945-6\end{array}$} & \multirow{3}{*}{$\begin{array}{c}1946 \\
1946-7\end{array}$} & \multicolumn{6}{|c|}{ Respiratory TUberculosis MORTality and Notifications in relation to OVercrowding } \\
\hline & & & \multicolumn{2}{|c|}{$\begin{array}{c}\text { Index P: } 1931 \\
\text { (Persons per room) }\end{array}$} & \multicolumn{2}{|c|}{$\begin{array}{c}\text { Index } \mathrm{T}: 1931 \\
\text { (Percentage living } 2+\text { per room) }\end{array}$} & \multicolumn{2}{|c|}{$\begin{array}{c}\text { Index O: } 1935 \\
\text { (Percentage houses overcrowded) }\end{array}$} \\
\hline & & & $1930-1$ & $1931-2$ & $1930-1$ & $1931-2$ & 1934-5 & $1935-6$ \\
\hline $\begin{array}{l}\cdot 775 \\
9 \cdot 60 \\
1 \cdot 31\end{array}$ & $\begin{array}{c}\cdot 832 \\
10 \cdot 37 \\
1 \cdot 15\end{array}$ & $\begin{array}{l}\cdot 748 \\
8 \cdot 54 \\
1 \cdot 26\end{array}$ & $\begin{array}{c}\cdot 811 \\
4 \cdot 77 \\
\cdot 581\end{array}$ & $\begin{array}{c}\cdot 869 \\
4 \cdot 88 \\
\cdot 463\end{array}$ & $\begin{array}{r}\cdot 828 \\
\cdot 122 \\
\cdot 014\end{array}$ & $\begin{array}{r}\cdot 839 \\
\cdot 118 \\
\cdot 013\end{array}$ & $\begin{array}{l}\cdot 687 \\
.131 \\
.023\end{array}$ & $\begin{array}{l}\cdot 706 \\
\cdot 151 \\
.025\end{array}$ \\
\hline $\begin{array}{c}\cdot 813 \\
\cdot 500 \\
\cdot 060 \\
66 \% \\
70 \cdot 2\end{array}$ & $\begin{array}{c}\cdot 861 \\
\cdot 550 \\
.054 \\
74 \% \\
103 \cdot 1\end{array}$ & $\begin{array}{c}\cdot 803 \\
.484 \\
.053 \\
65 \% \\
82 \cdot 3\end{array}$ & $\begin{array}{c}\cdot 849 \\
\cdot 292 \\
.031 \\
72 \% \\
90 \cdot 2\end{array}$ & $\begin{array}{c}\cdot 884 \\
\cdot 313 \\
\cdot 028 \\
78 \% \\
125 \cdot 2\end{array}$ & $\begin{array}{c}\cdot 872 \\
.0075 \\
.0007 \\
76 \% \\
111.0\end{array}$ & $\begin{array}{c}\cdot 823 \\
.0065 \\
.0007 \\
68 \% \\
75 \cdot 8\end{array}$ & $\begin{array}{c}\cdot 728 \\
.0083 \\
.0013 \\
53 \% \\
40 \cdot 7\end{array}$ & $\begin{array}{c}\cdot 742 \\
\cdot 0091 \\
\cdot 0014 \\
55 \% \\
44 \cdot 0\end{array}$ \\
\hline $\begin{array}{c}\cdot 752 \\
18 \cdot 75 \\
2 \cdot 74 \\
57 \% \\
46 \cdot 9\end{array}$ & $\begin{array}{c}\cdot 733 \\
17 \cdot 96 \\
2 \cdot 78 \\
54 \% \\
41 \cdot 8\end{array}$ & $\begin{array}{c}\cdot 728 \\
18 \cdot 16 \\
2 \cdot 85 \\
53 \% \\
40 \cdot 5\end{array}$ & $\begin{array}{c}\cdot 650 \\
6 \cdot 62 \\
1 \cdot 31 \\
42 \% \\
25 \cdot 6\end{array}$ & $\begin{array}{c}\cdot 701 \\
6 \cdot 73 \\
1 \cdot 16 \\
49 \% \\
33 \cdot 9\end{array}$ & $\begin{array}{c}\cdot 712 \\
\cdot 182 \\
\cdot 030 \\
51 \% \\
36 \cdot 0\end{array}$ & $\begin{array}{c}\cdot 760 \\
\cdot 182 \\
\cdot 026 \\
58 \% \\
47 \cdot 8\end{array}$ & $\begin{array}{c}\cdot 824 \\
\cdot 247 \\
\cdot 028 \\
68 \% \\
76 \cdot 1\end{array}$ & $\begin{array}{c}\cdot 783 \\
\cdot 264 \\
\cdot 035 \\
61 \% \\
57 \cdot 1\end{array}$ \\
\hline
\end{tabular}

\begin{tabular}{|c|c|c|c|c|c|c|c|c|c|c|c|}
\hline \multirow{3}{*}{$\frac{1945}{1944-5}$} & \multirow{3}{*}{$\begin{array}{c}1946 \\
1945-6\end{array}$} & \multirow{3}{*}{$\begin{array}{c}1947 \\
1946-7\end{array}$} & \multicolumn{9}{|c|}{ Respiratory Tuberculosis Mortality and Notifications in relation to Poverty } \\
\hline & & & \multicolumn{3}{|c|}{$\begin{array}{c}\text { Index V } \\
\text { (Valuation, 1931) }\end{array}$} & \multicolumn{3}{|c|}{$\begin{array}{c}\text { Index V } \\
\text { (Valuation, 1936) }\end{array}$} & \multicolumn{3}{|c|}{$\begin{array}{c}\text { Index R } \\
\text { (Poor Relief, 1945-6) }\end{array}$} \\
\hline & & & $1930-1$ & $1931-2$ & $1932-3$ & $1936-7$ & $1937-8$ & $1938-9$ & $1944-5$ & $1945-6$ & $1946-7$ \\
\hline $\begin{array}{c}\cdot 623 \\
2 \cdot 44 \\
\cdot 510\end{array}$ & $\begin{aligned} \cdot & 632 \\
2 \cdot & 70 \\
\cdot & 552\end{aligned}$ & $\begin{array}{c}\cdot 681 \\
3 \cdot 03 \\
\cdot 543\end{array}$ & $\begin{array}{l}\cdot 600 \\
\cdot 154 \\
\cdot 035\end{array}$ & $\begin{array}{l}\cdot 721 \\
\cdot 171 \\
\cdot 028\end{array}$ & $\begin{array}{l}\cdot 715 \\
\cdot 180 \\
\cdot 030\end{array}$ & $\begin{array}{r}\cdot 649 \\
\cdot 166 \\
\cdot 033\end{array}$ & $\begin{array}{r}.656 \\
.176 \\
.034\end{array}$ & $\begin{array}{r}\cdot 599 \\
\cdot 170 \\
\cdot 038\end{array}$ & $\begin{array}{c}\cdot 779 \\
1 \cdot 65 \\
\cdot 222\end{array}$ & $\begin{array}{c}\cdot 735 \\
1 \cdot 58 \\
\cdot 244\end{array}$ & $\begin{array}{c}\cdot 749 \\
1 \cdot 50 \\
\cdot 221\end{array}$ \\
\hline $\begin{array}{c}\cdot 631 \\
\cdot 119 \\
.024 \\
40 \% \\
23 \cdot 8\end{array}$ & $\begin{array}{c}\cdot 641 \\
\cdot 131 \\
\cdot 026 \\
41 \% \\
25 \cdot 1\end{array}$ & $\begin{array}{c}\cdot 673 \\
\cdot 149 \\
.027 \\
45 \% \\
29 \cdot 8\end{array}$ & $\begin{array}{c}\cdot 654 \\
.0098 \\
.0019 \\
43 \% \\
26 \cdot 1\end{array}$ & $\begin{array}{c}\cdot 788 \\
\cdot 0122 \\
\cdot 0016 \\
62 \% \\
57 \cdot 2\end{array}$ & $\begin{array}{c}\cdot 831 \\
\cdot 0138 \\
\cdot 0016 \\
69 \% \\
78 \cdot 0\end{array}$ & $\begin{array}{c}.679 \\
.0114 \\
.0021 \\
46 \% \\
30 \cdot 7\end{array}$ & $\begin{array}{c}\cdot 767 \\
\cdot 0140 \\
\cdot 0019 \\
59 \% \\
51 \cdot 3\end{array}$ & $\begin{array}{c}\cdot 709 \\
\cdot 0121 \\
\cdot 0020 \\
50 \% \\
36 \cdot 3\end{array}$ & $\begin{aligned} & \cdot 775 \\
& \cdot 0817 \\
& \cdot 0111 \\
& 60 \% \\
& 54 \cdot 2\end{aligned}$ & $\begin{array}{c}\cdot 723 \\
\cdot 0797 \\
.0127 \\
52 \% \\
39 \cdot 4\end{array}$ & $\begin{array}{c}\cdot 730 \\
\cdot 0691 \\
.0108 \\
53 \% \\
40.9\end{array}$ \\
\hline $\begin{array}{l}\cdot 701 \\
6 \cdot 76 \\
1 \cdot 15 \\
49 \% \\
34 \cdot 8\end{array}$ & $\begin{array}{c}\cdot 782 \\
7 \cdot 50 \\
0.996 \\
61 \% \\
56 \cdot 7\end{array}$ & $\begin{array}{c}\cdot 753 \\
7 \cdot 47 \\
1 \cdot 09 \\
57 \% \\
47 \cdot 2\end{array}$ & $\begin{array}{c}.495 \\
.220 \\
.065 \\
25 \% \\
11 \cdot 4\end{array}$ & $\begin{array}{c}\cdot 568 \\
\cdot 238 \\
\cdot 058 \\
32 \% \\
16 \cdot 7\end{array}$ & $\begin{array}{c}\cdot 675 \\
\cdot 249 \\
\cdot 046 \\
46 \% \\
29 \cdot 3\end{array}$ & $\begin{array}{r}.615 \\
.275 \\
.059 \\
38 \% \\
21.9\end{array}$ & $\begin{array}{c}\cdot 577 \\
\cdot 261 \\
\cdot 062 \\
33 \% \\
17 \cdot 9\end{array}$ & $\begin{array}{c}\cdot 500 \\
\cdot 204 \\
\cdot 059 \\
25 \% \\
11 \cdot 8\end{array}$ & $\begin{array}{c}\cdot 882 \\
3 \cdot 77 \\
\cdot 336 \\
78 \% \\
126 \cdot 3\end{array}$ & $\begin{array}{c}\cdot 833 \\
3 \cdot 53 \\
\cdot 391 \\
69 \% \\
81 \cdot 5\end{array}$ & $\begin{array}{c}\cdot 805 \\
3 \cdot 52 \\
\cdot 432 \\
65 \% \\
66 \cdot 4\end{array}$ \\
\hline
\end{tabular}

VARIANCE RATIO $F\{$ "unexplained" variance $\}:$ The probability of chance occurrence is

$\{$ less than 0.001 if $F$ is greater than 12.8

\{less than 0.01 if $F$ is greater than 7.4

well above $99.9 \%$ significance. 
These indications of the order of importance of the various social distributions in changing times were also brought out by the regression coefficients and the "explained" variance in the different relationships. Moreover, the regressions confirmed that the associations of the social distributions with mortality were more consistent than with notifications. The upward curve of the regressions in the mortality relationships evidences the steep increases in mortality rates which accompanied the worsening of social conditions. Where crowding or unemployment rates were double those of better wards, tuberculosis mortality was rather more than twice as high.

A fuller examination of correlations and variance absorbed reveals the strength of these associations, with correlations far above the 99.9 per cent. level of significance. Many of the correlation coefficients were as high as 0.75 to 0.85 . The proportions of total variance accounted for by regression were in many cases more than 65 per cent. In the post-war period ordinary crowding "accounted for" 70 per cent. of the mortality variance and 55 per cent. of the notifications variance, and unemployment and poverty absorbed similar proportions of the latter. That these relationships cannot be ascribed to chance is clear from the variance ratios: the likelihood of variance ratios of such magnitude arising by chance is less than 0.05 per cent. (i.e. less than 1 in 2,000) in all cases. The closeness of the estimated rates of mortality or notifications, as calculated from the regression equations, to the actual rates observed in the wards is demonstrated by the small standard deviation from regression. In most cases, the original standard deviation of the mean is almost halved by the regression.

The coefficients of regression can be translated into actual figures which show the relationship between social inequalities and tuberculosis rates. In pre-war years, a unit difference in density of dwelling-occupation was associated with approximately seven deaths and eleven notifications per 10,000 persons. These divergencies are brought out more sharply by the regression equations, which give the following estimates for notification and death rates according to degree of ordinary crowding in the 1930s:

\begin{tabular}{|c|c|c|}
\hline $\begin{array}{l}\text { Average Density of Dwelling-Occupation } \\
\text { in the Ward }\end{array}$ & $\begin{array}{l}\text { Mortality Rate } \\
\text { per } 10,000\end{array}$ & $\begin{array}{l}\text { Notification Rate } \\
\text { per } 10,000\end{array}$ \\
\hline $\begin{array}{l}3 \text { persons per house (below the mean) } \ldots \\
4 \text { persons per house (approx. the mean) } \ldots\end{array}$ & $\begin{array}{l}1 \text { to } 2 \\
8 \text { to } 9\end{array}$ & $\begin{array}{r}3 \text { to } 5 \\
14 \text { to } 16\end{array}$ \\
\hline
\end{tabular}

These striking differences in tuberculosis in very crowded wards became even greater in the post-war period, when a unit difference in ordinary crowding gave an estimated difference of nearly ten deaths and eighteen notifications per 10,000 persons. The equations give the following estimates for 1945-47:

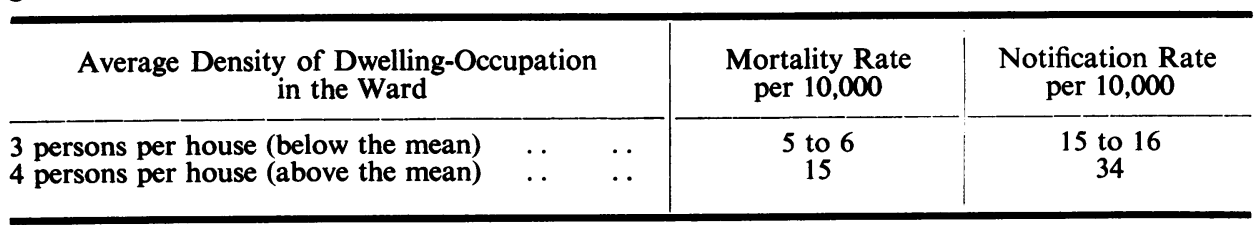

These figures evidence the excessive numbers of deaths and cases of tuberculosis in the heavily-occupied wards, and show also that the post-war increases added to the disadvantages of the more crowded wards.

Similarly, regression equations with overcrowding, unemployment, and poverty can be translated into actual numbers. But such translations have less importance in the interpretation of present-day tuberculosis rates, for the lack of post-war data on overcrowding, and the 
changes in unemployment levels and in conditions of poverty, make comparisons between the pre-war and post-war periods unreal. During the 1930s, unemployment differences between the wards were associated with gradually increasing differences in mortality and notifications; but these increases were slight, since the actual level of unemployment was declining. In the early 1930s, a difference of 5 per cent. (nearly half the range) in the ward unemployment index was associated with a difference of 2.5 in the death rate and of 4 in the notification rate per 10,000 . As unemployment declined, a smaller difference of 3.5 per cent. (again nearly half the range) in the male unemployment percentage gave similar estimates.

Overcrowding differences between the wards, on the other hand, were associated with increasing ward divergencies in tuberculosis in the 1930s. At first an overcrowding difference of 20 per cent. between wards was associated with differences of approximately 2.5 in the death rate and $3 \cdot 5$ in the notification rate per 10,000 , but later these differences increased to 3 deaths and more than 5 notifications per 10,000 persons.

The regression equations show the estimated rates of tuberculosis according to percentages overcrowded, and in the years 1935-39 the equations indicate the following rates:

\begin{tabular}{|c|c|c|}
\hline $\begin{array}{l}\text { Percentage Statutorily Overcrowded } \\
\text { in the Ward }\end{array}$ & $\begin{array}{l}\text { Mortality Rate } \\
\text { per } 10,000\end{array}$ & $\begin{array}{l}\text { Notification Rate } \\
\text { per } 10,000\end{array}$ \\
\hline 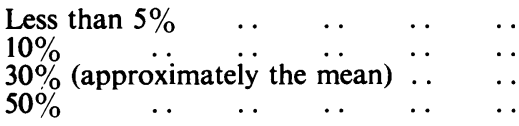 & $\begin{array}{r}4-4 \cdot 5 \\
5 \cdot 5 \\
8 \cdot 5 \\
11 \cdot 5\end{array}$ & $\begin{array}{l}7-8 \\
9 \cdot 5 \\
14 \cdot 5 \\
20\end{array}$ \\
\hline
\end{tabular}

These estimates show that in the less overcrowded areas the prevalence of tuberculosis was comparatively low. Poverty regressions also show the varying levels of the disease associated with the distribution of poverty in both pre-war and post-war periods. The postwar regressions indicate the following distribution of tuberculosis according to varying percentages of ward population on relief:

\begin{tabular}{|c|c|c|c|}
\hline $\begin{array}{l}\text { Percentage on Poor } \\
\text { in the Ward }\end{array}$ & elief & $\begin{array}{l}\text { Mortality Rate } \\
\text { per } 10,000\end{array}$ & $\begin{array}{c}\text { Notification Rate } \\
\text { per } 10,000\end{array}$ \\
\hline 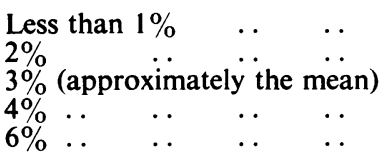 & $\begin{array}{l}\cdots \\
\cdots \\
\cdots \\
\cdots\end{array}$ & $\begin{array}{l}6-7 \\
9 \\
10 \cdot 5 \\
12 \\
15\end{array}$ & $\begin{array}{l}15-18 \\
22 \\
25 \cdot 5 \\
29 \\
36\end{array}$ \\
\hline
\end{tabular}

A comparison of the relationships between ordinary crowding or overcrowding and tuberculosis in Glasgow with the findings in Edinburgh (Stein, 1950) reveals a similarity in the estimates and in the time-trends in the two cities. In both sets of regressions, the correlation coefficients are of the same order, and the proportions of "explained" variance are similar. The regression coefficients in the Glasgow relationships are more consistent, and the increases in notifications concomitant with increases in ordinary crowding are greater in Glasgow wards than in Edinburgh wards. On the other hand, the increases in tuberculosis associated with increases in overcrowding seem to be slightly greater in Edinburgh wards. The stronger connexion of Glasgow tuberculosis with ordinary crowding than with overcrowding seems to be again indicated by this comparison with Edinburgh.

Thus the close association between ward differences in respiratory tuberculosis and ward variations in environmental circumstances is revealed by each examination of each relationship. The importance of the "social complex" is manifest, no matter 
which index of social conditions be used; yet the relationships of the different social variables to tuberculosis are not by any means identical with each other. Differences in time-trends and differing degrees of importance in relation to mortality or to notifications are apparent in these analyses.

\section{Respiratory Tuberculosis Mortality in Relation to Notification}

These analyses of the relationship between the two aspects of the disease were made in order to examine more closely a connexion indicated in the Edinburgh study. Table IV summarizes this relationship between notification rates in any biennial period and mortality in the same and subsequent years in terms of correlation and regression coefficients.

TABLE IV

ResPiratory Tuberculosis in Glasgow, 1930-47: MoRtality in Relation to Notification Rate. Correlation Coefficients between Notification Rates in any 2-year period and Mortality Rates in the Succeeding Period.

$\mathrm{N}$ : Notification Rate per 10,000 Ward Population (2-year moving average)

L: Log. of Mortality Rate per 10,000 Population (2-year moving average)

\begin{tabular}{|c|c|c|c|}
\hline Notifications: $\mathbf{N}$ & Log. of Mortality: L & $\begin{array}{l}\text { Correlation } \\
\text { Coefficient: } r\end{array}$ & $\begin{array}{c}\text { Standard Error } \\
\text { of } r\end{array}$ \\
\hline $\begin{array}{l}1930-31 \\
1931-32 \\
1932-33 \\
1933-34 \\
1934-35 \\
1935-36 \\
1936-37 \\
1937-38 \\
1938-39 \\
1939-40 \\
1944-45 \\
1945-46\end{array}$ & $\begin{array}{l}1931-32 \\
1932-33 \\
1933-34 \\
1934-35 \\
1935-36 \\
1936-37 \\
1937-38 \\
1938-39 \\
1939-40 \\
1940-41 \\
1945-46 \\
1946-47\end{array}$ & $\begin{array}{l}\cdot 776 \\
.803 \\
.787 \\
\cdot 781 \\
.754 \\
\cdot 714 \\
.815 \\
.778 \\
\cdot 703 \\
\cdot 716 \\
.831 \\
.825\end{array}$ & $\begin{array}{l}.0655 \\
.0576 \\
.0617 \\
.0632 \\
.0700 \\
.0796 \\
.0545 \\
.0639 \\
.0819 \\
.0791 \\
.0502 \\
.0525\end{array}$ \\
\hline
\end{tabular}

The likelihood that correlation coefficients of this magnitude would arise by chance is less than 1 in 1,000 if $r$ exceeds $\cdot 512$.

The results show, as expected, a close connexion between the two sets of rates. Curvilinear equations were again found better than simple proportional equations in describing the relationship between the two aspects of the disease. Increases in mortality rates became augmented where notification rates were high; in wards where notification rates were twice the mean, mortality rates were rather more than twice the mean. The relationship found in pre-war years in Edinburgh was confirmed; moreover, in Glasgow, the upward curve of mortality, increasing more rapidly than notification rates, was especially marked in the post-war period. Fig. 3 (opposite) illustrates the upward curve of the mortality-notification association.

A more detailed consideration of the correlations and regressions reveals that, during the early 1930s, mortality corresponded closely with the distribution of current notification rates, and was equally strongly associated with notifications in preceding years. But towards the end of the decade the correlations of mortality with preceding notification rates were greater. In the post-war years the highest correlations were found when the interval between notifications and mortality was 2 years.

The regression equations can be translated into figures illustrating the relationship 


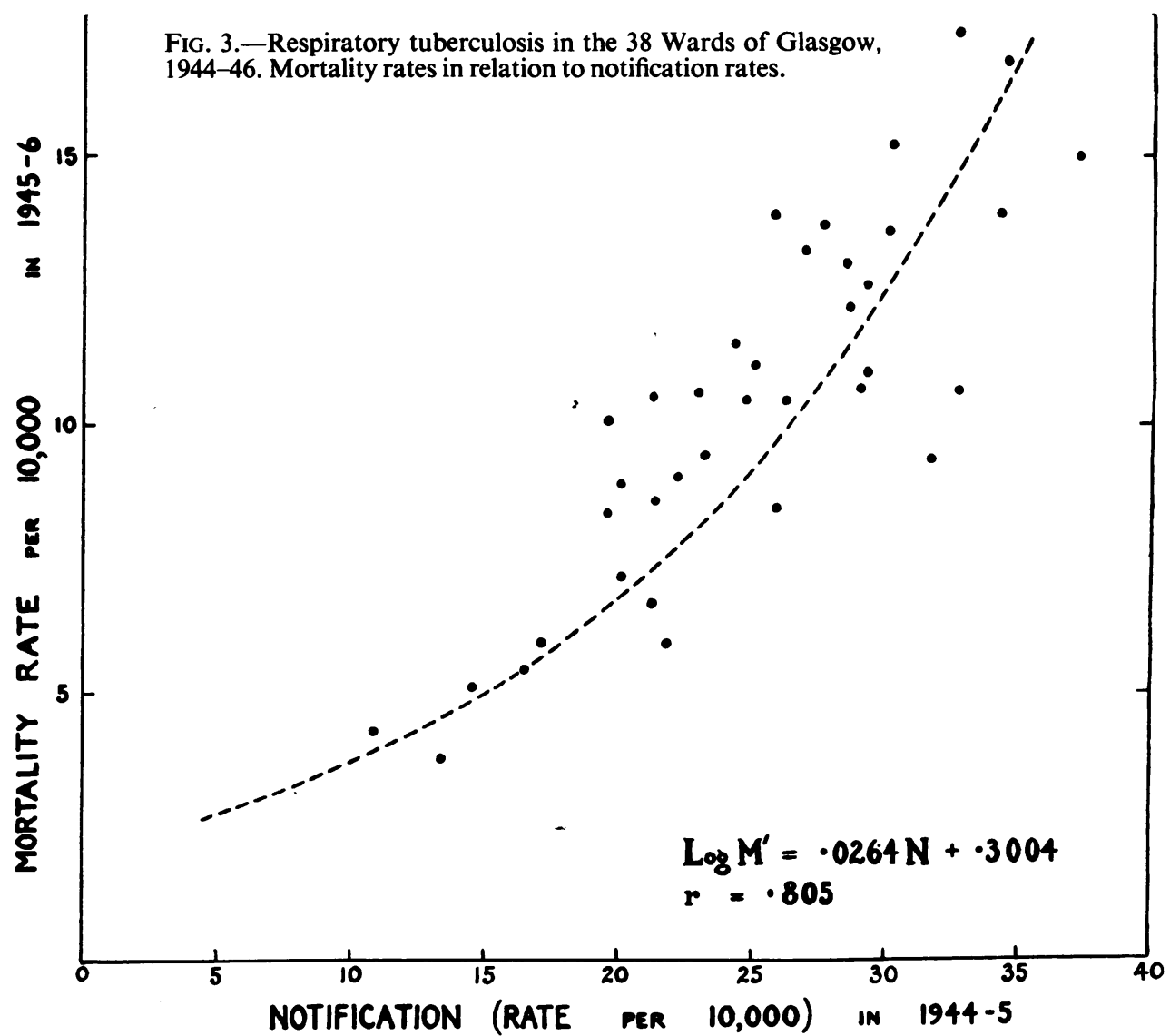

between the two disease rates. On the average, ward differences of 4 per 10,000 in notifications corresponded with differences of 1.5 to 2 per 10,000 in mortality, but the divergencies in mortality were smaller in wards where notification rates were low. The equations give the following estimates for the immediate post-war years.

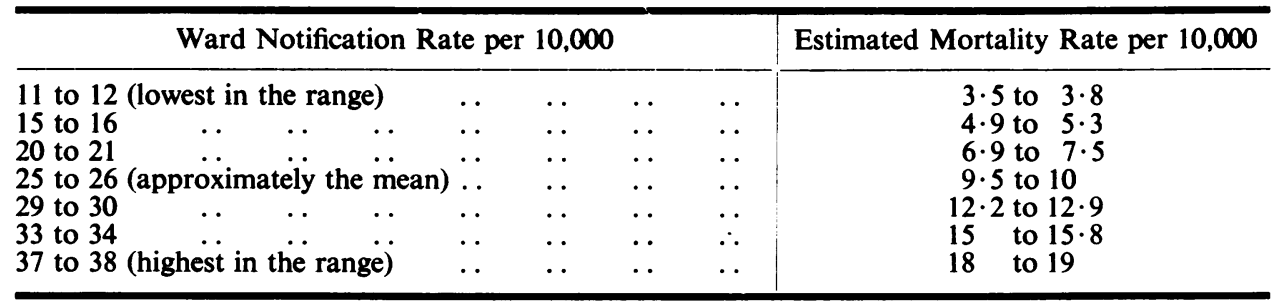

Thus in districts in which notification rates were high the population had not only more risk of contracting the disease, but had also a reduced chance of surviving after notification. The fact that this was no less marked in post-war than in pre-war years suggests that this relationship is not an illusory one attributable to lesser accuracy in notification in pre-war years. If pre-war notification practice were the explanation 
of this upward curve of mortality in relation to notifications, then the relationship could be expected to diminish in the post-war period.

\section{INCREASES IN ResPiratory Tuberculosis Between Pre-War aNd Post-War Years}

This investigation of increases in ward tuberculosis rates between 1936-38 and 1945-47 was undertaken to ascertain their relation to ward social conditions at the beginning of the period. The actual and percentage increases in ward mortality and notification rates are shown in Table V (opposite); Table VI (overleaf) summarizes the associations between these increases and each social distribution in 1935-36.

These analyses show that the mean mortality rate increased by 30 per cent. and the mean notification rate by 86 per cent. But many wards experienced greater increases, for both the ranges and variability of the ward increases were high. The regressions disclose that, though the associations between the increased tuberculosis rates in 1945-47 and the social distributions were stronger than before 1939, the actual increases in rates corresponded to a lesser degree with pre-war social conditions in the wards. Moreover, the percentage increases in each ward rate were negatively (though not highly) associated with poor social conditions. These consistently negative correlations with each social variable seem to indicate that the better-off wards experienced relatively greater increases in tuberculosis.

A more detailed consideration of these analyses discloses some interesting results. Firstly, the intensified association of the "social complex" with tuberculosis rates in the post-war triennium is apparent in the greater correlations and steeper slopes of the regressions with the various social indices. Regression coefficients and "explained" variance in the relationships of mortality with each social variable were greater in the post-war years. And in the notification equations with the social indices, the post-war increases in regression coefficients were still greater, the "explained" variance in the association with poverty being nearly double that of pre-war years. Fig. 4 (p. 19) shows the ordinary crowding and mortality rates in 1936-38 and in 1945-47, and indicates the regression curve in each relationship. It is evident that the whole level of mortality rates was higher in the post-war period, but in addition the upward curve of the mortality-crowding association was steeper in 1945-47.

Secondly, the actual ward increases in both mortality and notification rates were significantly associated with the distributions of certain social factors. Ward distributions of both unemployment and ordinary crowding in 1935-36 corresponded with increases in the disease rates; these social factors showed low correlations with the ward increases in mortality, and higher correlations with notification increases, significant at the 99 per cent. level. On the other hand, overcrowding and poverty distributions were related not at all to mortality increases, and only slightly to notification increases. Thus it seems that the distribution of increases in the disease was not related to excessively disadvantageous conditions such as statutory overcrowding or recognized poverty, but rather to the ordinary conditions of life in the 1930s, of general crowding and unemployment.

Thirdly (and surprisingly), each of the relationships between the percentage increases in ward tuberculosis rates and the pre-war social distributions revealed small negative correlations. The mortality correlations were in the main quite insignificant, but the negative association between overcrowding and percentage mortality increases was more than 97 per cent. significant. The notification correlations were higher, indicating more than 90 per cent. significance in connexion with ordinary crowding, unemployment, and poverty; and the negative association between overcrowding and percentage increases in notification rates was $99 \cdot 8$ per cent. significant. Although these correlations are small, the uniformly negative 
TABLE V

Respiratory Tuberculosis in Pre-War and Post-War Triennia

Mortality, Notifications, and Increases in the 38 Wards of Glasgow in 1936-38 and 1945-47

M : Mortality Rate per 10,000 Ward Population: 3-year average.

L : Log. of Mortality Rate.

$\mathrm{N}$ : Notification Rate per 10,000 Ward Population: 3-year average.

$I_{M}$ : Increase in Mortality-Actual increase in ward rate from 1936-38 to 1945-47.

$C_{M}$ : $\quad$ Percentage increase in mortality rate.

$I_{L}: \quad$ Actual increase in log. of mortality rate.

$I_{N}:$ Increase in Notifications-Actual increase in ward rate from 1936-38 to 1945-47.

$\mathrm{C}_{\mathrm{N}}$ : $\quad$ Percentage increase in notification rate.

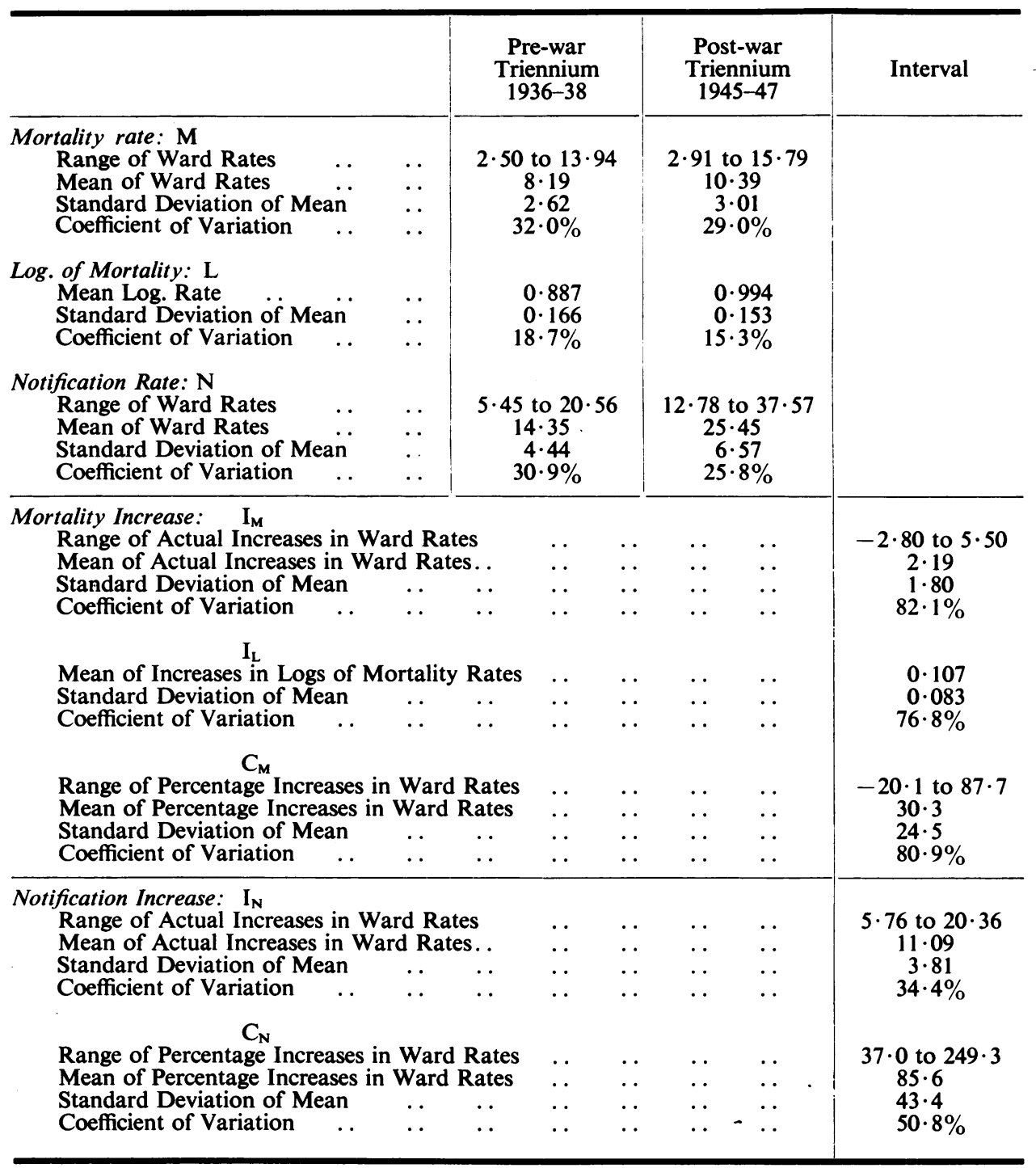


TABLE VI

Respiratory Tuberculosis in Pre-War and Post-War Triennia

Mortality and Notification Rates in relation to Ward Social Conditions in the 38 Wards OF GLASGOW, 1936-38 AND 1945-47

InCReases in Rates in Relation to Pre-war Social Conditions

\begin{tabular}{|c|c|c|c|c|c|c|c|}
\hline Social Index $\quad \ldots$ & \multicolumn{2}{|c|}{$\begin{array}{l}\text { Ordinary } \\
\text { Crowding }\end{array}$} & $\begin{array}{l}\text { Over- } \\
\text { crowding }\end{array}$ & \multicolumn{2}{|c|}{ Unemployment } & \multicolumn{2}{|c|}{ Poverty } \\
\hline $\begin{array}{lll}\text { Period } & . & \end{array}$ & $\begin{array}{c}1936-38 \\
\text { A }\end{array}$ & $\underset{\text { A }}{1945-47}$ & $\begin{array}{c}1936-38 \\
O\end{array}$ & $\underset{U}{1936-38}$ & $\stackrel{1945-47}{U}$ & $\underset{\mathrm{V}}{1936-38}$ & $\stackrel{1945-47}{R}$ \\
\hline $\begin{array}{l}\text { M: Mortality Rate } \\
\text { Correlation Coefficient } \\
\text { Regression Coefficient } \\
\text { Standard Error of } b\end{array}$ & $\begin{array}{c}\cdot 809 \\
7 \cdot 20 \\
\cdot 872\end{array}$ & $\begin{array}{l}\cdot 823 \\
9.37 \\
1.076\end{array}$ & $\begin{array}{l}\cdot 772 \\
\cdot 144 \\
\cdot 020\end{array}$ & $\begin{array}{l}\cdot 622 \\
\cdot 571 \\
\cdot 120\end{array}$ & $\begin{array}{c}.677 \\
2.96 \\
.536\end{array}$ & $\begin{array}{l}\cdot 640 \\
\cdot 163 \\
\cdot 033\end{array}$ & $\begin{array}{r}\cdot 771 \\
1.516 \\
\cdot 209\end{array}$ \\
\hline $\begin{array}{l}\text { L: Log. of Mortality } \\
\text { Correlation Coefficient } \\
\text { Regression Coefficient } \\
\text { Standard Error of } b \\
\text { "Explained" Variance } \\
\text { Variance Ratio F }\end{array}$ & $\begin{array}{l}\cdot 840 \\
\cdot 473 \\
.051 \\
71 \% \\
86 \cdot 2\end{array}$ & $\begin{array}{l}\cdot 847 \\
.488 \\
.051 \\
72 \% \\
91 \cdot 6\end{array}$ & $\begin{array}{l}\cdot 788 \\
.0093 \\
.0012 \\
62 \% \\
58 \cdot 9\end{array}$ & $\begin{array}{r}\cdot 644 \\
.037 \\
.007 \\
42 \% \\
25 \cdot 5\end{array}$ & $\begin{array}{l}.665 \\
.147 \\
.028 \\
44 \% \\
28 \cdot 6\end{array}$ & $\begin{array}{l}\cdot 703 \\
.011 \\
.002 \\
49 \% \\
35 \cdot 1\end{array}$ & $\begin{array}{l}.742 \\
.074 \\
.011 \\
55 \% \\
44 \cdot 2\end{array}$ \\
\hline $\begin{array}{l}\text { N: Notification Rate } \\
\text { Correlation Coefficient } \\
\text { Regression Coefficient } \\
\text { Standard Error of } b \\
\text { "Explained"Variance } \\
\text { Variance Ratio F }\end{array}$ & $\begin{array}{l}\cdot 757 \\
11 \cdot 41 \\
1 \cdot 64 \\
57 \% \\
48 \cdot 3\end{array}$ & $\begin{array}{l}\cdot 741 \\
18 \cdot 41 \\
2 \cdot 78 \\
55 \% \\
43 \cdot 9\end{array}$ & $\begin{array}{l}\cdot 823 \\
\cdot 261 \\
.030 \\
68 \% \\
75 \cdot 7\end{array}$ & $\begin{array}{l}\cdot 734 \\
1 \cdot 14 \\
\cdot 176 \\
54 \% \\
42 \cdot 0\end{array}$ & $\begin{array}{l}\cdot 786 \\
7 \cdot 50 \\
.982 \\
62 \% \\
58 \cdot 3\end{array}$ & $\begin{array}{l}\cdot 596 \\
\cdot 257 \\
.058 \\
36 \% \\
19 \cdot 9\end{array}$ & $\begin{array}{r}\cdot 833 \\
3 \cdot 576 \\
.396 \\
69 \% \\
81 \cdot 7\end{array}$ \\
\hline $\begin{array}{l}\text { Mortality Increases: } \\
\text { Correlation Coefficient }\end{array}$ & $\cdot 207$ & & -.018 & $\cdot 175$ & & $\cdot 133$ & \\
\hline Correlation Coefficient & $-\cdot 155$ & & $-\cdot 356$ & $-\cdot 130$ & & $-\cdot 066$ & \\
\hline Correlation Coefficient & $-\cdot 366$ & & -.467 & $-\cdot 258$ & & $-\cdot 161$ & \\
\hline $\begin{array}{l}\text { Notification Increases: I } \\
\text { Correlation Coefficient }\end{array}$ & $\cdot 407$ & & $\cdot 253$ & $\cdot 488$ & & $\cdot 254$ & \\
\hline Correlation Coefficient & $-\cdot 294$ & & -.484 & $-\cdot 270$ & & $-\cdot 280$ & \\
\hline
\end{tabular}

CORRELATION COEFFICIENTS

The significance level of a correlation coefficient $r$ is:

$\begin{array}{llll}\text { above } 90 \% & \text { (i.e. probability of chance occurrence less than } 1 \text { in } & 10 \text { ) if } r \text { exceeds } \cdot 271 \\ \text { above } 95 \% & \text { (i.e. probability of chance occurrence less than } 1 \text { in } & 20 \text { ) if } r \text { exceeds } \cdot 320 \\ \text { above } 98 \% & \text { (i.e. probability of chance occurrence less than } 1 \text { in } 50 \text { ) if } r \text { exceeds } \cdot 376 \\ \text { above } 99 \% & \text { (i.e. probability of chance occurrence less than } 1 \text { in 100) if } r \text { exceeds } \cdot 413 \\ \text { above } 99.9 \% & \text { (i.e. probability of chance occurrence less than } 1 \text { in 1000) if } r \text { exceeds } \cdot 512 \\ \text { above } 99.95 \% & \text { (i.e. probability of chance occurrence less than } 1 \text { in 2000) if } r \text { exceeds } \cdot 566\end{array}$

regressions are not to be ignored. They imply that there was a small but definite correspondence between pre-war social conditions and proportionally greater increases in tuberculosis, particularly in notification rates. Clearly this does not mean that districts with better environments experienced the greater increases in the disease: a connexion between greater percentage increases and better pre-war social conditions is easily explicable in view of the all-round increases in tuberculosis. But these negative correlations confirm-the fact that the increases were all-round, and not confined to one group of people or to a few localities. 


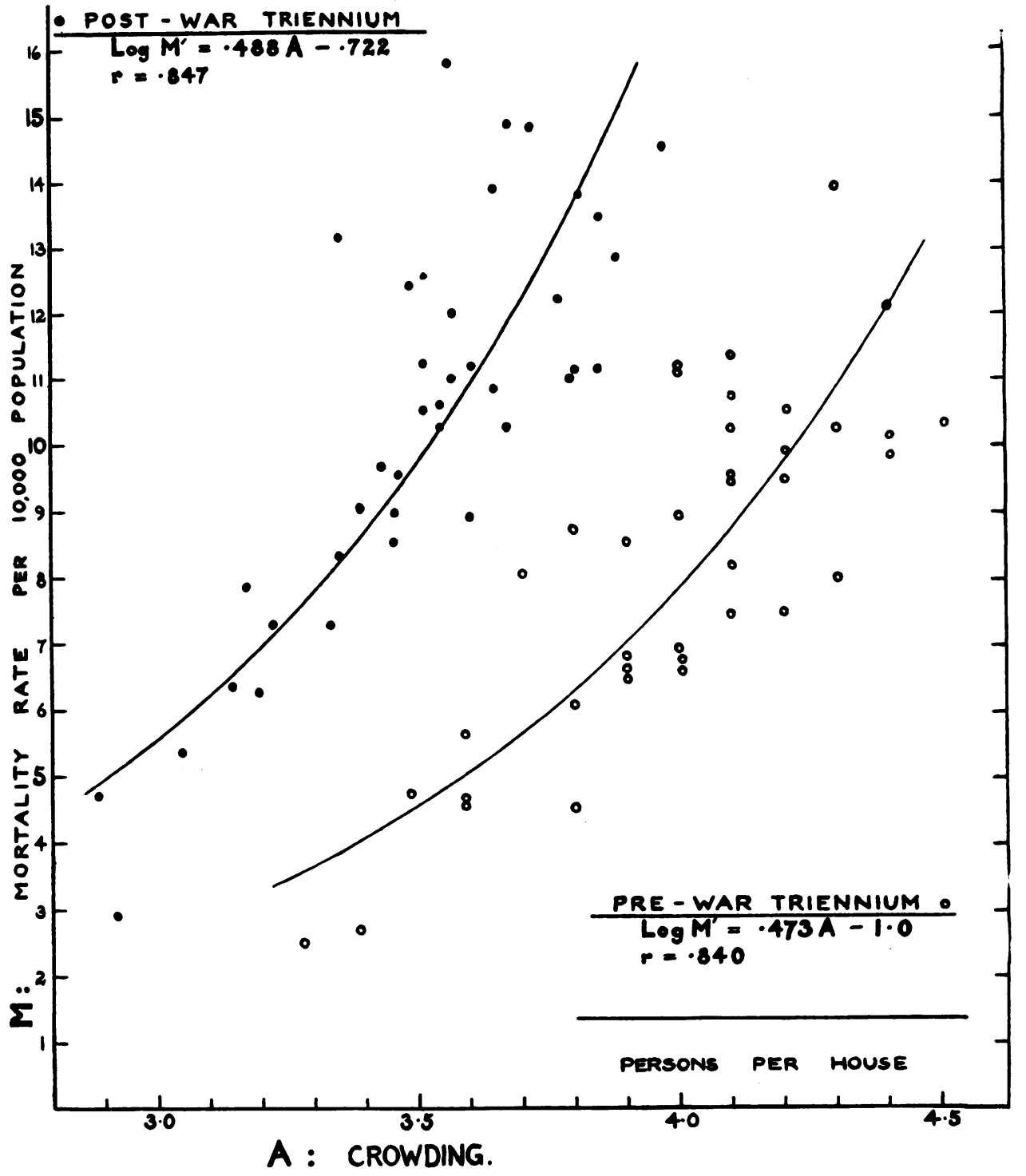

FIG. 4.-Respiratory tuberculosis in the 38 Wards of Glasgow. Mortality rates in relation to ordinary crowding in the pre-war triennium (1936-38), and in the post-war triennium (1945-47).

In general, these analyses indicate that the actual increases in ward tuberculosis rates added greatly to the disadvantageous experience of those districts in which prewar unemployment and ordinary crowding were disadvantageous and in which pre-war tuberculosis rates were already high. But the widespread increases made a relatively greater mark in wards which in pre-war days had lower disease rates and 
better environmental conditions. Such a result is to be expected when one considers that an infectious disease does not confine itself within the worst-housed wards, and that the spread of infection will inevitably be disadvantageous to areas previously least affected.

\section{Respiratory Tuberculosis and the "Social CompleX"}

Analyses of the relationships between the distributions of disease rates and the social variables, taken two, three, and four together, have been made for each triennium in the period 1930-47. Since space does not permit the inclusion of all the results, the regressions for the three triennia, 1930-32, 1936-38, and 1945-47, have been selected as representing the whole period. The relationships are summarized in Tables VII, VIII, and IX, in which are set forth partial regression coefficients, partial and total correlations, variance analyses, and significance levels of the associations found between the two aspects of tuberculosis and the many combinations of the social factors. In addition, several regression equations are discussed more fully, and are illustrated by diagrams of variance analyses or of regression estimates.

The findings demonstrate the strong and consistent association between tuberculosis and the group of social factors, and reveal the dominant role of ordinary crowding and overcrowding. Exceptionally large proportions of variance due to ward differences in tuberculosis rates were "explained" by ward divergencies in this complex of social conditions, and the housing factors alone contributed the greater part of this variance. The overlap of the social factors with each other, as shown by their residual inter-correlations was, in most cases, very small. The results confirm that the social factors are not related to notifications in precisely the same manner as to mortality, and that different factors are not of equal weight in the "complex" at all times.

The strength of the connexion between both mortality and notification distributions and the "complex" of social distributions is demonstrated by the high total correlations in the multiple relationships; all were above 0.875 and many were greater than $0 \cdot 9$. Partial correlations with individual social factors within each multiple relationship were also large; and partial regression coefficients of ordinary crowding and overcrowding were highly significant. The variance "explained", both for mortality and for notification distributions, was 80 per cent. or more-a proportion so high that the likelihood of chance occurrence is less than 1 in 2,000 (significant above the 99.95 per cent. level). In these amounts of variance absorbed, ordinary crowding contributed 30 to 50 per cent. in the mortality relationships, and 20 to 30 per cent. in the notification regressions. Overcrowding contributions to the "explained" variance were of similar magnitudes, but in the reverse order in relation to mortality and notifications. In the pre-war regressions poverty and unemployment contributed smaller percentages to "explained" variance; but in the post-war period (in which overcrowding was not considered), the variance "explained" by poverty in association with mortality was nearly 20 per cent. In all periods, the influence of poverty in the mortality relationships was considerable, whereas unemployment played a very small part. But in relation to notifications, poverty contributed little to variance "explained", and unemployment was of greater importance.

The differences in importance of the social factors in association with the two aspects of the disease will be revealed more clearly later in this section, in the analyses of pre-war and 


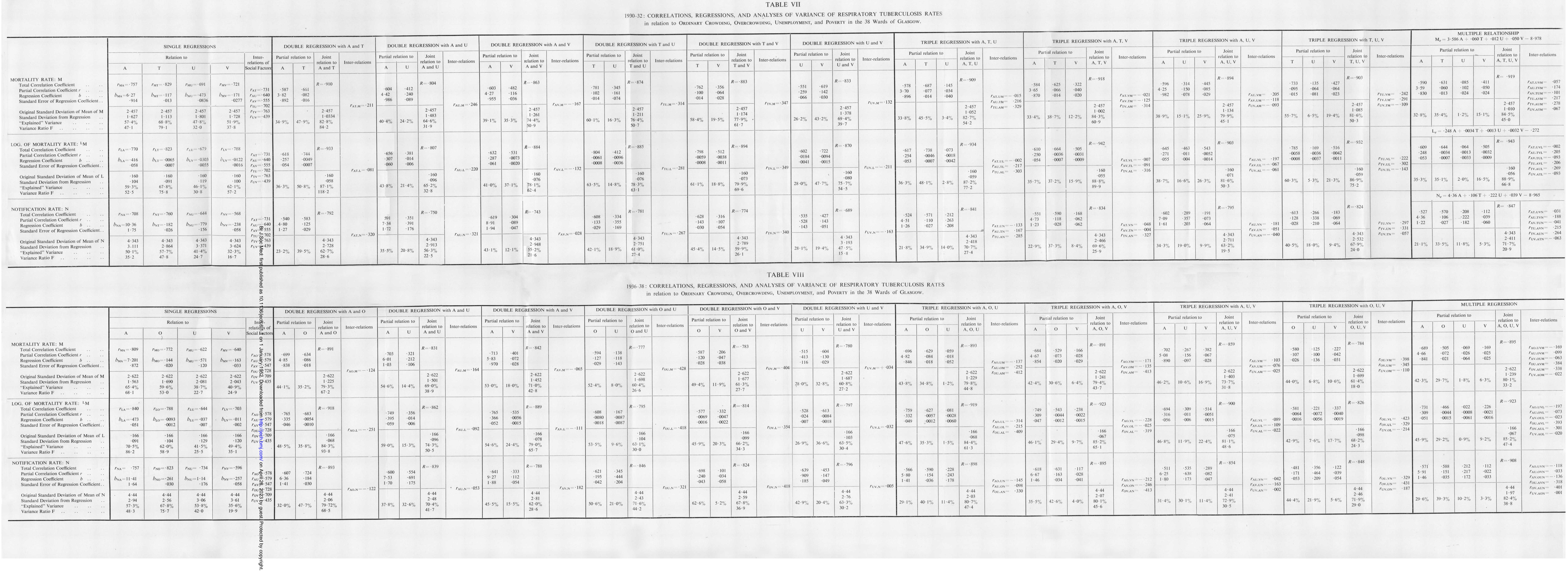


post-war regression equations and in the diagrams which illustrate them. The intercorrelations between the social factors in the multiple equations indicate that there was almost no "overlap" between the distribution of ordinary crowding and the distributions of the other social variables. But some correspondence was found between poverty and overcrowding, and again between unemployment and overcrowding in the later 1930s. To some extent, the poverty and unemployment distributions were described by the overcrowding distribution: at the same time, there seemed to be sufficient dissimilarity between these three to make their contributions to regression different and of some size. It was surprising to find little correlation between average crowding and overcrowding, and only small residual correlations between ordinary crowding and poverty or unemployment. In most of the multiple equations, the partial correlations between ordinary crowding and overcrowding were very small and negative, and not significant. The inter-correlations between the other three social variables were of a higher order, but varied with the years. The correspondence between poverty and unemployment in the pre-war years was small, but increased in the post-war period.

Pre-War Relationships.-The estimated relationships of tuberculosis with the social distributions in various triennia in the 1930s were similar to those for 1930-32 (Table VII). They show, as do also the regressions for later periods, that the equations expressing the disease rates in terms of the social variables give a remarkably good "fit": standard errors of estimate (or standard deviations from regression) were small, and were always less than half the original standard deviations of means of mortality or notification rates. A still better "fit" was obtained in the regressions in which the logarithms of martality rates were used, indicating again the upward curve of mortality as social conditions worsened. The equations for 1936-38 (Table VIII) not only indicate time-trends, but also include all four social variables. The estimated relationships of tuberculosis rates with these variables in 1936-38 were these:

$$
\begin{aligned}
& \mathbf{M}_{e}=4.655 \mathrm{~A}+.072 \mathrm{O}+.026 \mathrm{U}+.025 \mathrm{~V}-12.791 \\
& \mathbf{L}_{\boldsymbol{e}}=.309 \mathrm{~A}+.0044 \mathrm{O}+.0008 \mathrm{U}+.0021 \mathrm{~V}-.495 \\
& \mathbf{N}_{\boldsymbol{e}}=5.905 \mathrm{~A}+.151 \mathrm{O}+.217 \mathrm{U}+.022 \mathrm{~V}-14.955
\end{aligned}
$$

where $M_{e}$ represents estimated mortality rate (per 10,000 ward population).

$L_{e}$ represents estimated $\log _{10}$ of mortality rate.

$\mathrm{N}_{e}$ represents estimated notification rate (per 10,000 population).

$\mathrm{A}$ represents ordinary crowding (ward average of persons per house).

O represents statutory overcrowding (percentage overcrowded houses).

$\mathrm{U}$ represents unemployment (adult unemployed men per cent. of population).

$\mathrm{V}$ represents poverty (valuation of ward according to rentals).

The high total correlations of mortality with the social combination and the large proportion of "explained" variance, particularly in the logarithmic regression, are shown in Table VIII. These relationships were remarkably similar to the post-war mortality relationships which will be illustrated later; the relative importance of the different social factors is apparent in the partial correlations of each factor with mortality or with notifications.

The notification relationship, represented by the third of the above equations, is illustrated in Fig. 5 (overleaf). The "explained" variance, 82 per cent. of the total, was again dominated by contributions from ordinary crowding and overcrowding of nearly 30 and 40 per cent. respectively, and the partial correlation with unemployment was also significant.

The diagram illustrates the contributions of each social factor, individually and in combination with other factors, to the variance "explained" in the notification relationship. The first four columns illustrate the direct correlations in individual association with notifications. In these four correlations could be perceived the final order of importance of the social variables; and this ranking re-appears in the 
subsequent relationships when two or three social distributions are considered simultaneously. The second set of six columns, representing pairs of social factors, demonstrates also the extremely high proportion of variance "explained" by ordinary crowding coupled with overcrowding; other combinations gave a lesser correspondence with the distribution of notifications. The third set of six columns amplifies these conclusions, for it shows also that the earlier large contributions of overcrowding represented to some extent the contributions of poverty and unemployment. It is apparent that, though little was added to the "explained" variance when three social factors were combined, a clearer picture of the influence of each was presented.

The final column depicts the association between notification rates and the social complex in the wards. The contribution of poverty almost disappeared when the other social distributions were included, and the contribution of unemployment was still further reduced by the inclusion of poverty in the regression. It is manifest that, in this pre-war triennium, a single social variable did not adequately simulate the social complex in relation to tuberculosis. But a suitable pair of variables, ordinary crowding and overcrowding, gave in combination a good "model" which illustrated the total influence of the social complex on tuberculosisa "model", however, which could not bring out the magnitude of the contributions of poverty and unemployment.

Post-WAR ReLATIONSHIPS.-The preceding relationships for pre-war years gave some indications of the reduction in poverty and unemployment correlations when the overcrowding distribution was included in the equations. The post-war equations do not include overcrowding, since no data are available, and it is to be expected therefore that in the post-war regressions the contributions of poverty and unemployment to "explained" variance would be larger. The regressions for tuberculosis mortality and notification rates in terms of ward social conditions in the post-war years, however, are of interest at the present time. The summary in Table IX shows the high correlations and small standard deviations from regression, to which reference has already been made.
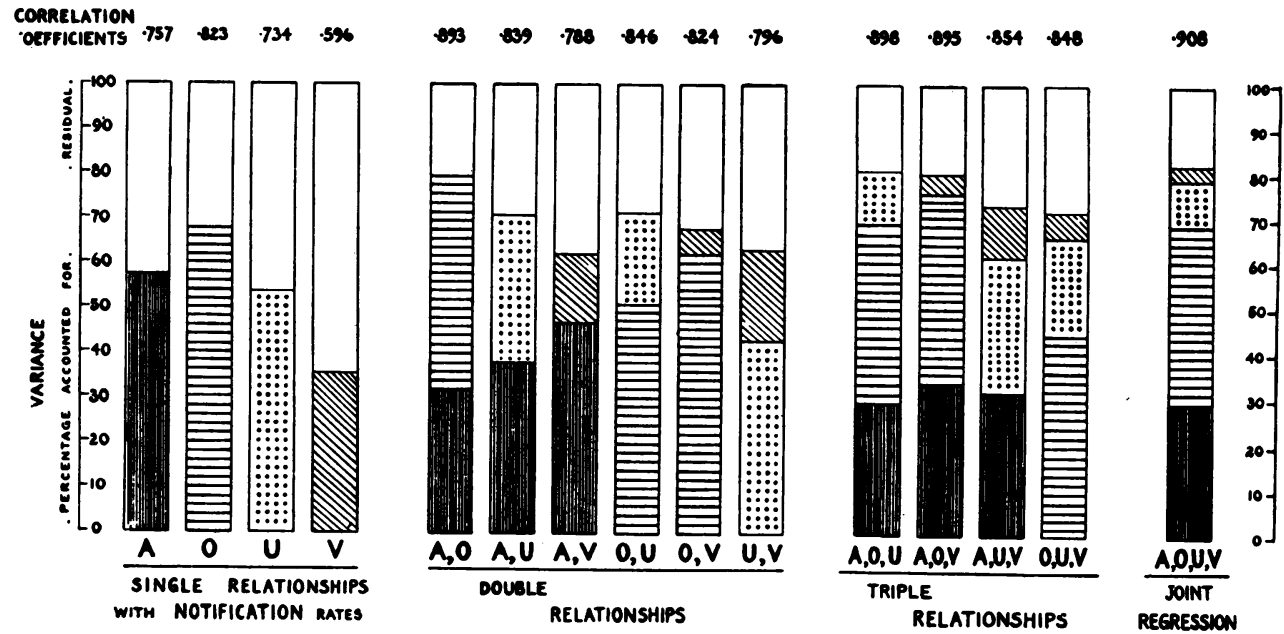

FIG. 5.-Respiratory tuberculosis notifications in the 38 wards of Glasgow, 1936-38. Contributions to variance of ward notification rates; percentages "explained" by A: ordinary crowding, $O$ : overcrowding, $U$ : unemployment, and $V$ : poverty, separately and in combination. 
TABLE IX

1945-47: CORR $\stackrel{\widehat{\Phi}}{\mathrm{D}}$ ATIONS, REGRESSIONS, AND ANALYSES OF VARIANCE OF RESPIRATORY TUBERCULOSIS RATES

\begin{tabular}{|c|c|c|c|c|c|c|c|c|c|c|c|c|c|c|c|c|c|c|c|c|c|}
\hline \multirow{5}{*}{ 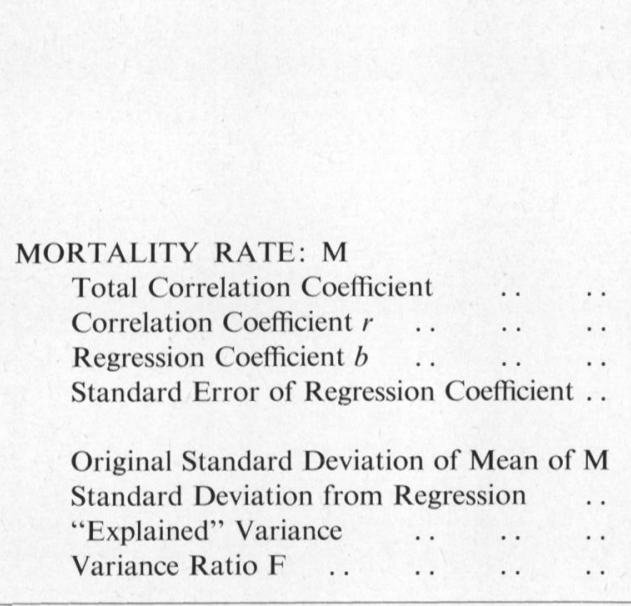 } & \multicolumn{4}{|c|}{ SINGLE REGRESSIONS } & \multicolumn{4}{|c|}{ DOUBLE REGRESSION with $\mathrm{A}$ and $\mathrm{U}$} & \multicolumn{4}{|c|}{ DOUBLE REGRESSION with $A$ and $R$} & \multicolumn{4}{|c|}{ DOUBLE REGRESSION with $U$ and $R$} & \multicolumn{5}{|c|}{ MULTIPLE REGRESSION } \\
\hline & \multicolumn{3}{|c|}{ Relation to } & \multirow{2}{*}{$\begin{array}{c}\text { Inter-r-elation } \\
\text { of Social } \\
\text { Factors }\end{array}$} & \multicolumn{2}{|c|}{ Partial relation to } & \multirow{2}{*}{$\begin{array}{l}\text { Joint } \\
\text { relation to } \\
\mathrm{A} \text { and } \mathrm{U}\end{array}$} & \multirow{2}{*}{ Inter-relations } & \multicolumn{2}{|c|}{ Partial relation to } & \multirow{2}{*}{\begin{tabular}{|c|} 
Joint \\
relation to \\
$\mathrm{A}$ and $\mathrm{R}$
\end{tabular}} & \multirow{2}{*}{ Inter-relations } & \multicolumn{2}{|c|}{ Partial relation to } & \multirow{2}{*}{$\begin{array}{l}\text { Joint } \\
\text { relation to } \\
\mathrm{U} \text { and } \mathrm{R}\end{array}$} & \multirow{2}{*}{ Inter-relations } & \multicolumn{3}{|c|}{ Partial relation to } & \multirow{2}{*}{\begin{tabular}{|l} 
Joint \\
relation to \\
A, U, R
\end{tabular}} & \multirow{2}{*}{ Inter-relations } \\
\hline & A & $\mathrm{u}$ & $\mathrm{R}$ & & A & u & & & A & $\mathrm{R}$ & & & $\mathrm{u}$ & $\mathrm{R}$ & & & A & $\mathrm{u}$ & $\mathrm{R}$ & & \\
\hline & $\begin{array}{r}r_{\mathrm{MA} A}=.823 \\
b_{\mathrm{MA}}=9.37 \\
1.08 \\
\end{array}$ & $\begin{aligned} & r_{\mathrm{MU}}= .677 \\
& b_{\mathrm{MU}}=2.96 \\
& .54\end{aligned}$ & $\begin{array}{r}r_{\mathrm{MR} R}=.771 \\
b_{\mathrm{MR}}=1.52 \\
.21\end{array}$ & \multirow[t]{2}{*}{$\begin{array}{l}r_{\mathrm{AA}}=.564 \\
r_{\mathrm{A}}=.646 \\
r_{\mathrm{URR}}=.780\end{array}$} & $\begin{array}{l}.726 \\
7.37 \\
1.18\end{array}$ & $\begin{array}{r}.453 \\
1.36 \\
\cdot 45\end{array}$ & \multirow[t]{2}{*}{$R=\cdot 862$} & \multirow[t]{2}{*}{$r_{\mathrm{AU}, \mathrm{M}}=\cdot 017$} & $\begin{array}{l}.669 \\
6 \cdot 35 \\
1 \cdot 19\end{array}$ & $\begin{array}{l}.552 \\
.81 \\
.21\end{array}$ & \multirow[t]{2}{*}{$R=\cdot 881$} & \multirow[t]{2}{*}{$r_{\mathrm{AR}, \mathrm{M}}=\cdot \mathbf{0 3 0}$} & $\begin{array}{l}.189 \\
.84 \\
.74\end{array}$ & $\begin{array}{l}.528 \\
1.22 \\
.33\end{array}$ & \multirow[t]{2}{*}{$R=\cdot 780$} & \multirow[t]{2}{*}{$r_{\text {UR.M } M}=450$} & $\begin{array}{l}.663 \\
6.22 \\
1.21\end{array}$ & $\begin{array}{l}.142 \\
.472 \\
.57\end{array}$ & $\begin{array}{l}.378 \\
.66 \\
.28\end{array}$ & \multirow{2}{*}{$\begin{array}{c}R=\cdot 883 \\
\\
\\
3 \cdot 01 \\
1 \cdot 47 \\
78 \cdot 0 \% \\
40 \cdot 3\end{array}$} & \multirow[t]{2}{*}{$\begin{array}{l}r_{\mathrm{A} \text { A.MR }}=\cdot 003 \\
r_{\mathrm{AR}, \mathrm{MU}}=.025 \\
r_{\mathrm{URR}, \mathrm{MA}}=-.326\end{array}$} \\
\hline & $\begin{array}{l}3 \cdot 01 \\
1.73 \\
67.8 \% \\
75 \cdot 7\end{array}$ & $\begin{array}{r}3.01 \\
2.25 \\
45.8 \% \\
30.4\end{array}$ & $\begin{array}{l}3 \cdot 01 \\
1 \cdot 94 \\
59 \cdot 4 \% \\
52 \cdot 7\end{array}$ & & $53 \cdot 3 \%$ & $21 \cdot 1 \%$ & & & $46.0 \%$ & $31 \cdot 6 \%$ & & & $13.0 \%$ & $47.9 \%$ & & & $45 \cdot 0 \%$ & $7 \cdot 3 \%$ & $25 \cdot 7 \%$ & & \\
\hline 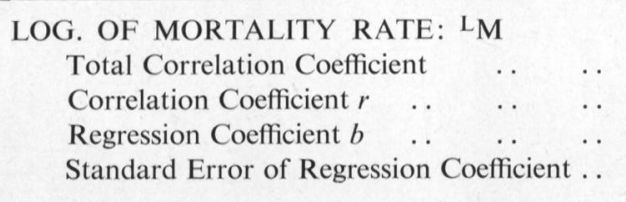 & $\begin{aligned} r_{\mathrm{LA}}= & \cdot 847 \\
b_{\mathrm{LA}}= & \cdot 488 \\
& .051\end{aligned}$ & $\begin{aligned} r_{\mathrm{LU}}= & \cdot 665 \\
b_{\mathrm{LU}}= & \cdot 147 \\
\cdot & .228\end{aligned}$ & $\begin{aligned} r_{\mathrm{LR}}= & .742 \\
b_{\mathrm{LR}}= & .074 \\
& .011\end{aligned}$ & \multirow[t]{2}{*}{$\begin{array}{l}r_{\mathrm{AU}}=.564 \\
r_{\mathrm{AR}}=.676 \\
r_{\mathrm{UR}}=.780\end{array}$} & $\begin{array}{l}.766 \\
.3999 \\
.057\end{array}$ & $\begin{array}{l}.427 \\
.061 \\
.022\end{array}$ & \multirow[b]{2}{*}{$\begin{array}{r}\quad 153 \\
\quad .075 \\
76.9 \% \\
58.4\end{array}$} & \multirow[t]{2}{*}{$r_{\mathrm{AU} . \mathrm{L}}=\cdot 001$} & $\begin{array}{l}.719 \\
.364 \\
.059\end{array}$ & $\begin{array}{l}.482 \\
.033 \\
.010\end{array}$ & \multirow[t]{2}{*}{$R=\cdot 885$} & \multirow[t]{2}{*}{$r_{\mathrm{AR} . \mathrm{L}}=\cdot 046$} & $\begin{array}{l}.206 \\
.049 \\
.039\end{array}$ & $\begin{array}{l}.479 \\
.057 \\
.018\end{array}$ & $R=.755$ & $r_{\text {UR.L }}=\cdot 471$ & $\begin{array}{l}.714 \\
.356 \\
.060\end{array}$ & $\begin{array}{l}.166 \\
.028 \\
.029\end{array}$ & $\begin{array}{l}.295 \\
.025 \\
.014\end{array}$ & $R=.888$ & $\begin{array}{l}r_{\text {AU.LR }}=-.031 \\
r_{\text {AR.LU }}=.056 \\
r_{\text {UR.LA }}=.362\end{array}$ \\
\hline 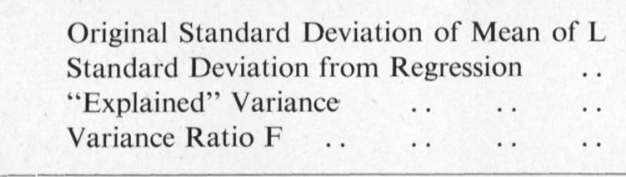 & $\begin{array}{r}\cdot 153 \\
.082 \\
71 \cdot 8 \% \\
91 \cdot 6\end{array}$ & $\begin{array}{r}\cdot 153 \\
.115 \\
4 \cdot 2 \% \\
28 \cdot 6\end{array}$ & $\begin{array}{r}.153 \\
.104 \\
55.1 \% \\
44 \cdot 2\end{array}$ & & $=2$ & $18 \cdot 2 \%$ & & & $53.5 \%$ & $24 \cdot 9 \%$ & & & $14 \cdot 6 \%$ & $42 \cdot 4 \%$ & $\begin{array}{r}\cdot 153 \\
\cdot 103 \\
57.0 \% \\
23 \cdot 2\end{array}$ & & $52 \cdot 4 \%$ & $8 \cdot 3 \%$ & $18 \cdot 3 \%$ & $\begin{array}{r}.153 \\
.073 \\
78.9 \% \\
42.5\end{array}$ & \\
\hline 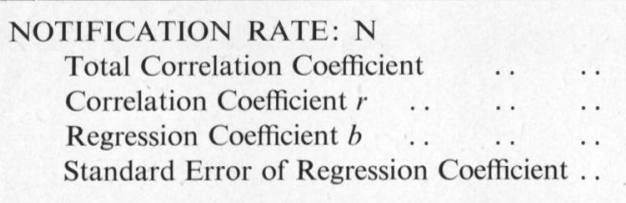 & $\begin{array}{r}r_{\mathrm{NA}}=.814 \\
b_{\mathrm{NA}}=21.75 \\
2.59\end{array}$ & $\begin{array}{r}r_{\mathrm{NU}}=.786 \\
b_{\mathrm{NU}}=7.50 \\
.98\end{array}$ & $\begin{aligned} & r_{\mathrm{NR}}==833 \\
& b_{\mathrm{NR}}=3.58 \\
& \cdot 40\end{aligned}$ & $\begin{array}{l}r_{\mathrm{AU}}=.564 \\
r_{\mathrm{AR}}=.645 \\
r_{\mathrm{UR}}=.780\end{array}$ & $\begin{array}{ll}6 & .664 \\
b_{5} & 14.22 \\
0 & 2.70\end{array}$ & $\begin{array}{l}.534 \\
3.93 \\
.92\end{array}$ & $R=\cdot 865$ & $r_{\mathrm{AU}, \mathrm{N}}=-.045$ & $\begin{array}{c}\cdot 642 \\
13 \cdot 43 \\
2 \cdot 71\end{array}$ & $\begin{array}{r}.545 \\
1.88 \\
.43\end{array}$ & $R=.875$ & $r_{\mathrm{AR} . \mathrm{N}}=.075$ & $\begin{array}{l}.395 \\
3 \cdot 32 \\
1.31\end{array}$ & $\begin{array}{r}.569 \\
2 \cdot 41 \\
.596\end{array}$ & $R=.861$ & $r_{\mathrm{UR}, \mathrm{N}}=\cdot 365$ & $\begin{array}{r}.574 \\
11.01 \\
2.69\end{array}$ & $\begin{array}{l}.384 \\
2.85 \\
1 \cdot 18\end{array}$ & $\begin{array}{r}.412 \\
1.21 \\
\cdot 46\end{array}$ & $R=.894$ & $\begin{array}{l}r_{\text {AU,NR }}=-.078 \\
r_{\text {AR.NU }}=.091 \\
r_{\text {UR.NA }}=.349\end{array}$ \\
\hline 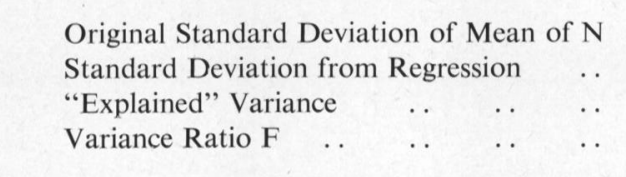 & $\begin{array}{r}6.57 \\
3.94 \\
65.0 \% \\
66.86\end{array}$ & $\begin{array}{l}6 \cdot 57 \\
4 \cdot 12 \\
61.8 \% \\
58 \cdot 3\end{array}$ & $\begin{array}{l}6.57 \\
3.68 \\
69.4 \% \\
81.7\end{array}$ & & 焉 $42 \cdot 4 \%$ & $32 \cdot 4 \%$ & $\begin{array}{l}6 \cdot 57 \\
3 \cdot 39 \\
74 \cdot 8 \% \\
52 \cdot 0\end{array}$ & & $40 \cdot 1 \%$ & $36 \cdot 4 \%$ & $\begin{array}{l}6.57 \\
3 \cdot 27 \\
76.5 \% \\
57 \cdot 0\end{array}$ & & $27.4 \%$ & $46 \cdot 8 \%$ & $\begin{array}{l}6 \cdot 57 \\
3 \cdot 43 \\
74 \cdot 2 \% \\
50 \cdot 3\end{array}$ & & $32 \cdot 9 \%$ & $23 \cdot 5 \%$ & $23 \cdot 6 \%$ & $\begin{array}{l}6 \cdot 57 \\
3.07 \\
80 \cdot 0 \% \\
45 \cdot 2\end{array}$ & \\
\hline
\end{tabular}


The actual equations give estimates of the disease rates in 1945-47 in relation to ordinary crowding, unemployment and poverty: the estimated mortality rates were these:

$$
\begin{aligned}
\mathrm{M}_{e} & =6.225 \mathrm{~A}+.472 \mathrm{U}+.656 \mathrm{R}-14.083 \\
\mathrm{~L}_{\boldsymbol{e}} & =.356 \mathrm{~A}+.028 \mathrm{U}+.025 \mathrm{R}-.369
\end{aligned}
$$

where $M_{e}$ represents estimated mortality rate (per 10,000 ward population).

$L_{e}$ represents estimated log. of mortality rate.

A represents ordinary crowding (ward average of persons per house).

U represents unemployment (adult unemployed men per cent. of population).

$R$ represents poverty (persons on relief per cent. of ward population).

In the first equation, in which the total correlation of mortality with the social distributions was $\cdot 883$, the partial correlations with ordinary crowding $(\cdot 663)$ and with poverty $(\cdot 378)$ are both significant. The influence of each social factor is also illustrated by each partial regression coefficient; in the case of ordinary crowding, this coefficient indicates that wards differing in average crowding by one person per house differed by more than six deaths per 10,000 persons. A similar difference of 6.225 in the death-rate would have been expected in wards which differed by 13 per cent. in the male unemployment percentage or by 9.5 per cent. in population living on relief. Since in 1945-47 the entire range of the unemployment index was only 2.4 per cent., and that of poverty 6.4 per cent., there were no ward differences in these social conditions sufficiently large to be associated with six deaths. The much greater association of ordinary crowding with mortality is evident.

The estimates of mortality obtained from the logarithmic equation given above corresponded still more closely to the actual ward rates, and in this regression the variance "explained" was 79 per cent. The parts played by the contributions of the three social variables are illustrated in Fig. 6, which analyses the mortality variance "explained" by the social distributions in simple and multiple associations. The first

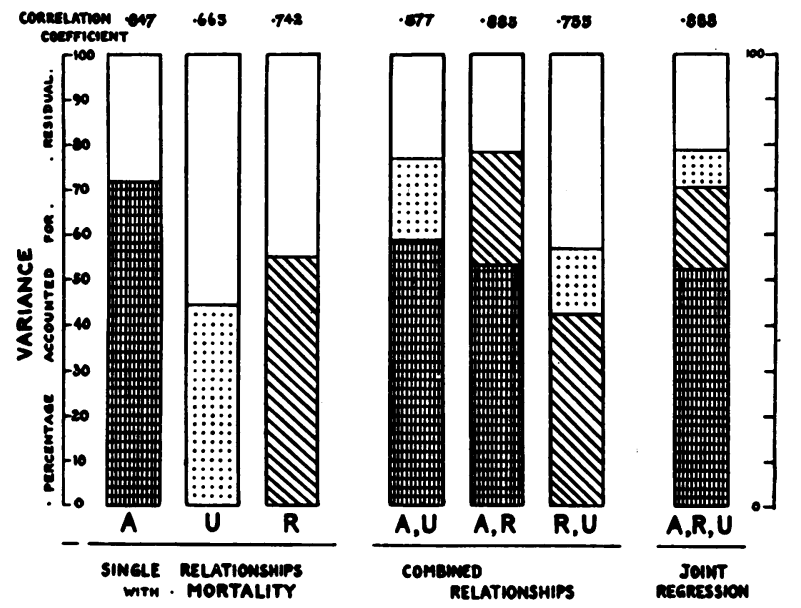

Fig. 6.-Respiratory tuberculosis mortality in the 38 wards of Glasgow, 1945-47. Contributions to variance of ward mortality - rates "explained" by A: ordinary crowding, $\mathrm{U}$ : unemployment, and $\mathrm{R}$ : poverty, separately and in combination. set of three columns depicts the variance accounted for in the simple association of mortality with each single factor; the order of importance implied by these correlations is repeated in the more complex relationships. The second set of columns demonstrates that there was some increase in "explained" variance when social distributions were combined, particularly when ordinary crowding and poverty were coupled; the combination of unemployment and poverty did not account for much more variance than did poverty alone. The final 
column illustrates the relative importance of each social component and it can be seen that the total "explained" variance was little more than that "explained" by the ordinary crowding-poverty distributions. Moreover, the contribution of ordinary crowding remained almost unchanged, but the percentage added by unemployment was nearly balanced by the reduction in the poverty contribution.

This diagram demonstrates, as does Fig. 5, that in the final regression of mortality with the social components ranked in the same order as the original simple correlation coefficients: but the magnitudes of their contributions were not in proportion to these simple correlations. The variance "explained" by poverty (18 per cent.) was smaller than might have been expected from the high simple correlation: and the still smaller contribution of unemployment ( 8 per cent.) showed a great reduction from the original 44 per cent. of mortality variance "explained" in the individual regression. It is apparent that conclusions regarding the influence of any social factor cannot be based on simple correlation coefficients alone.

The diagram shows also that the distribution of ordinary crowding did not duplicate completely the distributions of unemployment or poverty, but the latter did to some extent include within it the distribution of unemployment. If a single social variable were used as the only index of social conditions, it would not reproduce the total influence of the social complex on tuberculosis; but in individual association ordinary crowding did "explain" a very high percentage of mortality variance. But it is clearly preferable to combine at least two social distributions, and in this post-war triennium, in which no overcrowding index was considered, the combination of average crowding and poverty represented accurately the magnitude of the influence of social conditions on this disease. Moreover, it can be seen in the diagram that the residual "unexplained" variance was so small as to be of little significance in comparison with the "explained" variance; some of the total variance will always be due to chance variation, and can never be "explained" by any definite factor.

The relationship between notification distribution and social conditions in the 1945-47 triennium (as in the pre-war triennia) was not entirely like the mortality relationship; Table IX shows that the contributions of poverty and unemployment were approximately equal. Ordinary crowding, however, again played the major part in this association. The estimated ward notification rates in terms of social conditions were these:

$$
\mathrm{N}_{e}=11 \cdot 013 \mathrm{~A}+2 \cdot 855 \mathrm{U}+1 \cdot 213 \mathrm{R}-20 \cdot 754
$$

where $N_{e}$ represents estimated notification rate (per 10,000 ward population).

A represents ordinary crowding (ward average of persons per house).

U represents unemployment (adult unemployed men per cent. of population).

$R$ represents poverty (persons on relief per cent. of ward population).

The substitution in this equation of the ward indices of ordinary crowding, unemployment, and poverty gives estimated ward notification rates which were very close to the actual ward rates.

The upper part of Fig. 7 (opposite) shows the close agreement between actual rates and regression estimates; the latter shown adjacent to the actual ward rates, and the differences between estimated and observed rates in each ward are visible. Though there were some wards in which the calculated estimate did not correspond accurately. with the triennial average rate, in the great majority of wards the error of estimate was extremely small when compared with the actual ward rate or when contrasted with the original standard deviation (6.57) of the mean. The lower part of Fig. 7 shows the calculated estimates again, and illustrates the components of these estimates.

The relationships of the ward increases in tuberculosis rates in the years between 1936-38 and 1945-47 with the group of social factors were also examined, and a similar order of importance of the social distributions was apparent. As was expected, correlation coefficients were of a much lower order, and, though the total correlations were significant, many of the 


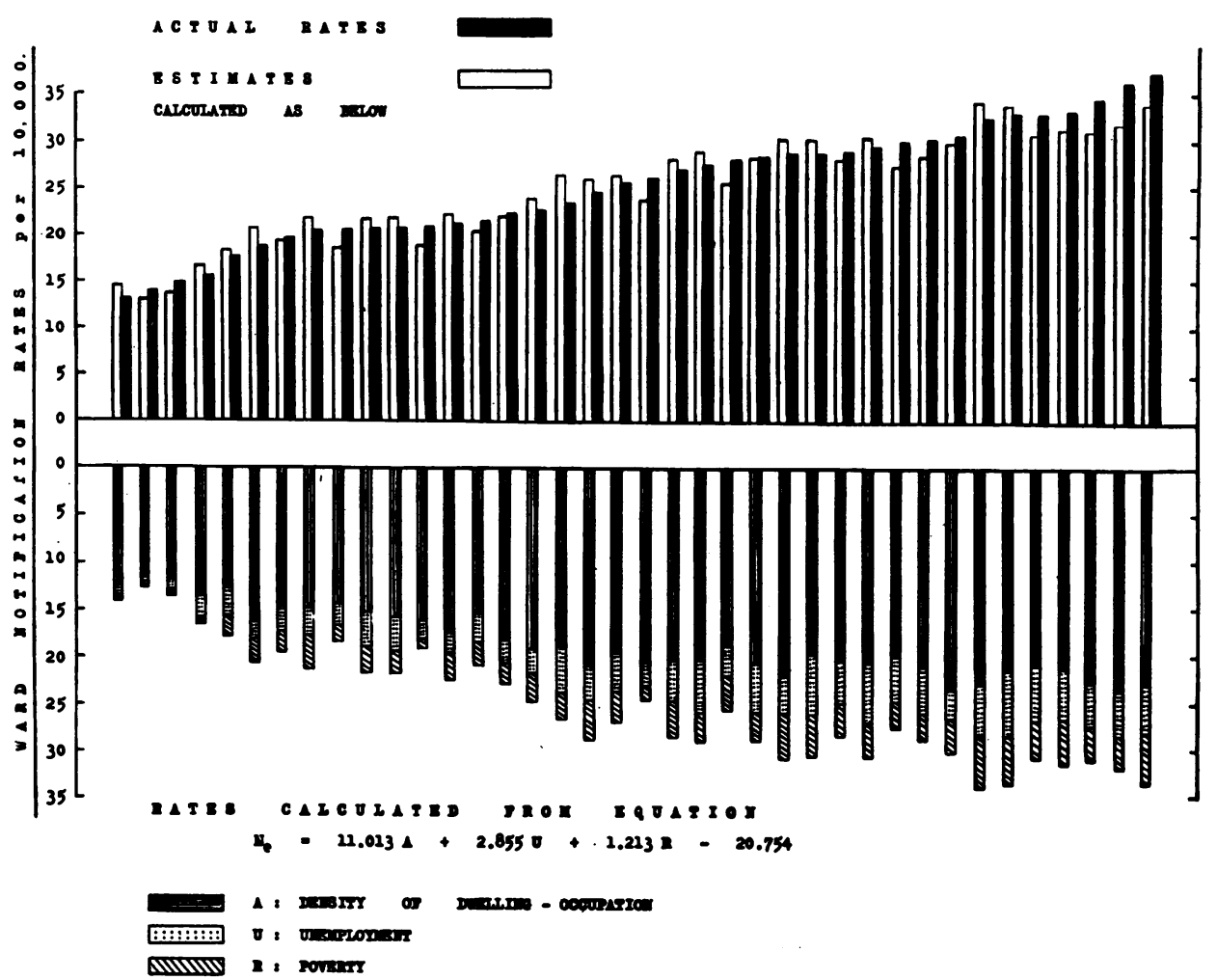

FIG. 7.-Respiratory tuberculosis notifications in the 38 wards of Glasgow, 1945-47. Actual notification rates (per 10,000 population) in the separate wards, and estimated rates calculated from the regression equation.

partial correlation and regression coefficients were not significant. The multiple associations of ward percentage increases in the disease rates with the social complex also showed partial correlation and regression coefficients which in most cases were not significant, but which were consistently negative. Furthermore, the total correlation between the social conditions in $1936-38$ and the percentage increases in notification rates $(-.51)$ was highly significant; and percentage mortality increases were also negatively and significantly correlated with indices of pre-war poor social conditions. Though these correlations seem small when compared with others found in the multiple regressions of mortality or notifications, they do indicate definite associations.

In general, then, the many aspects which have been examined all reiterate the significance of social conditions in relation to respiratory tuberculosis distribution. Within the group of social conditions the influence of each component and the importance of conditions of housing have become apparent. No single component can adequately represent the whole social complex; but the magnitude of its total effect in association with tuberculosis is indicated by the relationship of the disease with the combination of ordinary crowding and overcrowding. The high significance of this relationship in post-war as in pre-war years is manifest; the combination of these four 
social factors "explains" so large a proportion of variance arising from ward differences in tuberculosis, that little remains to be "explained" by some unknown factor.

\section{Discussion}

The earlier analyses in this study indicate a strong association between the distribution of respiratory tuberculosis rates and each social factor, and support the widely-held view that "tuberculosis is a social disease". They confirm also the conclusions drawn in the previous study of housing conditions and tuberculosis rates in Edinburgh (Stein, 1950). In these Glasgow analyses, however, the different magnitudes of correlations with the various social factors imply that there are real differences between the social distributions. It may be suggested that such divergencies are only the reflection of weaknesses in indices used to represent poverty and unemployment in the pre-war years. But the analyses of other mortality distributions, such as total mortality and infant mortality, and the analyses of non-respiratory tuberculosis distributions gave the expected high correlations with the indices used for poverty and unemployment; and these other mortality rates were also more highly associated with overcrowding than was respiratory tuberculosis. Hence the smaller connexions of respiratory tuberculosis with poverty and unemployment cannot be ascribed to unrepresentative indices. It has to be remembered that the relationships investigated were between distributions of social conditions and distributions of disease; and differences in the distribution of unemployment may not have as marked an effect on one disease as on another. The conclusion that respiratory tuberculosis was less strongly associated with poverty and unemployment would only seem surprising if the assumption were made that any one social index is equally representative of all social conditions. There is no basis for such an assumption. If the "social complex" is a complex, and separable into discrete factors, it is to be expected that these discrete components manifest their influence in individual ways. The strong connexion between respiratory tuberculosis and ordinary crowding, which is stronger for notifications in post-war years, is not to be considered as unreasonable: ordinary living conditions, as well as excessively bad ones, are reasonably to be expected to have considerable influence in this infectious disease.

This marked connexion, more marked when curvilinear regressions are used, leads to the obvious conclusion that notification rates are higher where the population -including the centres of infection within it-is more densely crowded. But it leads further to a more serious conclusion, that in such areas mortality increases are more than proportionally greater. This conclusion, which emerged also from the relationship of mortality to notification rates, cannot be dismissed as illusory on the grounds that in pre-war years notifications were not indicative of the true incidence of this disease. The upward curve of mortality is more marked in the post-war period; and since in these years there has been a general awareness of the need for early notification, and there have also been improvements in methods of early diagnosis, the post-war notifications should correspond more nearly with the real incidence of respiratory tuberculosis. It seems evident that the upward curve of mortality in relation to 
incidence and to social conditions represents a real relationship. This may be attributable to several causes. Possibly, in the wards with high rates, new cases were notified at a later stage of the disease. Or possibly social conditions in these wards operated to speed up the advance of the disease in notified cases. Both these explanations would account for the shorter period of survival after notification which was apparent in the more crowded wards. It seems evident that, in spite of the re-housing of overcrowded tuberculous families, and in spite of treatment, hospitalization, and other methods of removing centres of infection, both the spread of infection and the further advance of the disease in the individual are accelerated in wards with disadvantageous social conditions.

Some of the findings so far discussed were previously arrived at in the Edinburgh study, in which respiratory tuberculosis was shown to be more strongly associated with conditions of housing than were other infectious diseases. In this Glasgow study the correlations of respiratory tuberculosis with the crowding distributions in the same period of time were higher and more consistent than in the Edinburgh analyses. Moreover, the similarity between the respiratory tuberculosis relationships in Glasgow and in Edinburgh was in marked contrast to the dissimilarity between the regressions of infant mortality and social conditions in the two cities. It would have been of great value to compare all infectious diseases in Glasgow with those in Edinburgh. Moreover, it is important to consider to what extent respiratory tuberculosis exhibits the same tendencies as other infectious diseases and to what extent it differs from them. It might be suggested that the relationships of non-respiratory tuberculosis rates in Glasgow with social conditions indicate some answer to this question. But it is not justifiable to base conclusions concerning infectious diseases on results found only for one, particularly as non-respiratory tuberculosis can hardly be considered as typical of the infectious diseases.

The multiple relationships investigated in the later analyses to some extent bore out the findings of the earlier simple relationships, yet revealed new aspects of these earlier results. The compound regressions threw more light on the import of the components in the social complex, and confirmed the earlier indications that the social factors did not operate completely in unison. The divergencies between the social distributions were illustrated by the manner in which the connexions of mortality or notifications with social factors were augmented when the whole group of social factors was considered. The multiple correlations were far higher than the direct correlations found in simple regressions with individual social variables. While it is to be expected that multiple correlations would give increases on the greatest of any of the single correlations, the magnitude of these increases when additional social variables were brought into the regressions was surprising. These increases demonstrated again that the overlap between the social factors is not as extensive as is often assumed, and that a single social index is not equally representative of all.

The comparison of the percentages of variance "explained" in single, double, and multiple regressions leads to a further conclusion regarding the overlap of the social distributions. The consistently large percentages of variance explained by ordinary 
crowding were only slightly reduced when other social factors were included in the relationships. But the high correlation between overcrowding and respiratory tuberculosis rates in the earlier individual regressions was seen, in the multiple regressions, to include contributions of some size which were associated with poverty and unemployment. The "model" of the influence of the social complex which is obtained by using a single social index is at best not sufficiently accurate, and at worst misleading. A combination of two factors could simulate more nearly the total effect of the complex, and the ordinary crowding-overcrowding combination "explained" almost as large proportions of variance as did the whole group of factors. But no "model" can give a true picture of the relative importance of the different social factors; the addition of each index to the relationships investigated discloses more clearly the contribution of each social factor to the distribution of incidence and mortality from respiratory tuberculosis.

The suitability of the ordinary crowding-overcrowding combination as a model was thus limited, but indicated more accurately than any other pair the total variance "explained" by the whole complex. The importance of these two components was approximately equal, ordinary crowding being of more weight in mortality relationships, while overcrowding was of more weight in association with notification; each "explained" 30 to 50 per cent. of variance in one aspect of the disease and 20 to 30 per cent. of variance in the other. It is perhaps to be expected that in respiratory tuberculosis the two indices which best summarize the influence of a whole variety of social and environmental circumstances should be ordinary crowding and overcrowding. For they picture "ordinary conditions of life" and "excessively bad conditions", both important in the spread of infection and in the advance of the disease.

Though this study was concerned only with social conditions for which reliable data could be obtained, it is relevant here to consider the possible influence of other factors on the spread of respiratory tuberculosis in the general population. Certain people or groups of people are sometimes said to have a "natural tendency" towards this disease, and it is sometimes suggested that "the poor have a predisposition to tuberculosis". Those who hold such views might argue that indices of social and environmental conditions are all related to poverty, and that the present findings could still be interpreted to support their beliefs. The analyses in this study show such an argument to be fallacious: though the investigation is confined to small areas which make up the city of Glasgow, it demonstrates clearly that the contributions of different parts of the environment are of quite different importance. The residual association between the incidence of tuberculosis and poverty is of much lower order than that of other factors in the environment, and, even with the small number of social indices considered here, the weight of each contribution is different. Moreover, these variables leave a very small residuum of "unexplained" variance; and it has already been stated that some residuum due to chance variation must always be expected. The four social indices account for so much more of the variance than one would ordinarily expect, even if all factors relevant to tuberculosis (including nutrition) were taken into account, that there can be little of the variance remaining to be accounted for by 
"pre-disposition". Moreover, the residual inter-relations between the social factors are much too small to have a common factor of any size. The relationships of the Glasgow ward rates to the four social distributions give consistent evidence of the different contributions made by each, and show that the "social complex" is not explicable by any single factor such as "predisposition". The contribution of predisposition, if there be any, must be exceedingly small.

One more point is worthy of mention. The data originally obtained regarding the numbers of unemployed related to the ten Employment Exchange Areas of Glasgow, and single and multiple regressions and correlations were calculated for the relationships between respiratory tuberculosis rates and crowding, overcrowding, and unemployment indices in these ten large areas. The results obtained are not published here, since they were superseded by the more detailed analyses of the 38 wards. But they led to two conclusions: firstly, though there were inconsistencies in some years, the proportions of variance "explained" were not inconsiderable; secondly, the inconsistencies indicated that the social indices were not sufficiently accurate for the areas which they represented, and that results might be more revealing if more homogeneous and smaller areas were considered. The heterogeneous character of the Employment Exchange Areas was particularly marked in the peripheral exchanges; one of these stretched from the very centre of the city to the rural area beyond the city boundary, and included within its range more than one-fifth of the population of Glasgow. For these reasons the break-down of the unemployment data for the Exchange Areas into unemployment figures for the smaller and more homogeneous wards was undertaken. The results constitute a remarkable demonstration of the value of analysing relationships involving social indices in the smallest and most exact way possible; they show how contradictory may be the results, and how doubtful the conclusions, if social conditions in a large heterogeneous area are represented by a single index. The wards on which the present study is based are still too large and insufficiently homogeneous, but no smaller administrative units exist. The more social variables are precisely measured for small areas, the more will be learned of the influence of "social conditions" on disease.

\section{CONCLUSION}

The view that "social conditions" are of great importance in the spread of respiratory tuberculosis is widely held, yet it has been rather a matter of belief than of precise evidence. Precise knowledge of the total influence of "social conditions" in Scotland has not been available; and it has not been known which factors in the social complex are most important in connexion with this disease, nor what are their individual contributions to its incidence and mortality.

In this study of respiratory tuberculosis in the wards of Glasgow, the investigation of small, homogeneous areas reveals that the inequalities of incidence in this disease are very largely accounted for by disparities in social conditions. Moreover, these successive analyses with further combinations of social factors show clearly that it is possible to estimate the separate contribution of each social component to 
the divergencies in respiratory tuberculosis. Other mortality is also associated with social conditions, but the factors of dominant influence are not the same as those in respiratory tuberculosis. The relationship of respiratory tuberculosis with the social complex demonstrates the important role played in Glasgow by housing conditions. Ordinary density of dwelling occupation, together with overcrowding, represents the dominant influence in infection and in death from this disease.

\section{SUMMARY}

(1) This study was undertaken to assess the influence of the "social complex" and its constituent factors on respiratory tuberculosis notifications and mortality in Glasgow. The importance of Glasgow rates in any investigation of Scottish tuberculosis trends is discussed. The need to acquire precise knowledge of the complex of social conditions and to disentangle its components is emphasized.

(2) Respiratory tuberculosis rates in Glasgow are described, and trends in certain age groups illustrated. Comparisons indicate that Glasgow trends have diverged from those in towns in England and Wales and in most other cities in Scotland.

(3) The scope of this study of tuberculosis in the years 1930-47 is outlined, and the indices used are stated. The statistical methods applied in the analyses (correlation, regression, and analysis of variance) are discussed. Single regressions are used in the earlier analyses, and additional variables are successively brought into multiple regressions. The reasons for such duplication are given, and the possible inadequacies of conclusions drawn from simple correlation coefficients alone are debated.

(4) The single relationships between ward respiratory tuberculosis distributions and each separate social distribution are analysed. They evidence the strong and highly significant associations of this disease with all the social variables, but show that these associations are not equal in magnitude and that some of them vary with time. The high correlations with ordinary crowding and overcrowding are greater than those with unemployment or poverty.

(5) The strong and consistent association between mortality from respiratory tuberculosis and notification rates during the same and preceding years is shown. The upward curve of mortality in relation to notifications is more marked in post-war years.

(6) The examination of the respiratory tuberculosis rates in the pre-war and post-war triennia enlarges the earlier findings of the considerable increases in mortality and notifications. The increases themselves are significantly though not strongly associated with certain pre-war social conditions in the wards, the absolute increases being greatest in the worst-housed wards. But the percentage increases in individual wards are negatively associated with poverty and overcrowding. The implication is that during the decade the spread of respiratory tuberculosis affected all areas and was relatively more disadvantageous in wards which in pre-war years enjoyed the best environmental conditions.

(7) A number of relationships of respiratory tuberculosis rates with social variables 
taken two, three, and four at a time, clarify the strong and consistent connexion with the group of social factors. Total correlations in the multiple regressions are approximately 0.9 , and "explained" variance is 80 per cent. or more. The proportion of "unexplained" variance, some of it due to chance variation, is exceptionally small.

The factors in the social complex are shown to contribute differing amounts to the extraordinarily high proportions of "explained" variance. The variables in the social complex do not operate as one single factor, but contribute differently to mortality and to notification variances. Ordinary crowding and overcrowding play a most important part; together they "account for" 60 to 70 per cent. of variance, and have approximately equal weight. Poverty and unemployment contribute about 5 to 15 per cent. of variance in most regressions, poverty showing a more marked connexion with mortality.

Residual inter-correlations between the social variables indicate that the distribution of ordinary crowding is not related to the other social distributions. But between these latter some overlap is apparent, and here the overcrowding distribution seems to be dominant. The conclusion is clearly indicated that the "social complex" cannot be adequately depicted by a single social index.

(8) The findings of the more complex analyses are discussed in relation to the earlier results. It becomes evident that in some cases the conclusions indicated by direct correlations in single regressions are borne out by the multiple relationships; but in other cases they are shown to have been exaggerated conclusions. The use of a "model" in representing the effect of the social complex is considered.

The view sometimes expressed that the poor have a natural pre-disposition to tuberculosis is discussed; the evidence indicates the improbability of any sizeable contribution by "pre-disposition".

(9) In order to compare respiratory tuberculosis relationships and those of other diseases, the trends of other causes of mortality are examined (see Appendix A.1). Ward distributions of total mortality, infant mortality, and non-respiratory tuberculosis in Glasgow are described. Edinburgh rates in the pre-war years are compared with those of Glasgow, and infant mortality in the two cities is contrasted.

The single relationships of the distributions of total mortality, infant mortality, and non-respiratory tuberculosis with the separate social variables are investigated (see Appendix A.2). Infant mortality and non-respiratory tuberculosis notification rates are found to be strongly associated with the social factors, particularly with poverty and unemployment. The associations of the social factors with the distributions of other mortality rates are not similar to the relationships found for respiratory tuberculosis. Ordinary crowding plays a smaller part in association with other mortality.

(10) The divergencies between the social factors require clarification, and hence social conditions in Glasgow are more fully examined.

Housing conditions are described in some detail (see Appendix B.1). Comparisons of ordinary crowding, overcrowding, and numbers of 1-roomed and 2-roomed 
houses in other cities demonstrate that Glasgow housing deficiencies are so extensive as to constitute an exceptional local circumstance. Changes in sizes of houses and in densities of population in the last two decades have made only a small difference in crowding.

The trends and distributions of unemployment and poverty in Glasgow in the years 1930-47 are examined (see Appendix B.2). Ward differences in these conditions are considered, and the changing connexion between unemployment and measurable poverty is indicated.

The indices used for ordinary crowding, overcrowding, unemployment, and poverty are more fully described, and some reasons are given for the choice of pre-war and post-war poverty indices (see Appendix C).

The inter-correlations between the different social variables are discussed: though there is some overlap between certain distributions, ordinary crowding is not closely related to the other indices. It is evident that "social conditions" cannot be adequately investigated in terms of one component only.

(11) The conclusion is drawn that ordinary density of dwelling-occupation and additional overcrowding together constitute the major factors in the association of the social complex with respiratory tuberculosis in Glasgow, and play a significant part in the excess deaths from and cases of this disease in the crowded wards of the city.

I should like to express my gratitude to Professor F. A. E. Crew, whose interest and unfailing support encouraged this work. Grateful acknowledgements are also made to the Medical Officer of Health for Glasgow and to his staff, to the Controller for Scotland of the Ministry of Labour and National Service, to the Managers and Staffs of the Glasgow Employment Exchanges, and to the Scottish Controller of the National Assistance Board, for their kind co-operation and efforts in these investigations. I should like particularly to thank Dr. P. L. McKinlay and Dr. J. Bronowski for their continuing interest and valuable advice in these studies.

\section{REFERENCES}

Fisher, R. A. (1925). "Statistical Methods for Research Workers."

Glasgow. Medical Officer of Health (1943). Annual Report, p. 73.

(1949a). Ibid., p. 79.

- (1949b). Ibid., p. 115.

Greenwood, M. (1926). Communication to the Health Committee of the League of Nations, Geneva.

Hart, P. D'Arcy, and Wright, G. P. (1939). "Tuberculosis and Social Conditions in England." N.A.P.T., London.

McKinlay, P. L. (1947). Hlth. Bull. Dept. Hlth Scotland. 5, No. 3, p. 37.

Scotland, Department of Health (1951). "Tuberculosis." Report of Scottish Health Services Council, p. 15. Snedecor, G. W. (1934). "Calculation and Interpretation of Analyses of Variance and Covariance."

Stein, L. (1950). British Journal of Social Medicine, 4, 143.

Terris, M. (1948). Amer. J. publ. Hlth, 38, 1061. 


\section{APPENDIX A.}

This study has demonstrated that in the last two decades certain social factors were strongly associated with the notification and mortality rates of respiratory tuberculosis in the Glasgow wards; and that, among these social factors, ordinary crowding and overcrowding were outstanding. These associations were of such magnitude that their significance is undoubted; the likelihood of their being due to chance occurrence is less than 1 in 1,000. Yet these relationships with particular social conditions could not be considered peculiar to respiratory tuberculosis if similar associations with the same social factors were to be found for other mortality. It could be argued that the respiratory tuberculosis relationships were merely the reflection of the general association of all disease and mortality with social conditions. It is therefore desirable to carry this investigation further into the relationship borne by the social factors to different causes of mortality. These additional analyses are limited to total mortality, infant mortality, and non-respiratory tuberculosis mortality and notifications, for these were the only conditions for which ward data for the period were obtainable.

A.1. Trends of Mortality Rates in Glasgow from 1930 to 1947.-The general trends of respiratory tuberculosis in Glasgow have already been discussed. Table II showed that there was no downward direction of the rates before the war, as there had been in Edinburgh. In many wards of Glasgow the mortality and notification rates were moving upwards some years before the war.

General mortality from all causes exhibited a somewhat similar pre-war trend. The rate for the city fluctuated about an average of 14 per 1,000 , and there was no indication of any consistent decline. In the first years of the war the rate rose sharply, but towards the end of the war it fell below 14, and it continued to fall after the war. Table X (overleaf) shows that this general trend was also apparent in most of the wards. In the 1930s the upper end of the range of ward rates rose slightly, reaching 20 to 23 ; in the post-war years only one ward rate has exceeded 17. In Edinburgh in the 1930s the mean of general mortality was slightly lower than in Glasgow, but the difference is not significant.

The trends of non-respiratory tuberculosis rates, both mortality and notifications, differed from those described above. In this disease there was a progressive decline during the 1930s. At the outbreak of war, both mortality and notifications increased, and throughout the war they continued at high levels. In the post-war years, notifications and mortality resumed their decline, but the mortality rate still remained higher than in the mid-1930s. Table X shows that disparities between wards were again evident in this disease. In pre-war years the wards at the upper end of the range had rates nearly twice as high as the city mean, and in post-war years these disparities were still as great. However, a comparison with Edinburgh rates in the 1930s reveals little difference between the cities in non-respiratory tuberculosis.

During the years 1930-37, infant mortality, like general mortality, showed little evidence of decline from its extremely high average of 100 deaths per 1,000 live births. However, in 1938 and 1939 infant mortality decreased, and, though it rose during the war, it fell subsequently; and more recently it has fallen spectacularly. In the years 1930-39 the very high city average represented an exceedingly wide range of rates; Table $\mathrm{X}$ shows that in some wards infant mortality was extremely low, but that in many others the rates were far higher than the city average. There were, for example, ten wards which had rates of 125 to 150 throughout almost the entire period-that is to say, with one infant death in every seven or eight live births. In the post-war period under review, the highest rates in the ward range had fallen to less than 100. Comparison with the Edinburgh figures for the 1930s shows all the Glasgow rates to be significantly higher. In the pre-war years the Glasgow average was approximately 40 per cent. higher than the Edinburgh average; and in the worst wards of 
Glasgow infant mortality was 50 per cent. greater than in the worst wards of Edinburgh. At the same time, the best wards of Glasgow had rates as low as, or even lower than, the best wards of Edinburgh.

The disparities between wards and the dissimilarities between the various causes of disease and death are illustrated in another way by the coefficients of variation. In the 1930s the variability of general mortality distribution between the wards was relatively small, giving coefficients of variation between 15 and 17 per cent. In the post-war years this variability had become even less, as is shown by coefficients of variation of less than 10 per cent. On the other hand, respiratory tuberculosis and also infant mortality were much more unevenly distributed, and coefficients of variation were much higher, approximating to 30 per cent. This variability was as evident in the post-war as in the pre-war period.

The distribution of non-respiratory tuberculosis between the wards showed even greater variability. For notification rates the coefficients of variation approached 40 per cent., and for mortality rates they were well above $\mathbf{4 0}$ per cent.

On the whole, the trends of notification and mortality from the various causes exhibited some similarities in the pre-war period. But in the post-war years respiratory tuberculosis rates rose whilst all others declined. This is well known; yet it is of interest to observe that infant mortality, the traditional yardstick for "social conditions", though it fluctuated at a very high level throughout the pre-war years of widespread poverty and heavy unemployment, has fallen almost annually since 1944, whereas respiratory tuberculosis in the period under review kas pursued a rather different course.

A.2. Mortality from Various Causes in Relation to Social Factors.-The separate relationships between each social variable and each different distribution of notifications and mortality from certain causes, in the years from 1930 to 1947, are summarized in Table XI. Here are given the coefficients of correlation of general mortality, infant mortality, and notifications of and mortality from non-respiratory tuberculosis, with ordinary crowding,

Other Rates of Mortality and Notificatiōn Infant Mortality Rate: per 1,000 live births. Mortality due to all causes, Non-Respiratory Tuberculog్ is

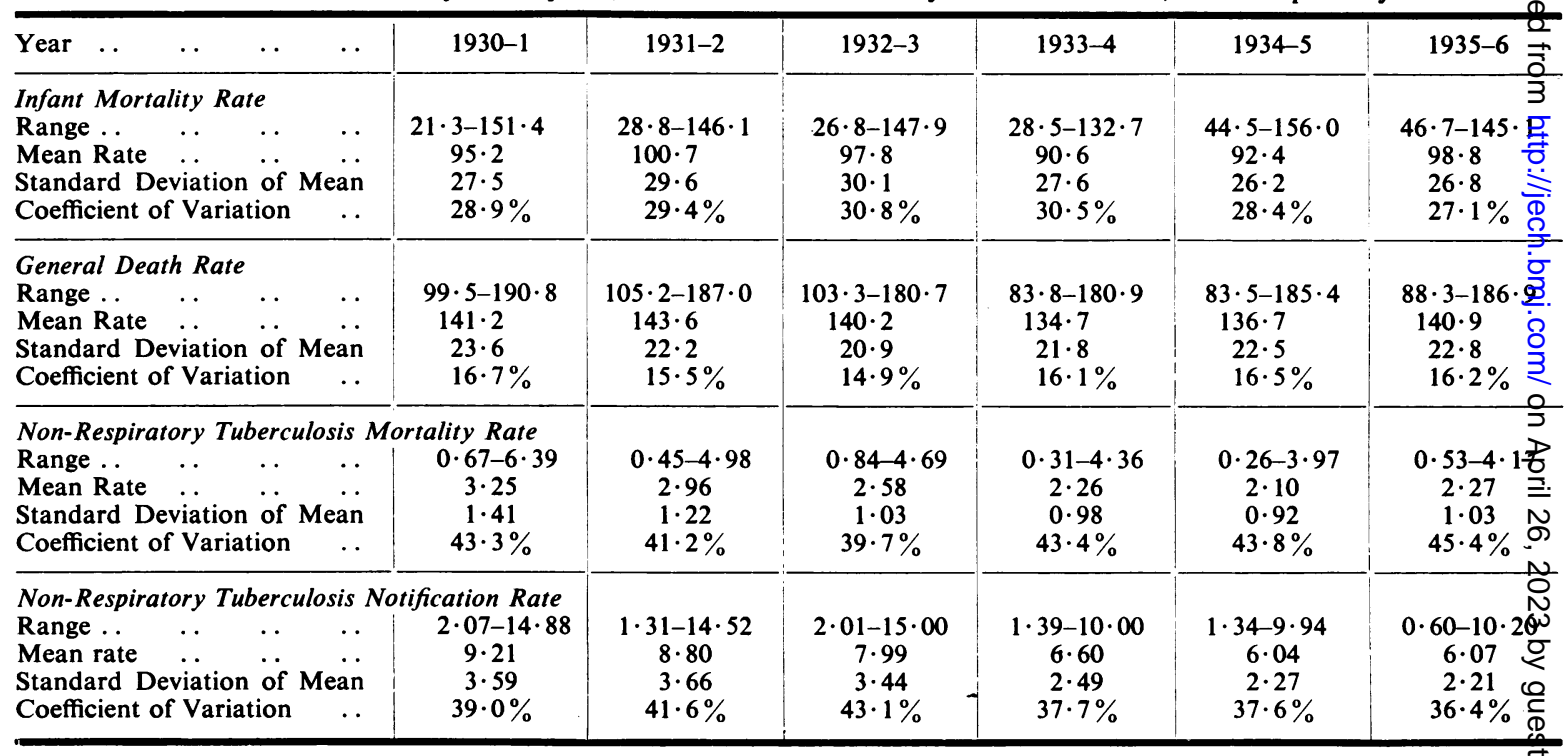


overcrowding, unemployment, and poverty. Coefficients of regression are also given in cases where the correlations were significant.

Briefly, these results indicate that there was a strong connexion between infant mortality and each social factor throughout the period. Non-respiratory tuberculosis notification rates were equally strongly associated with the social indices; but mortality from this disease corresponded less closely with the social distributions, and the correspondence diminished with the years. General mortality unexpectedly revealed a consistent association in the pre-war decade with certain social factors.

In the 1930s the ward rates of general mortality corresponded most nearly with the distribution of unemployment, the correlations being highly significant. Correlations with overcrowding in this period were also significant, but there was no significant association between general mortality and ordinary crowding or poverty. In the post-war period there seemed to be a considerable change in the distribution of general mortality, and there was no connexion between it and the social variables.

Non-respiratory tuberculosis in the pre-war decade was most closely associated with the distribution of overcrowding. This disease showed a lesser connexion with ordinary crowding and unemployment in the early 1930s, but in the later 1930s its association with the distribution of unemployment increased. The correspondence of non-respiratory tuberculosis with the distribution of poverty was most marked at all times. During the two decades under review, the association of notifications with all the social variables remained very strong; but the association of mortality with the social variables lessened.

Infant mortality displayed a remarkably strong association with overcrowding, and a connexion almost equally strong with unemployment and poverty. The association with ordinary crowding was significant but of a lower order. The time-trends of these relationships were interesting; the connexion between infant mortality and ordinary crowding changed little during the period, but its connexions with unemployment and with poverty increased.

A fuller study of the correlations and regressions of general mortality with the various social

$\mathrm{X}$

IN GLASGOW WaRd, 1930-47

Mortality, Non-Respiratory Tuberculosis Notifications: per 10,000 ward population (2-year moving averages).

\begin{tabular}{|c|c|c|c|c|c|c|c|}
\hline $1936-7$ & $1937-8$ & 1938-9 & $1939-40$ & $1940-1$ & $1944-5$ & $1945-6$ & 1946-7 \\
\hline $\begin{array}{c}35 \cdot 5-167 \cdot 5 \\
101 \cdot 1 \\
32 \cdot 2 \\
31 \cdot 9 \%\end{array}$ & $\begin{array}{c}37 \cdot 9-151 \cdot 9 \\
91 \cdot 3 \\
26 \cdot 9 \\
29 \cdot 5 \%\end{array}$ & $\begin{array}{c}46 \cdot 0-135 \cdot 6 \\
79 \cdot 6 \\
23 \cdot 1 \\
29 \cdot 0 \%\end{array}$ & $\begin{array}{c}36 \cdot 9-145 \cdot 3 \\
82 \cdot 2 \\
24 \cdot 2 \\
29 \cdot 4 \%\end{array}$ & & & $\begin{array}{c}30 \cdot 1-106 \cdot 1 \\
65 \cdot 6 \\
19 \cdot 2 \\
29 \cdot 4 \%\end{array}$ & $\begin{array}{c}30 \cdot 2-97 \cdot 5 \\
70 \cdot 6 \\
18 \cdot 5 \\
26 \cdot 2 \%\end{array}$ \\
\hline $\begin{array}{c}99 \cdot 0-192 \cdot 8 \\
144 \cdot 9 \\
23 \cdot 0 \\
15 \cdot 9 \%\end{array}$ & $\begin{array}{c}95 \cdot 1-204 \cdot 2 \\
140 \cdot 3 \\
23 \cdot 6 \\
16 \cdot 8 \%\end{array}$ & $\begin{array}{c}94 \cdot 8-203 \cdot 9 \\
134 \cdot 7 \\
23 \cdot 9 \\
17 \cdot 8 \%\end{array}$ & $\begin{array}{c}103 \cdot 7-226 \cdot 4 \\
150 \cdot 9 \\
25 \cdot 1 \\
16 \cdot 6 \%\end{array}$ & & & $\begin{array}{c}111 \cdot 1-161 \cdot 5 \\
132 \cdot 4 \\
12 \cdot 8 \\
9 \cdot 7 \%\end{array}$ & $\begin{array}{c}115 \cdot 5-168 \cdot 8 \\
136 \cdot 0 \\
13 \cdot 1 \\
9 \cdot 6 \%\end{array}$ \\
\hline $\begin{array}{c}0 \cdot 28-4 \cdot 22 \\
2 \cdot 26 \\
1 \cdot 07 \\
47 \cdot 2 \%\end{array}$ & $\begin{array}{c}0 \cdot 19-4 \cdot 14 \\
2 \cdot 24 \\
0 \cdot 98 \\
43 \cdot 8 \%\end{array}$ & $\begin{array}{c}0 \cdot 0-3 \cdot 85 \\
2 \cdot 32 \\
0 \cdot 91 \\
39 \cdot 2 \%\end{array}$ & $\begin{array}{c}1 \cdot 12-6 \cdot 23 \\
2 \cdot 73 \\
1 \cdot 22 \\
44 \cdot 7 \%\end{array}$ & $\begin{array}{c}0 \cdot 85-5 \cdot 69 \\
3 \cdot 22 \\
1 \cdot 26 \\
39 \cdot 2 \%\end{array}$ & $\begin{array}{c}0 \cdot 52-6 \cdot 65 \\
2 \cdot 71 \\
1 \cdot 22 \\
45 \cdot 1 \%\end{array}$ & $\begin{array}{c}0 \cdot 72-6 \cdot 12 \\
2 \cdot 48 \\
1 \cdot 17 \\
47 \cdot 3 \%\end{array}$ & $\begin{array}{c}0 \cdot 75-5 \cdot 34 \\
2 \cdot 29 \\
0 \cdot 92 \\
40 \cdot 1 \%\end{array}$ \\
\hline $\begin{array}{c}0 \cdot 79-9 \cdot 81 \\
5 \cdot 91 \\
2 \cdot 16 \\
36 \cdot 6 \%\end{array}$ & $\begin{array}{c}0 \cdot 82-9 \cdot 92 \\
5 \cdot 95 \\
2 \cdot 24 \\
37 \cdot 7 \%\end{array}$ & $\begin{array}{c}1 \cdot 34-9 \cdot 94 \\
5 \cdot 58 \\
2 \cdot 19 \\
39 \cdot 3 \%\end{array}$ & $\begin{array}{c}1 \cdot 40-11 \cdot 09 \\
5 \cdot 66 \\
2 \cdot 40 \\
42 \cdot 3 \%\end{array}$ & $\begin{array}{c}1 \cdot 22-12 \cdot 69 \\
6 \cdot 41 \\
2 \cdot 52 \\
39 \cdot 4 \%\end{array}$ & $\begin{array}{c}1 \cdot 38-11 \cdot 08 \\
5 \cdot 97 \\
2 \cdot 35 \\
39 \cdot 4 \%\end{array}$ & $\begin{array}{c}1 \cdot 54-9 \cdot 03 \\
5 \cdot 11 \\
1 \cdot 96 \\
38 \cdot 3 \%\end{array}$ & $\begin{array}{c}1 \cdot 18-8 \cdot 34 \\
4 \cdot 77 \\
1 \cdot 78 \\
37 \cdot 3 \%\end{array}$ \\
\hline
\end{tabular}


Other Mortality and Notification RATES in Relationito Correlation and Regression Coefficients of General Mortality, Infant Mortality, Non-Respiratory TuberculBasis,

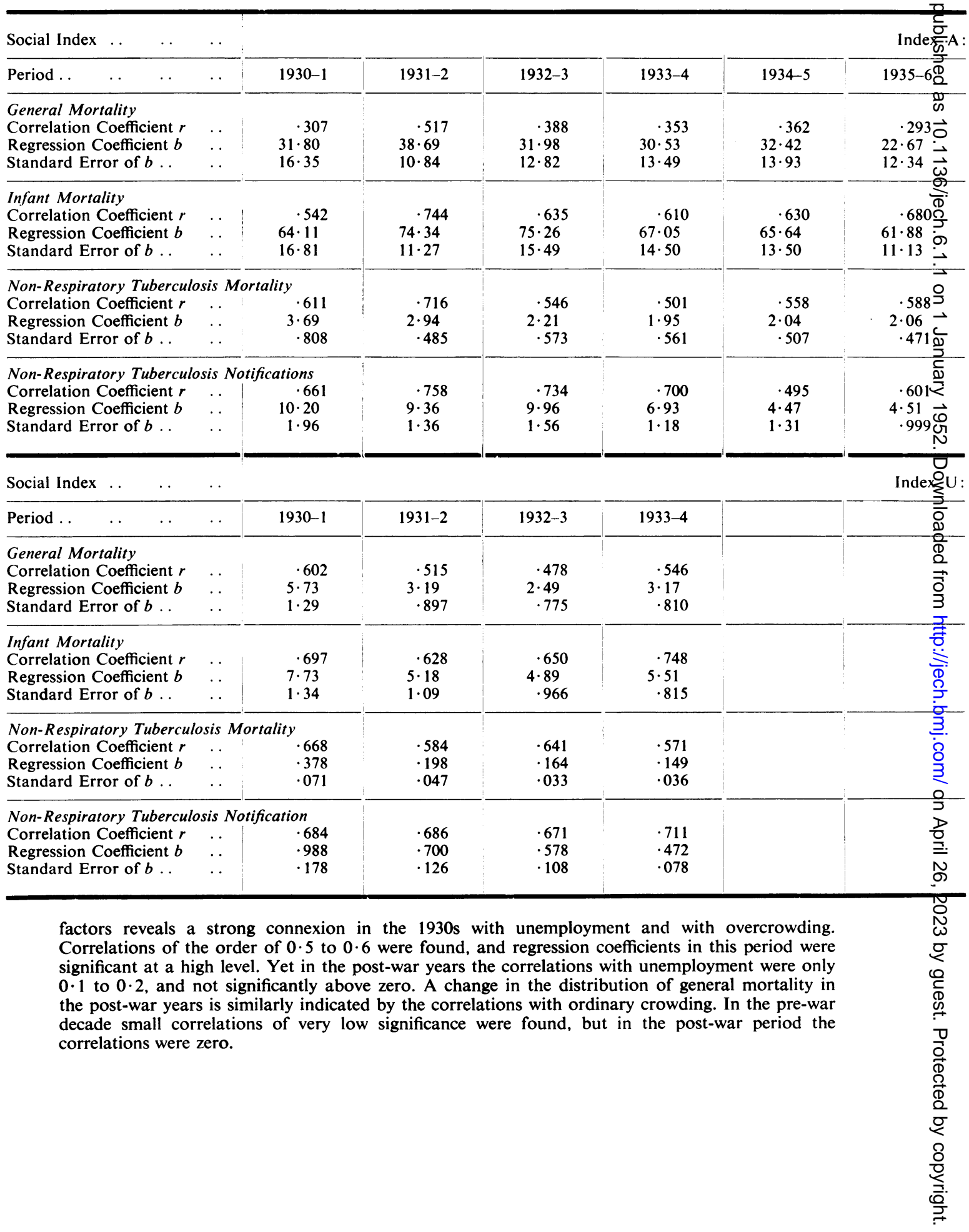


XI

SOCIAL Conditions in WardS OF Glasgow, 1930-47

in individual relationships with Ordinary Crowding, Overcrowding, Unemployment, Poverty.

ORDINARY CROWDING

\begin{tabular}{|c|c|c|c|c|c|c|c|}
\hline $1936-7$ & $1937-8$ & 1938-9 & $1939-40$ & 1941-1 & $1944-5$ & $1945-6$ & $1946-7$ \\
\hline $\begin{array}{l}\cdot 384 \\
29 \cdot 96 \\
12 \cdot 02\end{array}$ & $\begin{array}{l}\cdot 370 \\
30 \cdot 32 \\
12 \cdot 67\end{array}$ & $\begin{array}{l}\cdot 333 \\
27 \cdot 74 \\
13 \cdot 09\end{array}$ & $\begin{array}{l}\cdot 318 \\
27 \cdot 96 \\
13 \cdot 91\end{array}$ & & & $\begin{array}{c}-.001 \\
-\end{array}$ & $\begin{array}{l}.027 \\
-\end{array}$ \\
\hline $\begin{array}{r}\cdot 728 \\
79 \cdot 73 \\
12 \cdot 50\end{array}$ & $\begin{array}{r}\cdot 679 \\
63 \cdot 44 \\
11 \cdot 42\end{array}$ & $\begin{array}{c}\cdot 633 \\
50 \cdot 84 \\
10 \cdot 36\end{array}$ & $\begin{array}{r}\cdot 571 \\
48 \cdot 43 \\
11 \cdot 60\end{array}$ & & & $\begin{array}{c}\cdot 654 \\
48 \cdot 32 \\
9 \cdot 33\end{array}$ & $\begin{array}{c}\cdot 695 \\
49 \cdot 25 \\
8 \cdot 49\end{array}$ \\
\hline $\begin{array}{c}.495 \\
1 \cdot 79 \\
.524\end{array}$ & $\begin{array}{c}\cdot 512 \\
1 \cdot 73 \\
.485\end{array}$ & $\begin{array}{c}\cdot 572 \\
1 \cdot 82 \\
.433\end{array}$ & $\begin{array}{c}.451 \\
1.93 \\
.638\end{array}$ & $\begin{array}{c}\cdot 673 \\
3 \cdot 20 \\
\cdot 585\end{array}$ & $\begin{array}{c}.622 \\
2 \cdot 90 \\
.609\end{array}$ & $\begin{array}{c}\cdot 558 \\
2 \cdot 47 \\
.612\end{array}$ & $\begin{array}{c}\cdot 541 \\
1 \cdot 86 \\
.480\end{array}$ \\
\hline $\begin{array}{c}\cdot 728 \\
5 \cdot 34 \\
\cdot 838\end{array}$ & $\begin{array}{c}\cdot 714 \\
5 \cdot 55 \\
.908\end{array}$ & $\begin{array}{c}.647 \\
4 \cdot 94 \\
.970\end{array}$ & $\begin{array}{l}\cdot 590 \\
4 \cdot 97 \\
1 \cdot 13\end{array}$ & $\begin{array}{l}\cdot 700 \\
6 \cdot 66 \\
1 \cdot 13\end{array}$ & $\begin{array}{c}\cdot 748 \\
6 \cdot 71 \\
.991\end{array}$ & $\begin{array}{c}.747 \\
5 \cdot 53 \\
.818\end{array}$ & $\begin{array}{c}\cdot 625 \\
4 \cdot 15 \\
.863\end{array}$ \\
\hline
\end{tabular}

\section{UNEMPLOYMENT}

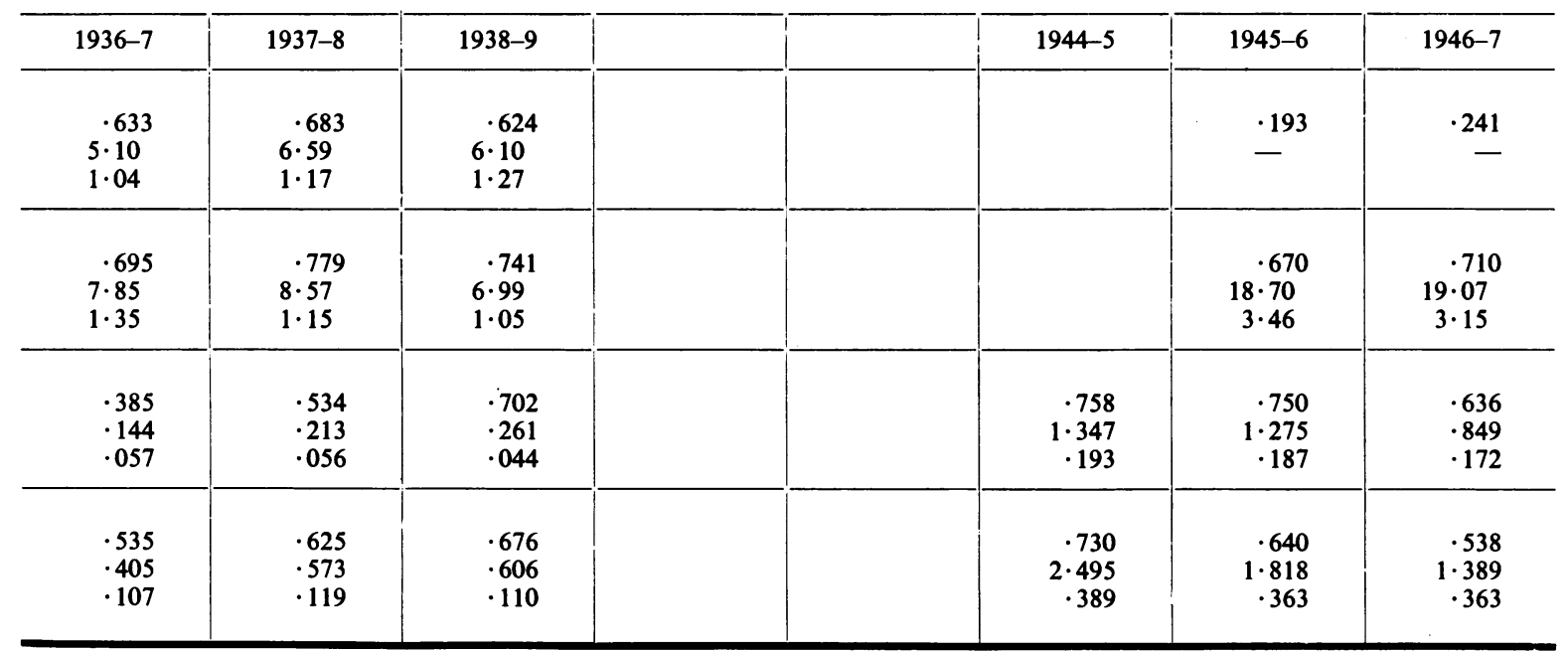

Non-respiratory tuberculosis relationships were rather more consistent. Correlations with overcrowding were high, about $\mathbf{0} \cdot \mathbf{8}$, higher than for respiratory tuberculosis. Similar differences between non-respiratory and respiratory tuberculosis were found in connexion with poverty and unemployment. In association with ordinary crowding, however, the correlations of non-respiratory mortality were much lower, and showed considerable fluctuations within the generally-declining trend. Non-respiratory notifications were more strongly and consistently associated with ordinary crowding, although the correlations were still less than those in the respiratory tuberculosis relationships. 
TABLE XI-cont.

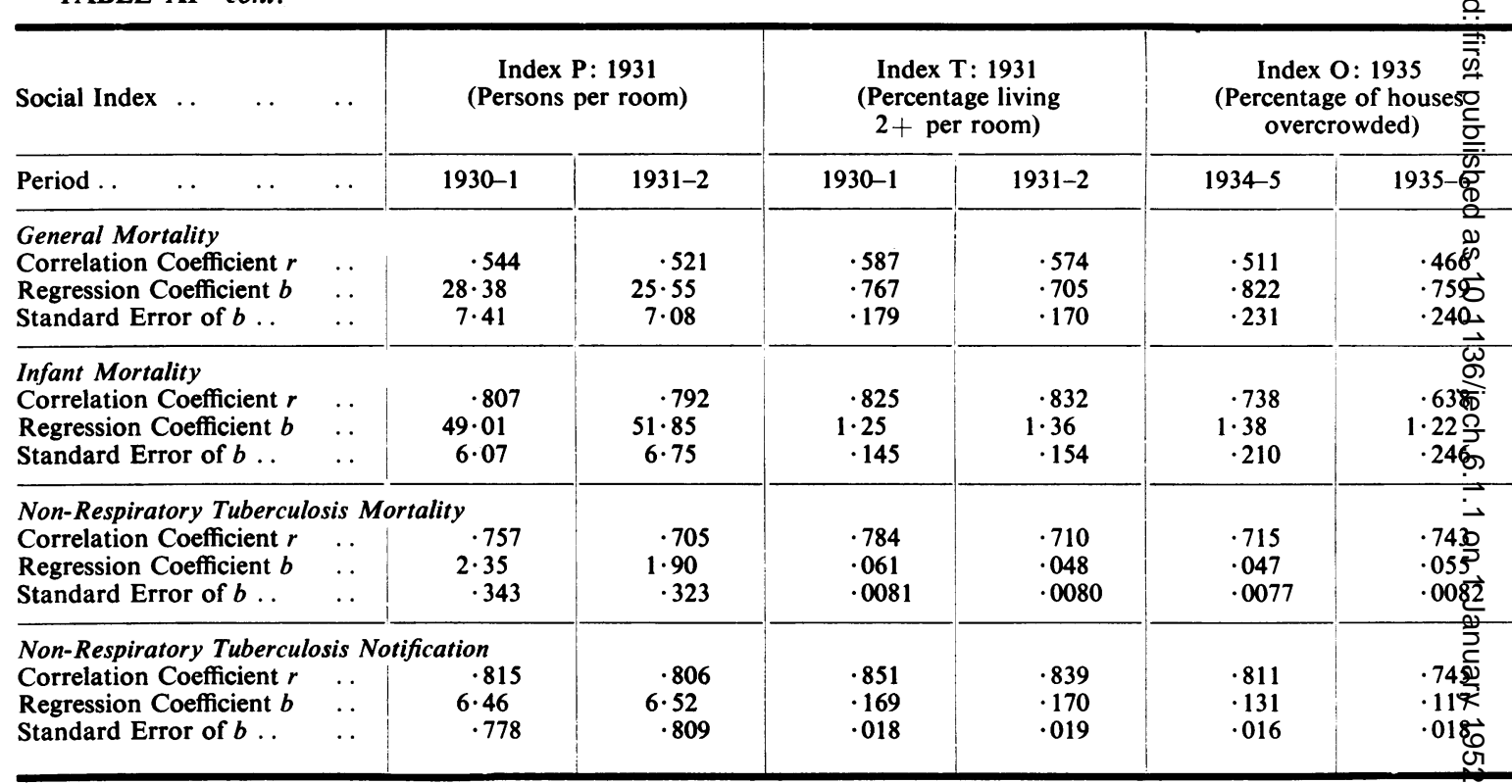

The connexions between infant mortality and the various social indices were all strong. Correlation coefficients with overcrowding and unemployment were much higher than those obtained for respiratory tuberculosis. Infant mortality correlations with unemployment were consistently in the region of 0.7 . Regression coefficients indicate that, in the early 1930s, wards differing by 1 in the unemployment index (about one-twelfth of the range) differed by more than five infant deaths per 1,000 live births. In the post-war period, wards differing by 0.2 in the unemployment index (again, about one-twelfth of the post-war unemployment range) differed by approximately four infant deaths per 1,000 live births: though this indicated some improvement, the differences in infant mortality concomitant with social inequalities were marked. Poverty was much more strongly and consistently associated with infant mortality throughout the entire period than with any other mortality distribution investigated. Infant mortality was not so consistently associated with ordinary crowding; in the early 1930s, the correlations were not high, and later in the pre-war decade they became higher. In the post-war years, however, the correspondence between infant mortality and ordinary crowding diminished again.

Regression equations again disclosed the great influence of social conditions on infant mortality. It appeared more marked in Glasgow than in Edinburgh in the pre-war decade. Some of the regression coefficients are translated below to illustrate this comparison of pre-war infant mortality differences in the two cities.

\begin{tabular}{|c|c|c|}
\hline \multicolumn{2}{|c|}{ Difference between Ward Social Conditions } & Difference in Infant Mortality Rate \\
\hline \multirow{2}{*}{$\begin{array}{l}\text { Wards differing by } 5 \text { per cent. in percentage } \\
\text { of overcrowded houses }\end{array}$} & Glasgow & 7 deaths per 1,000 live births \\
\hline & Edinburgh & 3 to $3 \cdot 5$ deaths per 1,000 live births \\
\hline \multirow{2}{*}{$\begin{array}{l}\text { Wards differing in ordinary crowding by } \\
1 \text { person per house }\end{array}$} & Glasgow & 60 to 75 deaths per 1,000 live births \\
\hline & Edinburgh & 20 to 25 deaths per 1,000 live births \\
\hline
\end{tabular}

In the post-war years, no regressions for Edinburgh were available. But in Glasgow, in the post-war years, wards having on an average a difference of one person per house differed by nearly fifty infant 


\begin{tabular}{|c|c|c|c|c|c|c|}
\hline \multicolumn{2}{|c|}{$\begin{array}{c}\text { Index V } \\
\text { (Valuation, 1931) }\end{array}$} & \multicolumn{2}{|c|}{$\begin{array}{c}\text { Index V } \\
\text { (Valuation, 1936) }\end{array}$} & \multicolumn{3}{|c|}{$\begin{array}{c}\text { Index R } \\
\text { (Poor Relief, 1945-6) }\end{array}$} \\
\hline $1930-1$ & 1931-2 & $1934-5$ & $1935-6$ & $1944-5$ & $1945-6$ & $1946-7$ \\
\hline $\begin{array}{l}\cdot 332 \\
\cdot 756 \\
\cdot 363\end{array}$ & $\begin{array}{r}\cdot 316 \\
\cdot 677 \\
\cdot 344\end{array}$ & $\cdot 199$ & $\cdot 158$ & & $\cdot 158$ & $\cdot 193$ \\
\hline $\begin{array}{r}.726 \\
1.925 \\
.308\end{array}$ & $\begin{array}{r}.695 \\
1.984 \\
.347\end{array}$ & $\begin{array}{r}.486 \\
1 \cdot 235 \\
.370\end{array}$ & $\begin{array}{r}\cdot 372 \\
\cdot 968 \\
\cdot 209\end{array}$ & & $\begin{array}{r}\cdot 767 \\
9 \cdot 647 \\
1 \cdot 343\end{array}$ & $\begin{array}{r}\cdot 775 \\
9 \cdot 363 \\
1 \cdot 272\end{array}$ \\
\hline $\begin{array}{l}\cdot 646 \\
\cdot 0874 \\
\cdot 0175\end{array}$ & $\begin{array}{l}\cdot 605 \\
\cdot 0711 \\
\cdot 0158\end{array}$ & $\begin{array}{l}.405 \\
.0362 \\
.0136\end{array}$ & $\begin{array}{l}\cdot 591 \\
\cdot 0527 \\
\cdot 0141\end{array}$ & $\begin{array}{l}\cdot 825 \\
\cdot 660 \\
\cdot 0754\end{array}$ & $\begin{array}{l}.819 \\
.626 \\
.0731\end{array}$ & $\begin{array}{l}\cdot 778 \\
\cdot 468 \\
\cdot 0629\end{array}$ \\
\hline $\begin{array}{l}\cdot 658 \\
\cdot 228 \\
\cdot 0440\end{array}$ & $\begin{array}{l}\cdot 645 \\
\cdot 228 \\
\cdot 0456\end{array}$ & $\begin{array}{l}\cdot 528 \\
\cdot 1302 \\
\cdot 0296\end{array}$ & $\begin{array}{l}\cdot 607 \\
\cdot 1300 \\
\cdot 0283\end{array}$ & $\begin{array}{r}\cdot 892 \\
1 \cdot 371 \\
\cdot 116\end{array}$ & $\begin{array}{r}\cdot 811 \\
1 \cdot 036 \\
\cdot 125\end{array}$ & $\begin{array}{r}\cdot 743 \\
\cdot 863 \\
\cdot 130\end{array}$ \\
\hline
\end{tabular}

deaths per 1,000 live births. It can be seen that the great divergence between infant mortality in the two cities was especially marked in the more crowded wards.

Thus it is evident that differences in social conditions were strongly but not equally operative in mortality and notifications from various causes. Respiratory tuberculosis was more strongly associated with factors which had relatively smaller influence in other mortality, and poverty and unemployment were of greater importance in their connexions with infant mortality and non-respiratory tuberculosis notifications. The social complex is again shown to have different effects upon different diseases.

\section{APPENDIX B.}

The diversity of the associations found between the various causes of death or disease and the components of the social constellation has been demonstrated repeatedly in the foregoing analyses. It is apparent that other distributions of mortality do not resemble respiratory tuberculosis in its exceptionally strong association with conditions of housing. It is of interest, therefore, to study more fully these social circumstances which bear so strongly and yet differently on the distributions of disease. The following paragraphs describe social circumstances in Glasgow, and particularly conditions of housing, in the years from 1930 to 1947 , and go on to analyse more fully the ward distributions and the inter-relations of these components of the social complex.

B.1. Housing IN Glasgow.-The peculiarities and shortcomings of Scottish housing in general are especially evident in Glasgow. Here the peculiarities lie in the large proportion of one-roomed and two-roomed dwellings, the great quantity of old tenement housing, and the resultant density of houses and persons per acre. The shortcomings are apparent in the lack of amenities in these small "houses"*, in the disrepair and insanitary conditions, and in the overcrowding superimposed on generally-crowded conditions. These conditions in

* A house in Scotland is a self-contained dwelling with its own entrance. 
themselves are possibly worse than those in the slums of other cities; but their exceptional character is due not so much to the nature of the deficiencies as to their great quantity. The extent to which these circumstances prevail is not commonly known; the "housing problem" in Glasgow is not confined, as in other cities, to a few areas forming only a small proportion of the total, but is acute in almost all regions of the city. Overcrowding is generally regarded as excessively serious if the official figure approaches 5 per cent.; thus it is difficult to imagine a picture of "slum" housing exceeding 50 per cent., of houses condemned as unfit being nearly 8 per cent., and of official overcrowding figures approaching 40 per cent. Yet that was the picture in Glasgow, and post-war building has so far made no radical change. The comparison shown in Table XII, of pre-war houses in Glasgow and in some English towns, was made recently by the Medical Officer of Health for Glasgow (1949b).

TABLE XII

OCCupied Houses of Different Sizes, 1931

Percentage distribution according to number of rooms

\begin{tabular}{|c|c|c|c|c|c|c|c|c|}
\hline \multicolumn{2}{|c|}{$\begin{array}{l}\text { Number of Rooms } \\
\text { in House } \ldots\end{array}$} & 1 & 2 & $\begin{array}{l}\text { Total } \\
1 \text { or } 2\end{array}$ & 3 & 4 & $\begin{array}{l}\text { Total } \\
3 \text { or } 4\end{array}$ & 5 or more \\
\hline \multirow{3}{*}{$\begin{array}{l}\text { Per- } \\
\text { centage } \\
\text { of } \\
\text { Houses } \\
\text { of this } \\
\text { size }\end{array}$} & Glasgow & $14 \cdot 8$ & $43 \cdot 7$ & $58 \cdot 5$ & $23 \cdot 7$ & $9 \cdot 1$ & $32 \cdot 8$ & $8 \cdot 7$ \\
\hline & Liverpool & $0 \cdot 3$ & $2 \cdot 7$ & $3 \cdot 0$ & $8 \cdot 7$ & $21 \cdot 7$ & $31 \cdot 4$ & $65 \cdot 6$ \\
\hline & Manchester & $0 \cdot 2$ & $1 \cdot 7$ & $1 \cdot 9$ & $10 \cdot 0$ & $39 \cdot 9$ & $49 \cdot 9$ & $48 \cdot 2$ \\
\hline
\end{tabular}

OVERCROWDED HOUSES, 1935

Percentage of houses of $£ 45$ or less rental found overcrowded, according to the standard of the 1935 Acts.

Glasgow, $31 \cdot 2$ per cent. Liverpool, $7 \cdot 4$ per cent. Manchester, $2 \cdot 1$ per cent.

Similarly, the data on population density disclosed by the Census Reports and the Overcrowding Survey is illustrated in Table XIII.

TABLE XIII

Density of Population, 1931-49

Persons per Acre, according to Census and Survey Reports

\begin{tabular}{|c|c|c|c|c|c|c|c|}
\hline Year & . & 1931 & 1935 & 1938 & 1945 & 1947 & 1949 \\
\hline $\begin{array}{l}\text { England and Wales } \\
\text { Greater London } \\
\text { County boroughs } \\
\text { Other urban areas } \\
\text { Rural districts }\end{array}$ & $\begin{array}{l}\cdots \\
\cdots \\
\cdots \\
\cdots \\
\cdots\end{array}$ & $\begin{array}{r}1 \cdot 1 \\
18 \cdot 5 \\
17 \cdot 1 \\
3 \cdot 3 \\
0 \cdot 2\end{array}$ & & & & & \\
\hline Glasgow .. & . & $36 \cdot 9$ & $37 \cdot 4$ & $28 \cdot 4^{*}$ & $26 \cdot 4$ & $27 \cdot 7$ & $27 \cdot 9$ \\
\hline Edinburgh & .. & $13 \cdot 6$ & $14 \cdot 2$ & $14 \cdot 4$ & $13 \cdot 1$ & $14 \cdot 9$ & $14 \cdot 7^{*}$ \\
\hline
\end{tabular}

* Extension of city boundaries, taking in more acreage, took place in Glasgow in 1938, and Edinburgh 1949.

The actual magnitude of the Glasgow problem is seen in the more recent figures shown in Table XIV (opposite); the improvements of the last 20 years have made only a small difference to the numbers of occupied one-roomed and two-roomed houses. 
TABLE XIV

OCCupied Houses of Different Sizes, 1935-49

Percentage distribution, according to rooms: and actual numbers of 1-roomed and 2-roomed houses

\begin{tabular}{|c|c|c|c|c|c|c|c|c|c|}
\hline \multicolumn{3}{|c|}{ Number of Rooms in House } & . & 1 & 2 & 3 & 4 & 5 or more & Total \\
\hline \multirow{4}{*}{$\begin{array}{c}\text { Houses } \\
\text { of } \\
\text { this } \\
\text { Type }\end{array}$} & \multirow{3}{*}{ Glasgow } & $1935^{*}$ & $\begin{array}{l}\text { Per cent. of total } \\
\text { Actual number }\end{array}$ & $\begin{array}{c}13 \cdot 5 \\
34,700\end{array}$ & $\begin{array}{c}43 \cdot 5 \\
112,200\end{array}$ & $27 \cdot 9$ & $11 \cdot 5$ & $(3 \cdot 6)$ & $\begin{array}{c}100 \\
257,600\end{array}$ \\
\hline & & 1945 & $\begin{array}{l}\text { Per cent. of total } \\
\text { Actual number }\end{array}$ & $\begin{array}{c}12 \cdot 8 \\
37,000\end{array}$ & $\begin{array}{c}38 \cdot 4 \\
111,000\end{array}$ & $27 \cdot 5$ & $13 \cdot 2$ & $8 \cdot 1$ & $\begin{array}{r}100 \\
289,000\end{array}$ \\
\hline & & 1949 & $\begin{array}{l}\text { Per cent. of total } \\
\text { Actual number }\end{array}$ & $\begin{array}{c}12 \cdot 1 \\
35,900\end{array}$ & $\begin{array}{c}37 \cdot 2 \\
110,400\end{array}$ & $28 \cdot 1$ & $14 \cdot 6$ & $8 \cdot 0$ & $\begin{array}{c}100 \\
296,400\end{array}$ \\
\hline & Edinburgh & 1946 & $\begin{array}{l}\text { Per cent. of total } \\
\text { Actual number }\end{array}$ & $3 \cdot 9$ & $25 \cdot 4$ & $32 \cdot 3$ & $20 \cdot 3$ & $18 \cdot 1$ & $\begin{array}{c}100 \\
120,300\end{array}$ \\
\hline
\end{tabular}

* The numbers for 1935 relate to houses of $£ 45$ or less rental.

In 1944 the Medical Officer of Health for Glasgow estimated the city's housing needs for replacing unfit houses, relieving overcrowding, and fulfilling general needs (Glasgow, 1943). His estimate totalled 100,000 new houses, overcrowding being assessed by the old standard of the Housing (Scotland) Act of 1935. His further estimate, if the 1944 standard of occupancy used in England and Wales were adopted, showed that 158,000 new houses were needed: of these, 108,000 were required to relieve overcrowding alone. At that time the total number of occupied houses in Glasgow was less than 290,000 . Thus the extent of overcrowding in the city, even by statutory standards, is manifest.

These tables show only the average figures for the city taken as a whole. Many wards had conditions much below the average in every respect, and Table XV illustrates the range of population densities in the wards. Similar ward variations exist in overcrowding and in

TABLE XV

Density of Population in Wards of Glasgow

Pre-war and post-war distribution by Persons per Acre

\begin{tabular}{c|c|c|c|c|c|c|c|c|c|c|c|c}
\hline Year & Persons per Acre & $0-10$ & $11-30$ & $31-40$ & $41-50$ & $51-70$ & $71-100$ & $101-130$ & $130+$ & \multicolumn{2}{|c|}{$\begin{array}{c}\text { Wersons per Acre } \\
\text { City }\end{array}$} & $\begin{array}{c}\text { Densest } \\
\text { Ward }\end{array}$ \\
\hline 1934 & & & & & & & & & & & & \\
$1938^{\circ}$ & Number of Wards & 3 & 8 & 2 & 3 & 6 & 7 & 6 & 4 & 37 & 190 \\
1945 & $\begin{array}{c}\text { in each Range } \\
1947\end{array}$ & 4 & 8 & 1 & 5 & 4 & 9 & 4 & 4 & 28 & 188 \\
\hline
\end{tabular}

- The extension of city boundaries, taking in more acreage, took place in Glasgow in 1938.

general crowding. In the 1930s the old standard of overcrowding (three "persons"* per room) was abandoned in Scotland as being too harsh, and overcrowding was recognized if the occupancy exceeded two "persons" per room. Yet in Glasgow the 1931 Census disclosed that over 42 per cent. of the population were living more than two per room; moreover, 19 per cent. were living more than three per room, and $7 \frac{1}{2}$ per cent. more than four per room. Table XVI (overleaf) shows that these conditions, though worse-in some wards than in others, were not confined to a few areas, but were general in the great majority.

Such housing conditions are quite exceptional, even in Scotland where the nineteenth century has left this legacy of one- and two-roomed dwellings located in tenements. For example, though the Edinburgh Survey of 1946 revealed that nearly 14 per cent. of all families

* Children aged 1 to 9 years count only as "half persons", and infants under 1 year are not counted at all. 
TABLE XVI

Distribution of Population in the Wards of Glasgow, 1931

Percentages living in 1-roomed and 2-roomed houses and living $3+$ per room or $4+$ per room

\begin{tabular}{|c|c|c|c|c|c|c|c|c|}
\hline $\begin{array}{l}\text { Percentage of warc } \\
1 \text {-roomed or } 2 \text {-ro }\end{array}$ & $\begin{array}{l}\text { d population } \\
\text { omed houses }\end{array}$ & $\begin{array}{l}\text { living in } \\
\ldots \quad \ldots\end{array}$ & Under 10 & $10-19$ & $20-29$ & $30-49$ & $50-69$ & $70+$ \\
\hline Number of wards & . & . & 2 & 3 & 1 & 7 & 15 & 9 \\
\hline $\begin{array}{l}\text { Percentage of ward } \\
\text { per room } \ldots\end{array}$ & $\begin{array}{l}\text { population } 1 \\
\ldots\end{array}$ & $\begin{array}{cc}\text { living } & 3+ \\
\ldots & \ldots\end{array}$ & Under 5 & $5-9$ & $10-14$ & $15-19$ & $20-29$ & $30+$ \\
\hline Number of wards & . & . & 6 & 3 & 2 & 10 & 12 & 4 \\
\hline $\begin{array}{l}\text { Percentage of ward } \\
\text { per room } \ldots\end{array}$ & $\begin{array}{l}\text { population } \\
\ldots \\
\end{array}$ & $\begin{array}{cc}\text { living } & 4+ \\
\ldots & \ldots\end{array}$ & Under 5 & $5-9$ & $10-14$ & $15-19$ & $20-29$ & $30+$ \\
\hline Number of wards & . & . & 10 & 20 & 5 & 2 & - & - \\
\hline
\end{tabular}

were statutorily overcrowded by Scottish standards, and nearly 33 per cent. by English standards, Edinburgh compares most favourably with Glasgow. Table XVII (pp. 44-45) shows the ranges and means of Glasgow ward housing rates and other social indices from 1930 to 1948. The general crowding (average number of persons per house)* changed little in the pre-war decade, the mean falling from $4 \cdot 05$ to $3 \cdot 86$.

By contrast, the mean of the ward averages in Edinburgh fell from 3.93 to 3.65 , and the statutory overcrowding figures for 1931 and for 1935 similarly demonstrate that dwellingoccupation was considerably more dense in Glasgow than in Edinburgh. In 1931 the Glasgow ward rates gave averages of 1.63 persons per room and more than 40 per cent. living $2+$ per room, and in 1935 over 29 per cent. of houses were overcrowded. $\dagger$ In Edinburgh in 1931 there were $1 \cdot 19$ persons per room and 27 per cent. living $2+$ per room, and in 193517 per cent. of houses were overcrowded.

This long and detailed description of certain aspects of Glasgow housing indicates the possible part played in the spread of infectious disease by such exceptional local circumstances; their relative influence seems to be much greater in respiratory tuberculosis than other diseases or in other localities.

B.2. LeVels of UNemployment and Poverty in Glasgow.-The extent of male unemployment in the city has changed considerably during the last 20 years, first as the depression of 1930 began to reach local industry, then as its effects were felt in other occupations, and subsequently as the periods of partial recovery, of war, and of post-war full employment followed upon each other. In the "good" period of 1927-29 the city average was three unemployed adult men per 100 persons. In 1930 and 1931 this rate rose steeply. Early in 1933 the peak was reached: in every 100 persons of all ages, nine men aged $21-64$, one younger man, and two women were registered unemployed. When one remembers those not registered and those not insurable, and considers also the wives, children, and dependants of the twelve registered, it is manifest that a large percentage of the population was directly affected by unemployment. The high rates continued for some years and then fell slowly, but even in the years immediately before the war the unemployed adult men numbered nearly 5 per cent. of the population. In recent years the rate has been much lower, approximately 1 per cent. of the population.

\footnotetext{
* "Persons per house" rather than "persons per room" is used as a measure of general crowding, since the small Glasgow houses have only one kitchen-living room for all general purposes.

$t$ In the worst wards over 65 per cent. of the people lived $2+$ per room and 54 per cent. of houses were overcrowded.
} 
In different wards the proportions of unemployed varied widely from the city average (Table XVII). Early in 1931 the unemployed adult men numbered 15 per cent. of the population in some wards, which implies that in these wards 40 per cent. to 50 per cent. of the population were directly affected. For several years there were nine wards with rates of 12 or more per cent. Even in 1938 there were some wards with rates as high as the peak city rates during the depression.

The changes in the numbers living in poverty were also particularly evident in the mid1930s, as more and more people exhausted their unemployment insurance. There was a time-lag between the changes in employment levels and the numbers dependent on relief, and though the number of able-bodied unemployed receiving assistance began to lessen after 1936, those on ordinary poor relief continued to increase. At the beginning of the decade the heads of household receiving relief on the Ordinary Outdoor and Able-bodied Rolls averaged 17,000 and 8,000 respectively. From 1934 until 1936 the unemployed heads of households on assistance were always between 26,000 and 29,000 , but in 1937 they fell greatly. The numbers of "ordinary poor" continued to mount sharply until 1935, when heads of households alone totalled 40,000 , and from then until the outbreak of war they remained at or above this level. In 1940 the heads of households on the Ordinary Roll fell to 19,000, and in the following years diminished very slowly. Thus the effects of the depression years were reflected first in the numbers of "able-bodied" on relief, which reached a peak from 1934 to 1936, and more gradually in the "ordinary poor", who reached their highest numbers from 1935 to 1939.

The applicants for assistance, together with their dependants, varied in the different wards, but numbers were high even during the war. From 1945 to 1947 the total numbers chargeable on the Outdoor Rolls averaged 3 per cent. of the city population. Some wards had less than 1 per cent. but seven wards had more than 5 per cent. of their population depending on relief.

The disparities in social and environmental circumstances in the different wards are further illustrated by a comparison in Table XVII of the coefficients of variation for the different indices.* The variability in the distribution of general crowding (as measured by average persons per house) was small, the standard deviation being consistently from 6 to 8 per cent. of the mean. But the variability in ward rates of persons per room in 1931 was much greater; and the distribution of overcrowding both in 1931 and in 1935 showed still greater variation, with coefficients nearing 50 per cent. The distribution of unemployment throughout the whole period also varied greatly, with coefficients comparable to those of overcrowding; as did the distribution of poverty in 1945-47. The great variability of ward valuation rates, with standard deviations nearly double the means, reflects the character of the actual distribution; four well-off wards, with extremely high valuation, stand out against fourteen very poor wards with almost zero valuation and six others with extremely low rates. It has to be remembered that "valuation" is in reality an index of wealth rather than of poverty.

B.3. Changes and Inter-Relations in the Social Distributions.-Changes in the different social distributions are evidenced by the correlations between the same index in different years (Table XVIII). The high correlations of ordinary crowding show that, though average numbers per house lessened slightly with the years, the distribution of crowding among the wards changed little. Similarly, the overcrowding distributions were highly correlated with each other, indicating that the relative inequalities between the wards remained almost the same. These indices, however, relate only to the 1930s, and since no overcrowding data for more recent times are available, no conclusion can be drawn about the present distribution of overcrowding. The distribution of unemployment in the different wards changed slightly

\footnotetext{
* The indices used and the reason for their selection are described in Appendix C.
} 


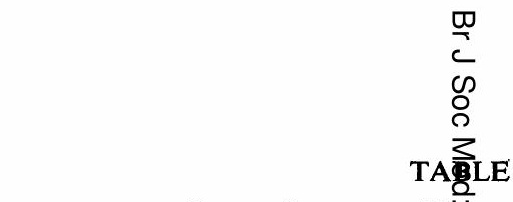

SOCIAL INDICES IN WARDS

ORdiNARY CROWDING, UNEMPLOYMA

A : Ordinary Crowding: Density of dwelling-occupation (average persons per house in each ward).

$\mathrm{U}$ : Unemployment: Adult males registered as unemployed, per cent. of total population in each ward.

P : Overcrowding: Density of room-occupation-average persons per room in each ward.

T : Excess room-crowding-percentage of ward population living 2+ per room.

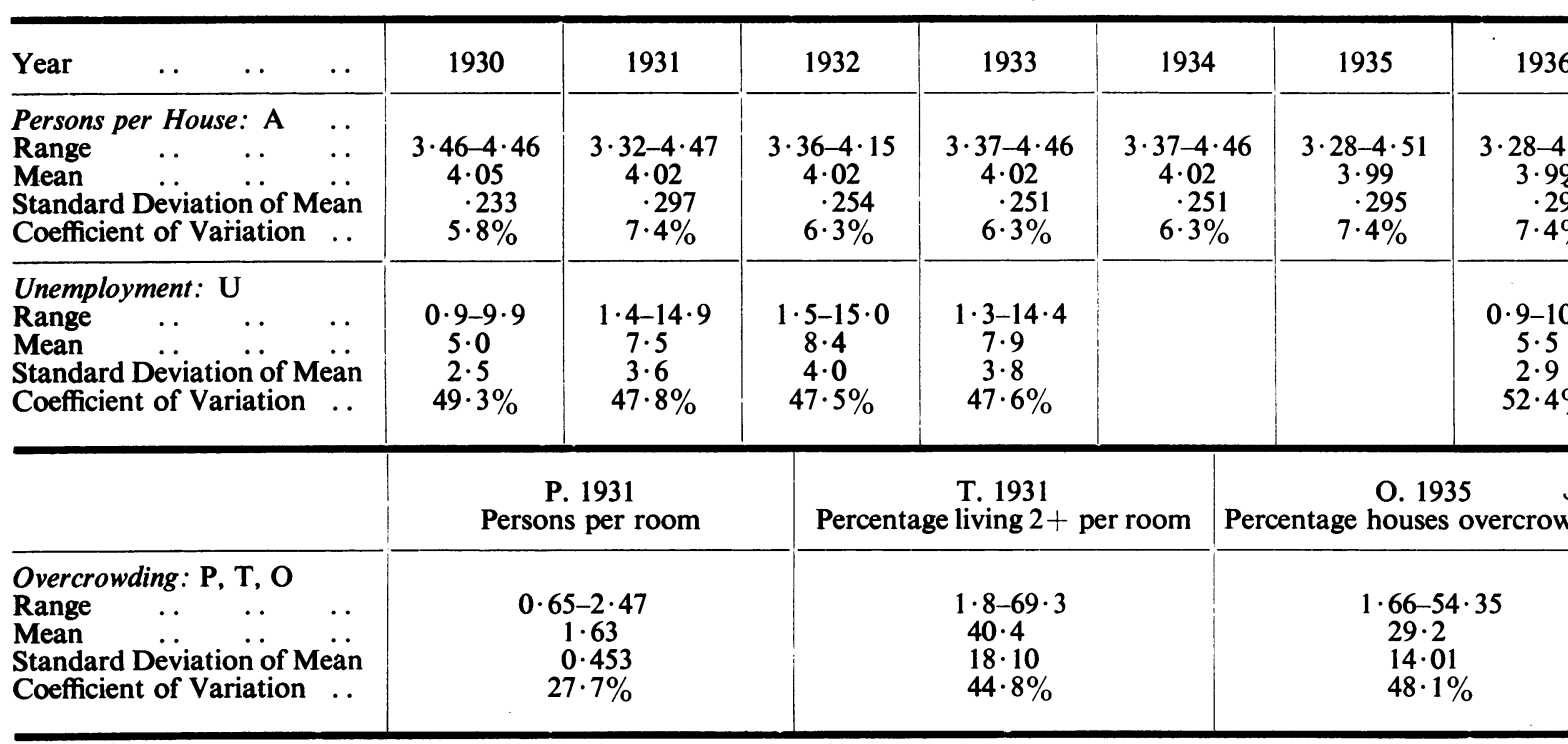

but noticeably in the later years of the period investigated. During the early 1930s it was unaltered, as is shown by the correlations of 0.99 in adjacent years; by 1936-38 it was somewhat differently distributed between the wards, and gave a lower correlation with the 1930-33 distribution.

The relationships between the social factors are indicated by the inter-correlations between the different indices (Table XVIII, overleaf). The associations may be described as follows:

Ordinary Crowding and Overcrowding, stronger in 1931 than in 1935, but not high; correlation coefficients fell from about 0.7 to about 0.6 .

Ordinary Crowding and Unemployment not high; correlation coefficients in the early 1930s slightly above 0.6 ; in the later 1930 s and after the war somewhat lower.

Poverty and Ordinary Crowding rose slightly; pre-war correlation coefficients $0 \cdot 55$, and post-war $0 \cdot 65$.

Unemployment and Overcrowding strong in the 1930s; the correlation coefficients mostly well above $0 \cdot 7$.

Unemployment and Poverty, slight in the 1930s; correlation coefficients only just above $0 \cdot 4$. After the war closely allied; correlation coefficient of 0.8 higher than any previously mentioned.

Poverty and Overcrowding, in the 1930 s comparatively high; correlation coefficients of about $\mathbf{0} \cdot 8$.

These relationships demonstrate that, though each social factor is to some extent associated with others, the social variables are by no means identical. The overlap between some of them is small, and they stand in different relation at different times. Ordinary crowding was not distributed in the same way as unemployment and poverty; and unemployment in the 
XVII

OF GLASGOW, 1930-1948

OVERCROWDING, and POVERTY

O: Statutory overcrowding-percentage of houses in each ward found to be overcrowded.

$V$ : Poverty: Valuation of district-proportion of houses over $£ 45$ rental in relation to other rentals in ward.

R: Outdoor Relief-percentage of ward population on Outdoor Rolls chargeable to Welfare Department.

\begin{tabular}{|c|c|c|c|c|c|c|c|c|}
\hline 1937 & 1938 & 1939 & 1940 & 1944 & 1945 & 1946 & 1947 & 1948 \\
\hline \multirow[t]{3}{*}{$\begin{array}{c}3 \cdot 21-4 \cdot 42 \\
3 \cdot 91 \\
\cdot 289 \\
7 \cdot 4 \%\end{array}$} & $\begin{array}{c}3 \cdot 21-4 \cdot 30 \\
3 \cdot 89 \\
\cdot 287 \\
7 \cdot 4 \%\end{array}$ & $\begin{array}{c}3 \cdot 19-4 \cdot 40 \\
3 \cdot 86 \\
\cdot 285 \\
7 \cdot 4 \%\end{array}$ & $\begin{array}{c}2 \cdot 93-4 \cdot 03 \\
3 \cdot 56 \\
\cdot 265 \\
7 \cdot 5 \%\end{array}$ & $\begin{array}{c}2 \cdot 89-3 \cdot 98 \\
3 \cdot 51 \\
\cdot 262 \\
7 \cdot 5 \%\end{array}$ & $\begin{array}{c}2 \cdot 89-3 \cdot 97 \\
3 \cdot 51 \\
\cdot 265 \\
7 \cdot 5 \%\end{array}$ & $\begin{array}{c}2 \cdot 95-4 \cdot 01 \\
3 \cdot 59 \\
\cdot 268 \\
7 \cdot 5 \%\end{array}$ & $\begin{array}{c}3 \cdot 00-4 \cdot 14 \\
3 \cdot 65 \\
\cdot 273 \\
7 \cdot 5 \%\end{array}$ & $\begin{array}{c}3 \cdot 23-4 \cdot 54 \\
3 \cdot 69 \\
\cdot 301 \\
8 \cdot 1 \%\end{array}$ \\
\hline & $\begin{array}{c}0 \cdot 7-8 \cdot 9 \\
4 \cdot 5 \\
2 \cdot 4 \\
54 \cdot 2 \%\end{array}$ & & & & $\begin{array}{c}0 \cdot 4-4 \cdot 8 \\
2 \cdot 5 \\
1 \cdot 3 \\
51 \cdot 3 \%\end{array}$ & & $\begin{array}{c}0 \cdot 2-2 \cdot 6 \\
1 \cdot 4 \\
0 \cdot 7 \\
50 \cdot 7 \%\end{array}$ & \\
\hline & & \multicolumn{2}{|c|}{$\begin{array}{l}\text { V. 1931-2 } \\
\text { Valuation }\end{array}$} & \multicolumn{2}{|r|}{$\begin{array}{l}\text { V. } 1935-6 \\
\text { Valuation }\end{array}$} & & \multicolumn{2}{|c|}{$\begin{array}{l}\text { R. } 1946 \\
\text { Outdoor Relief }\end{array}$} \\
\hline \multicolumn{2}{|c|}{$\begin{array}{l}\text { Poverty: V } \\
\text { Range } \quad \ldots \\
\text { Mean } \quad \ldots\end{array} \begin{array}{l}\text { Standard Deviation of Mean } \\
\text { Coefficient of Variation }\end{array}$} & \multicolumn{2}{|c|}{$\begin{array}{c}0.08-54 \cdot 02 \\
6 \cdot 44 \\
10 \cdot 58 \\
164 \cdot 3 \%\end{array}$} & \multicolumn{2}{|r|}{$\begin{array}{c}0.09-53 \cdot 83 \\
6 \cdot 57 \\
10 \cdot 32 \\
156 \cdot 9 \%\end{array}$} & & \multicolumn{2}{|c|}{$\begin{array}{c}0 \cdot 35-6 \cdot 74 \\
2 \cdot 99 \\
1 \cdot 53 \\
51 \cdot 2 \%\end{array}$} \\
\hline
\end{tabular}

depression years of 1930-34 was not distributed in the same way as in 1946-47. Moreover, the associations found in Glasgow indicate that the connection of ordinary crowding with poverty and unemployment is much smaller than is sometimes assumed. Thus the same conclusion is reached as in the multiple analyses of respiratory tuberculosis in relation to the social complex, that one social index is not equally representative of all, and that "social conditions" cannot be adequately investigated in terms of one component only.

\section{APPENDIX C.}

C.1. INDICES USED.-The disease indices used in the preceding analyses are ward rates of mortality and ward rates of notification. The social indices are average densities of dwellingoccupation and of room-occupation, percentages of population having excessive roomcrowding, percentages of houses statutorily overcrowded, male unemployment rates relative to total population, ward valuation according to rentals, and poverty indicated by proportions of population on relief. All these rates, percentages, and averages refer to the individual wards of Glasgow, and the means used are the means of the ward rates, not the averages for the city taken as a whole.

Disease Rates.-Mortality and notification rates are calculated as 2-year moving averages; in addition, for the pre-war and post-war comparison, triennial averages are used. For most causes, the rates refer to the total deaths or cases per 10,000 population, but infant mortality is reckoned in the usual way per 1,000 live births. Logarithms of mortality rates are to the base 10.

Crowding.-The average density of dwelling-occupation, the index used as a measure 
TABLE XVIII

INTER-Relations between Social Variables in Wards of Glasgow, 1930-47

Ordinary Crowding, Overcrowding, Unemployment, and Poverty

(a) Correlations of each social variable at different periods

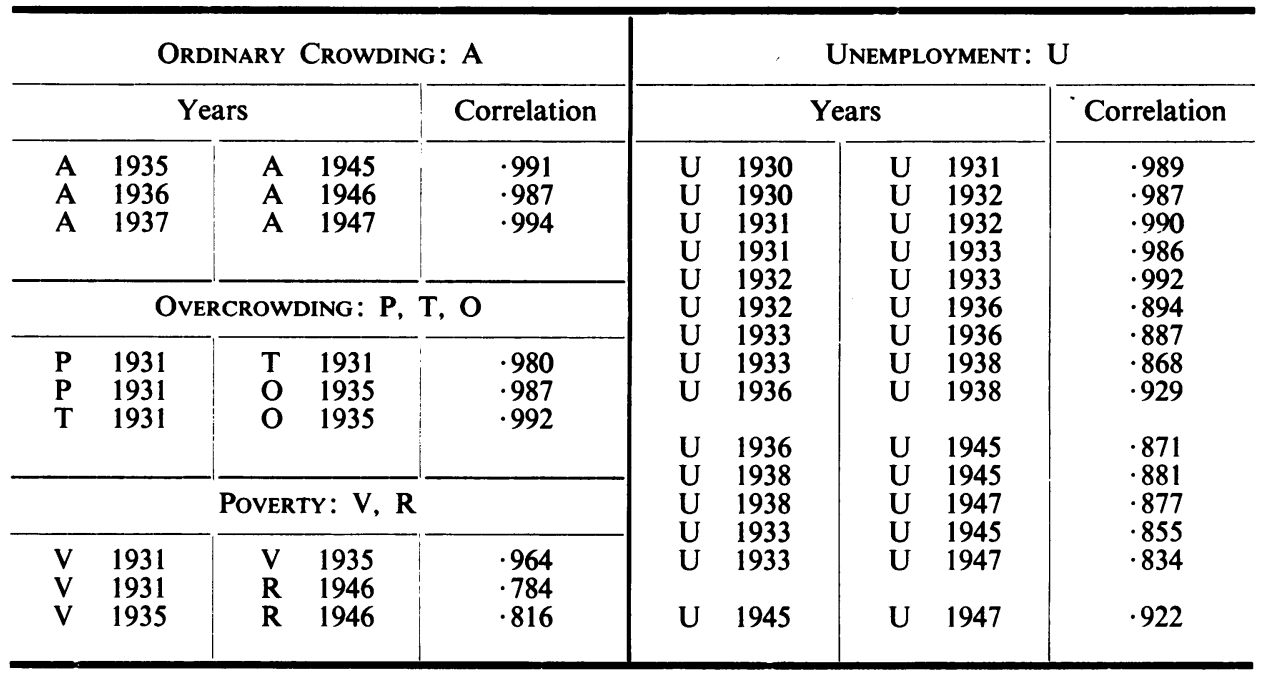

(b) Inter-correlations between different variables

\begin{tabular}{|c|c|c|c|c|c|c|c|c|c|}
\hline \multicolumn{5}{|c|}{ 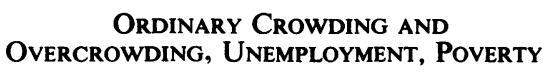 } & \multicolumn{5}{|c|}{$\begin{array}{l}\text { UNEMPLOYMENT AND } \\
\text { OVERCROWDING, POVERTY }\end{array}$} \\
\hline \multicolumn{4}{|c|}{ Variables } & Correlation & \multicolumn{4}{|c|}{ Variables } & Correlation \\
\hline A & 1931 & $\mathbf{P}$ & 1931 & $\cdot 695$ & \multirow{7}{*}{\multicolumn{2}{|c|}{$\begin{array}{cc}U & 1930 \\
U & 1930 \\
U & 1931 \\
U & 1931 \\
U & 1932 \\
U & 1932 \\
U & 1936 \\
U & 1938 \\
U & 1947\end{array}$}} & \multirow{7}{*}{$\begin{array}{l}\mathbf{P} \\
\mathrm{T} \\
\mathbf{P} \\
\mathrm{T} \\
\mathbf{P} \\
\mathbf{T} \\
\mathbf{O} \\
\mathbf{O} \\
\mathbf{O}\end{array}$} & \multirow{7}{*}{$\begin{array}{l}1931 \\
1931 \\
1931 \\
1931 \\
1931 \\
1931 \\
1935 \\
1935 \\
1935\end{array}$} & \multirow{7}{*}{$\begin{array}{l}\cdot 741 \\
\cdot 757 \\
\cdot 683 \\
\cdot 720 \\
\cdot 623 \\
\cdot 701 \\
\cdot 728 \\
\cdot 714 \\
\cdot 775\end{array}$} \\
\hline A & 1931 & $\mathrm{~T}$ & 1931 & $\cdot 731$ & & & & & \\
\hline A & 1931 & 0 & 1935 & $\cdot 548$ & & & & & \\
\hline A & 1935 & $\mathbf{T}$ & 1931 & .622 & & & & & \\
\hline A & 1935 & $\mathrm{O}$ & 1935 & $\cdot 578$ & & & & & \\
\hline A & 1930 & $\mathbf{U}$ & 1930 & $\cdot 546$ & & & & & \\
\hline A & 1931 & $\mathbf{U}$ & 1931 & .640 & & & & & \\
\hline A & 1932 & $\mathbf{U}$ & 1932 & $\cdot 612$ & \multirow{6}{*}{$\begin{array}{l}\mathbf{U} \\
\mathbf{U} \\
\mathbf{U} \\
\mathbf{U} \\
\mathbf{U}\end{array}$} & \multirow{6}{*}{$\begin{array}{l}1931 \\
1936 \\
1938 \\
1947 \\
1945 \\
1947\end{array}$} & \multirow{6}{*}{$\begin{array}{l}\text { V } \\
\text { V } \\
\text { V } \\
\text { V } \\
\text { R } \\
\text { R }\end{array}$} & \multirow{6}{*}{$\begin{array}{l}1931 \\
1935 \\
1935 \\
1935 \\
1946 \\
1947\end{array}$} & \multirow{6}{*}{$\begin{array}{l}.571 \\
.435 \\
.409 \\
.463 \\
.812 \\
.780\end{array}$} \\
\hline A & 1933 & $\mathbf{U}$ & 1933 & $\cdot 631$ & & & & & \\
\hline A & 1936 & $\mathbf{U}$ & 1936 & $\cdot 579$ & & & & & \\
\hline A & 1938 & $\mathbf{U}$ & 1938 & .570 & & & & & \\
\hline A & 1945 & U & 1945 & $\cdot 573$ & & & & & \\
\hline A & 1947 & U & 1947 & $\cdot 562$ & & & & & \\
\hline A & 1931 & V & 1931 & $\cdot 555$ & \multicolumn{5}{|c|}{ OVERCROWDING AND POVERTy } \\
\hline A & 1935 & V & 1935 & $\cdot 547$ & $\mathbf{P}$ & & & & .787 \\
\hline A & 1946 & $\mathbf{R}$ & 1946 & .655 & $\begin{array}{l}\mathbf{P} \\
\mathbf{T}\end{array}$ & $\begin{array}{l}1931 \\
1931\end{array}$ & $\mathbf{V}$ & 1931 & .763 \\
\hline A & 1947 & $\mathbf{R}$ & 1947 & $\cdot 646$ & $\mathbf{O}$ & 1935 & $\mathbf{V}$ & 1935 & $\cdot 709$ \\
\hline
\end{tabular}


of ordinary crowding, is calculated for each year from 1930 to 1947 in each ward as the average number of persons of all ages per house.* For 1930-32 and 1935-38 indices of overcrowding as well as of ordinary crowding are used. In the 1930-32 period, two overcrowding indices are obtainable: the first is density of room-occupation, calculated as the average number of persons per room, and the second is excess room-crowding, calculated as the percentage of the ward population living more than two persons per room. In the 1935-38 period one index, based on statutory overcrowding as revealed by the 1935 Survey, is considered; ward rates are calculated according to the percentages of houses found to be overcrowded according to the Scottish standard.

Unemployment.-These rates are based on the numbers of insured adult males in each ward who registered as unemployed in the summer months in each year, and are calculated as percentages of entire ward populations. Various indices to represent the distribution of unemployment in the wards were considered, and the rates used were limited to those for adult males for three periods: the "depression" years of the early 1930s, the "recovery" years of the late 1930s, and the post-war "full employment" period.

The limitations were adopted for the following reasons:

Firstly only summer unemployment has been taken into account in order to minimize the effects of seasonal interruptions of work.

Secondly, a high correlation was found between the different unemployment distributions in the years 1930,1931,1932, and 1933; it was therefore thought preferable to use one set of rates for this period rather than the separate sets for each of the years. High correlations found in the immediate pre-war years and again in the post-war period also led to the use of a single set of rates for each period.

Thirdly, female and juvenile unemployment have been excluded in arriving at the index, since both fluctuate in other ways and for other reasons than does the unemployment of the chief wageearners. This is particularly evident in the depression years, in which the extractive, engineering, shipbuilding, and other heavy industries of Glasgow were strongly affected. Furthermore, in the period under review there have been several changes in the categories of insurable female and juvenile workers, and the numbers of registered unemployed are therefore not comparable.

Lastly, unemployment among insured adult males relative to the entire ward population indicates to some extent the effects of unemployment upon families as a whole. It might have been desirable to examine the relationship between tuberculosis and economic status by using a positive index of employment rather than an index of unemployment. But unfortunately such investigation is impossible, since employment records are in no way related to the residence of the persons employed: the exchange of employment books is normally carried out in the area of the head office, or possibly of the accounting section, of the employers.

The unemployment index finally selected may, perhaps, in times of full or near-full employment in the city, be more representative of poverty than of the effects of unemployment itself; but in times of depression and crisis the proportions of adult males unemployed were highest not in the poorest wards but in those with skilled and industrial populations. The relationship between unemployment and a disease such as respiratory tuberculosis with an undetermined incubation period is inevitably difficult to investigate from past records: it would be desirable to relate tuberculosis incidence and mortality to previous, and particularly to long-term, unemployment. But this again was found impossible since records of the duration of unemployment by residence are not available.

Poverty.-The "valuation" index is based on the rents of houses in each ward and the percentage of houses with high rentals; it is calculated by relating the number of houses of over $£ 45$ rental to the numbers of houses of various lower rentals. This is taken as an inverse measure of the poverty of the ward: in fact, it measures, not poverty in an area, but the proportion of well-to-do houses in relation to various other categories and is therefore an index of "wealth" rather than of poverty. Its weakness is that it does not differentiate sufficiently between the poorer and the poorest wards, and does not distinguish greatly between stages of poyerty. But it discriminates clearly between degrees of "wealth", and

* A "house" in the Scottish sense is a self-contained dwelling with its own entrance, and may be subdivided or shared between two or more households while still counting as a single house. 
separates accurately the wealthy and moderately well-off wards from each other and from the poorer wards.

The poverty index used for the post-war period is a direct one, based on the number of persons in each ward in receipt of assistance from the Welfare Department of the Corporation of Glasgow, chargeable on the Ordinary and Able-bodied Outdoor Rolls, These comprised applicants for ordinary poor-law relief, together with their dependants, and able-bodied unemployed applicants who had exceeded the statutory period of receipt of unemployment insurance; but persons in institutions and persons receiving domiciliary assistance owing to blindness were excluded. The percentages of "ordinary and able-bodied poor" in the post-war years in relation to the total ward populations give a measure of poverty, as distinct from unemployment, in the wards. This index has not been used for any pre-war period, since the numbers chargeable on the Ordinary Outdoor Roll in the 1930s, during and after the long depression, were tremendously increased by the unemployed; hence for the 1930s the distribution of persons on relief is highly correlated with the unemployment distribution and does not give an independent measure of poverty.

The "relief" index has the opposite weakness to the "valuation" index, in that it does not differentiate greatly between the better-off and average wards, since in almost every area there are a few families dependent on relief. "Poor-law relief" indicates a degree of destitution rather beyond the ordinary meaning of poverty, and the index therefore does discriminate between the extreme stages of poverty, and does separate the very poorest wards from each other and from the better-off areas.

C.2. SourCes of DATA.-Through the co-operation and assistance of the Glasgow Public Health Department, the deaths and cases of respiratory and non-respiratory tuberculosis in each of the wards of Glasgow in the years 1930-47 were obtained. The annual births in each ward and the deaths of infants under one year old were published in the Reports of the Glasgow Public Health Department, as were also the annual deaths from all causes combined.

Estimates of ward populations and numbers of houses were for some years published in the Reports of the Glasgow Public Health Department; for other years, estimates were obtained with the aid of the Medical Officer of Health.

Overcrowding data were taken from the Report on the 14th Decennial Census of Scotland (1931) and from the Report on Overcrowding issued after the survey made under the Housing (Scotland) Act of 1935.

The rating of houses in each ward, from which valuation figures have been calculated, was also extracted from data in these reports.

Unemployment figures for the ten Employment Exchange Areas were obtained from the Statistics Division of the Ministry of Labour and National Service; these figures, covering large areas of Glasgow, were analysed and broken down for the smaller ward units with the assistance of the managers and staffs of the Glasgow Employment Exchanges.

The numbers of persons receiving Relief or Public Assistance, and chargeable on the Outdoor Rolls of the Welfare Department of the Corporation of Glasgow, were obtained from the Annual Reports published by that Department.

Tuberculosis deaths and notifications in Scotland as a whole and in the cities of Scotland since 1900 were published in the Annual Reports of the Registrar-General for Scotland and in the Public Health Reports of the various burghs. 